INSTITUTO DE PESQUISAS ENERGÉTICAS E NUCLEARES

Autarquia associada à Universidade de São Paulo

\title{
AVALIAÇÃO DOS METAIS AMBIENTALMENTE DISPONÍVEIS EM AMOSTRAS DE SEDIMENTO DE PONTOS DE CAPTAÇÃO DE ÁGUA PARA ABASTECIMENTO PÚBLICO DE PALMAS, TO
}

\author{
BRUNA RAFAELA DE OLIVEIRA
}

Dissertação apresentada como parte dos requisitos para obtenção do Grau de Mestre em Ciências na Área de Tecnologia Nuclear - Materiais

Orientadora:

Profa. Dra. Elizabeth Sonoda Keiko Dantas

SÃO PAULO

2012 
Dedico este trabalho aos meus pais, Reginaldo e Cleide, que nunca mediram esforços para garantir uma boa educação para seus filhos. E ao meu noivo, Fábio, pelo apoio, compreensão e, principalmente, pela paciência que teve durante os últimos anos. 


\section{AGRADECIMENTOS}

Agradeço primeiramente à Deus, por estar sempre iluminando o meu caminho.

À minha família, pelo amor, carinho, respeito, sabedoria e apoio na conclusão de mais uma etapa de minha vida profissional.

À Dra. Casuê Nakanishi pelo incentivo na realização de meus estudos no IPEN.

À Dra. Elizabeth Sonoda Keiko Dantas, pela confiança em meu trabalho, pela paciência na orientação e pelos ensinamentos.

À Dra. Maria A. F. Pires pelo apoio institucional e disponibilização dos laboratórios e equipamentos do CQMA.

À equipe de Tocantins, UFT e SANEATINS, pela parceria e realização das coletas das amostras de sedimento.

À Dra. Marycel E. B. Cotrim e à Dra. Liliana P. Naval pela participação na banca e pelas contribuições para a conclusão deste trabalho.

À MSc. Lucilena Rebelo pelos ensinamentos, discussões técnicas e valiosas sugestões.

À equipe do Laboratório de Análises Química e Ambiental, em especial aos colegas Douglas Batista e Mainara Faustino, pela contribuição com as análises de metais e elementos-traço e pela ajuda e parceria sempre presente no laboratório.

Às meninas, Juliana Silva, Flávia Junqueira, Gisela Martini, Caroline Lima e Daniele Seo, pela força, companheirismo, risadas, conversas, enfim, pela amizade.

Ao apoio financeiro recebido pelo IPEN e CAPES.

Enfim, à todos aqueles que de algum modo colaboraram para que a realização e conclusão deste projeto fosse possível. 
"Agradeço todas as dificuldades que enfrentei; não fosse por elas, eu não teria saído do lugar. As facilidades nos impedem de caminhar. Mesmo as críticas nos auxiliam muito". (Chico Xavier) 


\title{
AVALIAÇÃO DOS METAIS AMBIENTALMENTE DISPONÍVEIS EM AMOSTRAS DE SEDIMENTO DE PONTOS DE CAPTAÇÃO DE ÁGUA PARA ABASTECIMENTO PÚBLICO DE PALMAS, TO
}

\author{
Bruna Rafaela de Oliveira
}

\section{RESUMO}

Os sedimentos são um importante compartimento utilizado como ferramenta para a avaliação da qualidade dos ecossistemas aquáticos, por indicar a presença de contaminantes liberados continuamente para o meio ambiente em decorrência das atividades humanas. Dentre as substâncias químicas lançadas nas águas superficiais, estão os metais que, em quantidades indesejáveis, podem ser tóxicos para a biota. Em virtude da importância dos sedimentos e da carência de dados de qualidade das águas do sistema hidrográfico Tocantins-Araguaia, o presente estudo realizou uma avaliação dos metais ambientalmente disponíveis em amostras de sedimento provenientes de pontos de captação de água para abastecimento público de Palmas, em Tocantins, Brasil. Foram analisadas as concentrações de As, Cd, Pb e Se por Espectrometria de Absorção Atômica com Atomização Eletrotérmica em Forno de Grafite (GFAAS), de Ag, Al, B, Ba, Be, Ca, Co, Cr, Cu, Fe, K, Li, Mg, Mn, Mo, Na, Ni, P, Sb, Sc, Si, Ti, V e Zn por Espectrometria de Emissão Óptica com Plasma Indutivamente Acoplado (ICPOES) e de Hg por Espectrometria de Absorção Atômica com Geração de Vapor Frio (CVAAS). Foram realizados dois processos de solubilização parcial de sedimentos para um estudo comparativo, um com $\mathrm{HCl} 0,1 \mathrm{M}$ e agitação em temperatura ambiente, considerado um método mais brando para extração dos metais de origem antropogênica, e outro com $\mathrm{HNO}_{3} 8 \mathrm{M}$ e aquecimento em forno de microondas, considerado uma alternativa para os métodos mais complexos de digestão total, visto que fornece uma boa estimativa da concentração total dos elementos. A avaliação da qualidade dos sedimentos foi realizada pela comparação dos valores de concentração dos elementos $\mathrm{As}, \mathrm{Cd}, \mathrm{Cr}, \mathrm{Cu}, \mathrm{Hg}, \mathrm{Ni}$, $\mathrm{Pb}$ e $\mathrm{Zn}$ com os valores orientadores (TEL e PEL) adotados pelo Canadian Council of Minister of the Environment (CCME), para assim contribuir com a qualidade ambiental das águas do sistema hidrográfico Tocantins-Araguaia. 


\title{
ASSESSMENT OF ENVIRONMENTALLY AVAILABLE METALS IN SEDIMENT SAMPLES FROM WATER FOR PUBLIC SUPPLY OF THE CITY OF PALMAS, TOCANTINS
}

\author{
Bruna Rafaela de Oliveira
}

\begin{abstract}
The sediments are an important compartment used as a tool for assessment of aquatic ecosystems quality, for indicating the presence of contaminants released continuously into the environment as a result of human activities. Among chemical substances discharged to surface water, there are metals that in undesirable amounts, can be toxic to biota. Due to the importance of sediment and of shortage of data of water quality of the Araguaia-Tocantins river system, the present study conducted an assessment of environmentally available metals in sediment samples from water for public supply of the city of Palmas, in Tocantins, Brazil. The concentrations of $\mathrm{As}, \mathrm{Cd}, \mathrm{Pb}$ and Se were analyzed by Graphite Furnace Atomic Absorption Spectrometry (GFAAS), Ag, Al, B, Ba, Be, $\mathrm{Ca}, \mathrm{Co}, \mathrm{Cr}, \mathrm{Cu}, \mathrm{Fe}, \mathrm{K}, \mathrm{Li}, \mathrm{Mg}, \mathrm{Mn}, \mathrm{Mo}, \mathrm{Na}, \mathrm{Ni}, \mathrm{P}, \mathrm{Sb}, \mathrm{Sc}, \mathrm{Si}, \mathrm{Ti}, \mathrm{V}$ and $\mathrm{Zn}$ were analyzed by Inductively Coupled Plasma Optical Emission Spectrometry (ICPOES) and $\mathrm{Hg}$ by Cold Vapor Atomic Absorption Spectrometry (CVAAS). Two partial solubilization processes were performed for a comparative study, one with $\mathrm{HCl} 0,1 \mathrm{M}$ and agitation at room temperature, considered a milder method for metal extraction from anthropogenic origin, and another with $\mathrm{HNO}_{3} 8 \mathrm{M}$ and microwave heating, considered as an alternative to more complex methods of total digestion, since it provides a good evaluation of the total concentration of the elements. The sediment quality evaluation was realized by comparing the concentration values of the elements $\mathrm{As}, \mathrm{Cd}, \mathrm{Cr}, \mathrm{Cu}, \mathrm{Hg}, \mathrm{Ni}, \mathrm{Pb}$ and $\mathrm{Zn}$ with the quality guidelines (TEL and PEL) adopted by Canadian Council of Minister of the Environment (CCME), to thereby contribute to the environmental quality of the water of the Araguaia-Tocantins river system.
\end{abstract}




\section{SUMÁRIO}

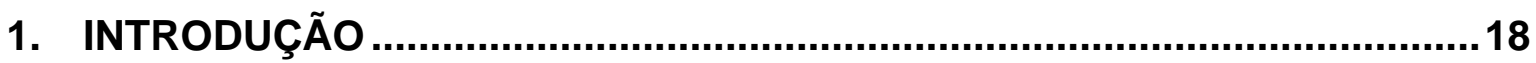

2. OBJETIVOS

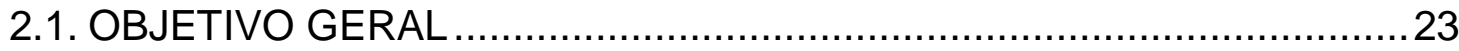

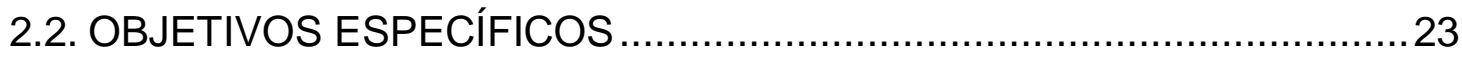

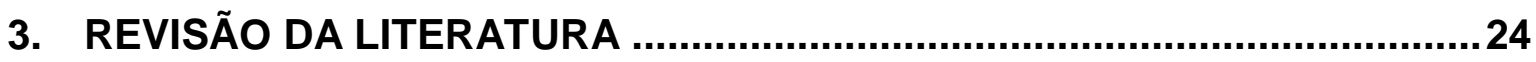

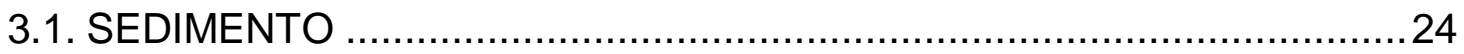

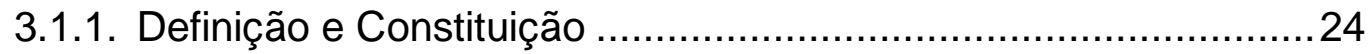

3.1.2. Importância na Avaliação da Qualidade Ambiental ......................25

3.1.2.1. Fatores de Mobilização de Metais em Sedimentos .................26

3.1.2.2. Fatores de Remobilização de Metais para a Água ..................29

3.1.3. Elementos-Traço ............................................................... 30

3.1.4. Metais Ambientalmente Disponíveis ........................................ 42

3.1.5. Valores Orientadores da Qualidade de Sedimento ..................... 49

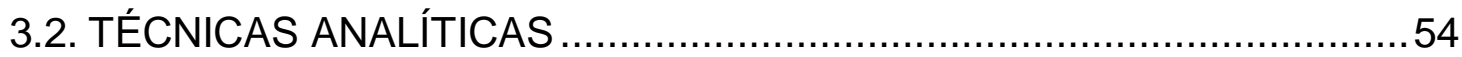

3.2.1. Espectrometria de Absorção Atômica com Atomização

Eletrotérmica em Forno de Grafite (GFAAS) ........................................54

3.2.2. Espectrometria de Absorção Atômica com Geração de Vapor

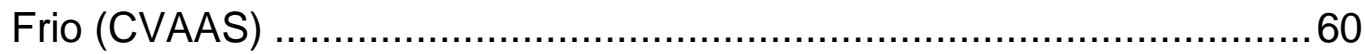

3.2.3. Espectrometria de Emissão Óptica com Plasma Indutivamente

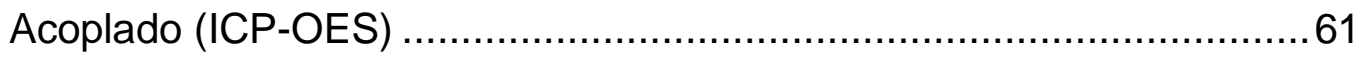

3.2.4. Validação de Metodologia Analítica .............................................65

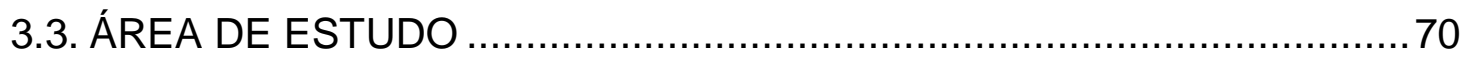

3.3.1. Sistemas Hidrográficos ......................................................... 72

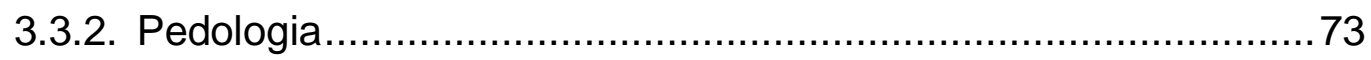

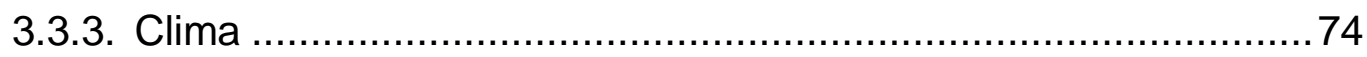




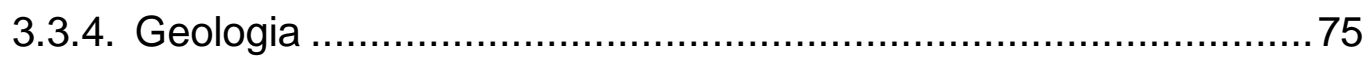

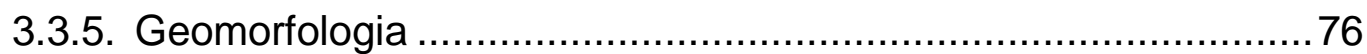

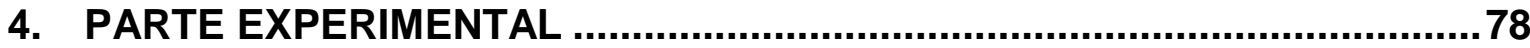

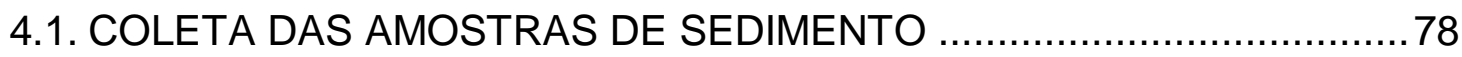

4.2. PRÉ-TRATAMENTO DAS AMOSTRAS DE SEDIMENTO .....................81

4.2.1. Digestão com $\mathrm{HNO}_{3} 8 \mathrm{M}$ e Aquecimento em Equipamento Microondas.

4.2.2. Digestão com $\mathrm{HCl} 0,1 \mathrm{M}$ e Agitação em Temperatura

Ambiente .82

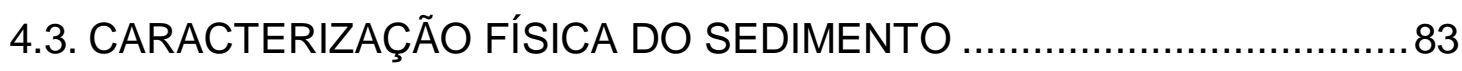

4.3.1. Determinação do teor de matéria orgânica ................................. 83

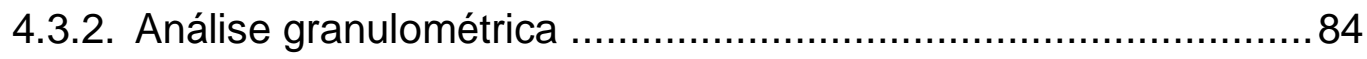

4.4. DETERMINAÇÃO DE METAIS NAS AMOSTRAS DE SEDIMENTO .......85

4.4.1. Espectrometria de Absorção Atômica com Atomização Eletrotérmica em Forno de Grafite (GFAAS) …….............................. 86

4.4.1.1. Validação da Metodologia Analítica...................................... 87

4.4.2. Espectrometria de Absorção Atômica com Geração de Vapor

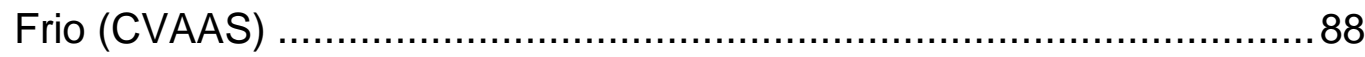

4.4.3. Espectrometria de Emissão Óptica com Plasma Indutivamente

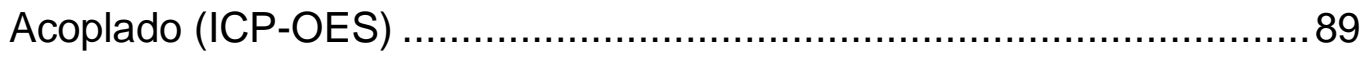

4.4.4. Tratamento Estatístico dos Dados - Análise Multivariada...........92

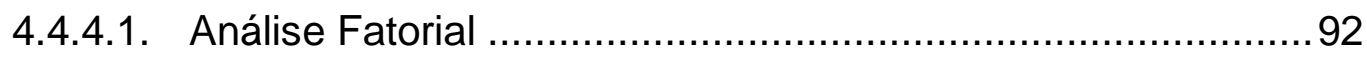

4.4.4.2. Análise de Conglomerados (Clusters Analysis) .....................92

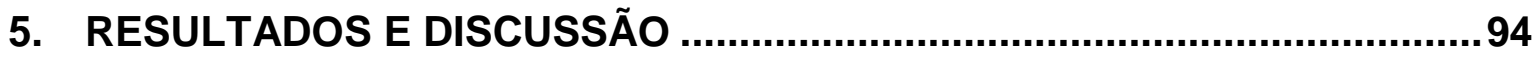

5.1. CARACTERIZAÇÃO FÍSICA DO SEDIMENTO .....................................94

5.1.1. Teor de Matéria Orgânica ....................................................... 94

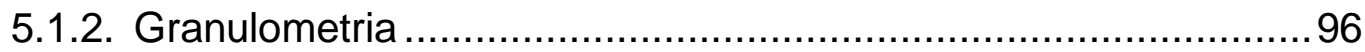

5.2. ESTUDO COMPARATIVO DOS MÉTODOS DE DIGESTÃO …..............98

5.2.1. Otimização das Temperaturas de Pirólise e Atomização .............98 
5.2.2. Validação da Metodologia .99

5.2.3. Análise de Metais 103

5.3. ESTUDO DA AVALIAÇÃO DA QUALIDADE DO SEDIMENTO 107

5.3.1. Variação da Concentração dos Metais Ambientalmente Disponíveis

5.3.2. Análise Estatística 115

5.4. DISCUSSÃO DOS RESULTADOS OBTIDOS 123

6. CONCLUSÕES 126

6.1. COMPARAÇÃO DOS MÉTODOS DE DIGESTÃO DE SEDIMENTO....126

6.2. CARACTERIZAÇÃO FÍSICA DO SEDIMENTO 126

6.3. AVALIAÇÃO DA QUALIDADE DO SEDIMENTO 126

APÊNDICES 128 


\section{LISTA DE TABELAS}

TABELA 1 Classificação granulométrica dos sedimentos

TABELA 2 Esquema de extração seletiva em sedimentos

TABELA 3 Valores orientadores utilizados pelo Canadá para metais em sedimentos de água doce (base seca)

TABELA 4 Valores orientadores utilizados pelo Brasil na Resolução 344/04 para metais em sedimentos (base seca)

TABELA 5 Classificação de contaminantes em sedimento de água doce estabelecida pela CETESB a partir do TEL e PEL

TABELA 6 Limites de detecção $\left(\mu \mathrm{g} \mathrm{L}^{-1}\right)$ para técnicas de espectrometria atômica

TABELA 7 Relação entre a concentração do analito e a precisão esperada

TABELA 8 Localização dos pontos de coleta

TABELA 9 Programa de aquecimento utilizado no equipamento microondas (indicação do tempo e potência nominal aplicada)

TABELA 10 Numeração das peneiras da Bertel e suas respectivas aberturas (em $\mathrm{mm})$

TABELA 11 Resumo das técnicas utilizadas para a determinação dos metais ambientalmente disponíveis nas amostras de sedimento

TABELA 12 Condições operacionais do forno de grafite THGA

TABELA 13 Faixa de concentração e limite de quantificação para determinação de $\mathrm{Hg}$ por CVAAS

TABELA 14 Condições operacionais do sistema (ICP-OES)

TABELA 15 Linhas de emissão, faixas de concentração e limites de quantificação utilizados na análise de sedimentos por ICP-OES

TABELA 16 Resultado da matéria orgânica (em \%)

TABELA 17 Resultado das frações granulométricas (em \%) obtidas em cada amostra de sedimento

TABELA 18 Temperaturas ótimas $\left(\mathrm{em}^{\circ} \mathrm{C}\right)$ obtidas para a pirólise e a atomização dos elementos em estudo, para cada matriz analisada

TABELA 19 Faixa de trabalho, linearidade e limites de quantificação e detecção obtidos para a determinação dos metais por GFAAS 
TABELA 20 Valores de recuperação e desvio padrão relativo obtidos na solubilização do material de referência certificado SRM 8704 utilizando o método USEPA $3051 \mathrm{~A}$

TABELA 21 Valores de recuperação e desvio padrão relativo obtidos na solubilização do material de referência certificado SRM 8704 utilizando $\mathrm{HCl}$ 0,1 $\mathrm{M}$ e agitação em temperatura ambiente

TABELA 22 Resumo da análise fatorial com extração dos componentes principais

TABELA 23 Resultado da análise fatorial com extração dos componentes principais e rotação Varimax (valores $>0,75$ selecionados) 


\section{LISTA DE FIGURAS}

FIGURA 1 Esquema de um espectrômetro de absorção atômica com forno de grafite de óptica seqüencial

FIGURA 2 Esquema da tocha em espectrômetro de emissão óptica com plasma indutivamente acoplado

FIGURA 3 Regiões hidrográficas do Brasil

FIGURA 4 Sistemas hidrográficos da região em estudo

FIGURA 5 Pedologia da região em estudo

FIGURA 6 Clima da região em estudo

FIGURA 7 Geologia da região em estudo

FIGURA 8 Geomorfologia da região em estudo

FIGURA 9 Mapa com a localização geográfica dos pontos de coleta

FIGURA 10 Draga de Petersen

FIGURA 11 Distribuição de As nas amostras de sedimento solubilizadas nos pontos de coleta da região hidrográfica do Tocantins-Araguaia

FIGURA 12 Distribuição de Cd nas amostras de sedimento solubilizadas nos pontos de coleta da região hidrográfica do Tocantins-Araguaia

FIGURA 13 Distribuição de Pb nas amostras de sedimento solubilizadas nos pontos de coleta da região hidrográfica do Tocantins-Araguaia

FIGURA 14 Distribuição de Se nas amostras de sedimento solubilizadas nos pontos de coleta da região hidrográfica do Tocantins-Araguaia

FIGURA 15 Distribuição de Al nos sedimentos nos pontos de coleta

FIGURA 16 Distribuição de Ba nos sedimentos nos pontos de coleta

FIGURA 17 Distribuição de Ca nos sedimentos nos pontos de coleta

FIGURA 18 Distribuição de Cd nos sedimentos nos pontos de coleta

FIGURA 19 Distribuição de Pb nos sedimentos nos pontos de coleta

FIGURA 20 Distribuição de Co nos sedimentos nos pontos de coleta

FIGURA 21 Distribuição de Cu nos sedimentos nos pontos de coleta 
FIGURA 22 Distribuição de Fe nos sedimentos nos pontos de coleta

FIGURA 23 Distribuição de Mg nos sedimentos nos pontos de coleta

FIGURA 24 Distribuição de Mn nos sedimentos nos pontos de coleta

FIGURA 25 Distribuição de K nos sedimentos nos pontos de coleta

FIGURA 26 Distribuição de Si nos sedimentos nos pontos de coleta

FIGURA 27 Distribuição de Na nos sedimentos nos pontos de coleta

FIGURA 28 Distribuição de V nos sedimentos nos pontos de coleta

FIGURA 29 Distribuição de Zn nos sedimentos nos pontos de coleta

FIGURA 30 Análise de fatores: Fator 1 x Fator 2

FIGURA 31 Dendograma resultante da análise de agrupamento utilizando os pontos de amostragem como variáveis

FIGURA 32 Dendograma resultante da análise de agrupamento utilizando os metais analisados e o teor de matéria orgânica 


\section{LISTA DE SIGLAS}

AAN Análise por Ativação Neutrônica

ABNT Associação Brasileira de Normas Técnicas

ANVISA Agência Nacional de Vigilância Sanitária

BPCs Bifenilas Policloradas

CAPES Coordenação de Aperfeiçoamento de Pessoal de Nível Superior

CCME Canadian Council of Ministers of the Environment

CETESB Companhia de Tecnologia de Saneamento Ambiental do Estado de São Paulo

CNEN Comissão Nacional de Energia Nuclear

CONAMA Conselho Nacional do Meio Ambiente

CQMA Centro de Química e Meio Ambiente

CVAAS Espectrometria de Absorção Atômica com Geração de Vapor Frio

FAAS Espectrometria de Absorção Atômica com Chama

FF Plintossolo Pétrico

GFAAS Espectrometria de Absorção Atômica com Atomização Eletrotérmica em Forno de Grafite

HGAAS Espectrometria de Absorção Atômica com Geração de Hidreto

HPAs Hidrocarbonetos Policíclicos Aromáticos

ICP-MS Espectrometria de Massas com Plasma Indutivamente Acoplado

ICP-OES Espectrometria de Emissão Óptica com Plasma Indutivamente Acoplado

INMETRO Instituto Nacional de Metrologia, Qualidade e Tecnologia

IPEN Instituto de Pesquisas Energéticas e Nucleares

ISQG Interim Sediment Quality Guidelines

LVA Latossolo Vermelho-Amarelado

NIST National Institute of Standards and Technology

PEL Probable Effect Level 
SANEATINS Companhia de Saneamento do Tocantins

TEL Threshold Effect Level

THGA Atomizador de Grafite Aquecido Transversalmente

TO Tocantins

UFT Universidade Federal do Tocantins

USEPA United States Environmental Protection Agency 


\section{LISTA DE SÍMBOLOS}

\begin{tabular}{|c|c|}
\hline$\%$ & por cento \\
\hline$\circ$ & grau \\
\hline , & minuto \\
\hline$"$ & segundo \\
\hline${ }^{\circ} \mathrm{C}$ & grau Celsius \\
\hline$g$ & grama \\
\hline $\mathrm{h}$ & hora \\
\hline $\mathrm{K}$ & Kelvin \\
\hline $\mathrm{Km}$ & kilômetro \\
\hline $\mathrm{Km}^{2}$ & kilômetro quadrado \\
\hline$L \min ^{-1}$ & litro por minuto \\
\hline$\mu g g^{-1}$ & micrograma por grama \\
\hline$\mu g \mathrm{~L}^{-1}$ & micrograma por litro \\
\hline$\mu \mathrm{g} \mathrm{mL} L^{-1}$ & micrograma por mililitro \\
\hline$\mu \mathrm{L}$ & microlitro \\
\hline $\mathrm{mg}$ & miligrama \\
\hline $\mathrm{mg} \mathrm{Kg}^{-1}$ & miligrama por kilograma \\
\hline $\mathrm{mg} \mathrm{L}^{-1}$ & miligrama por litro \\
\hline $\mathrm{mg} \mathrm{m}^{-3}$ & miligrama por metro cúbico \\
\hline $\mathrm{mL}$ & mililitro \\
\hline $\mathrm{mL} \min ^{-1}$ & mililitro por minuto \\
\hline $\mathrm{mm}$ & milímetro \\
\hline$M$ & molaridade $\left(\mathrm{mol} \mathrm{L}^{-1}\right)$ \\
\hline$n g L^{-1}$ & nanograma por litro \\
\hline $\mathrm{nm}$ & nanômetro \\
\hline rpm & rotação por minuto \\
\hline
\end{tabular}


segundo

W

Watts 


\section{INTRODUÇÃO}

O planeta Terra tem $70 \%$ de sua superfície coberta por água, sendo que somente uma pequena parte é apropriada para consumo humano. Cerca de 97\% da água de nosso planeta está distribuída nos mares e oceanos, portanto, água salgada. Dos $3 \%$ restantes, que é de água doce, a maior parte é constituída de geleiras e calotas polares, sendo estas regiões de difícil acesso. Lagos e rios são as principais fontes de água potável, somando pouco mais de $0,3 \%$ de toda a água doce disponível (MMA, 2006a).

A água é um elemento fundamental para a manutenção da vida em nosso planeta. Segundo a Organização das Nações Unidas (ONU), cada ser humano necessita de 20 a 50 litros de água doce para suprir suas necessidades básicas diárias, distribuídos entre ingestão direta, higiene e saneamento e preparação de alimentos (MMA, 2006a). Além de ser utilizada no abastecimento para consumo humano, a água é indispensável para um amplo ramo de atividades humanas, destacando-se o abastecimento industrial, a irrigação, a produção de energia elétrica, o lazer e a recreação, além da preservação das comunidades aquáticas.

O enorme e rápido crescimento das populações humanas, observado nas últimas décadas, tem levado a uma necessidade sempre crescente do aumento da produção de bens de consumo, que resultam na proliferação das indústrias, que consomem quantidades cada vez maiores de energia e matériasprimas, gerando poluição e outros inconvenientes para o meio ambiente.

O Brasil é o país mais rico do mundo em recursos hídricos, com cerca de 6 bilhões de $\mathrm{m}^{3}$ de água doce, porém, enfrenta vários problemas no que diz respeito à sua preservação e ao seu manejo. Em nosso país a idéia de que os efluentes industriais são os principais causadores da degradação dos recursos hídricos é ainda bastante divulgada. Porém, salvo alguns bolsões de alta concentração industrial, os efluentes domésticos ainda são os principais 
responsáveis pela situação em que se encontram os nossos mananciais (ROCHA et al., 2004).

As atividades humanas, tanto em seu consumo diário quanto nas operações industriais, geram quantidades significativas de resíduos. Tais substâncias têm normalmente três caminhos: são lançados na atmosfera, quando tal ação é possível; são lançados na massa líquida mais próxima, que é mais cômodo e mais barato, sendo tal massa, na maioria das vezes, um recurso hídrico utilizado como fonte de água para abastecimento público; ou são depositados em aterros sanitários ou industriais (MACÊDO, 2006).

O lançamento dos efluentes industriais e domésticos, o intemperismo e outros processos pedogênicos geram uma grande liberação de compostos indesejáveis ao meio ambiente, que podem vir a causar danos às vidas animal e vegetal. Os compostos inorgânicos, dentre eles os metais, podem agir de duas maneiras na fisiologia dos organismos, sendo tanto indispensáveis para a vida, quanto tóxicos, tendo estes a capacidade de afetar a atividade das espécies, levando, em alguns casos, à morte (BELO et al., 2010).

Os metais podem ocorrer naturalmente no ambiente e nos seres vivos em pequenas concentrações, atingindo desde partes por bilhão até partes por milhão. Alguns destes elementos, tais como $\mathrm{Zn}, \mathrm{Fe}, \mathrm{Mn}, \mathrm{Cu}$, Co e $\mathrm{Mo}$ são essenciais para os organismos, por participarem de processos fisiológicos vitais para a manutenção da vida, enquanto que outros elementos, tais como $\mathrm{Hg}, \mathrm{Pb}$ e Cd não têm nenhuma função biológica conhecida, tornando-se responsáveis por efeitos adversos na comunidade aquática, podendo afetar a atividade das espécies, causando perda de funções vitais, deformidades de órgãos, levando à morte. No entanto, ambos os elementos, essenciais e não essenciais, quando em altas concentrações, podem ser tóxicos (BONAl et al., 2009).

O abastecimento público e a preservação do equilíbrio das comunidades aquáticas estão entre os usos preponderantes dos recursos hídricos. A água é parte vital no desenvolvimento e na manutenção das espécies, sendo de fundamental importância o monitoramento de sua qualidade. 
O controle da qualidade da água no Brasil é realizado por meio de legislações ambientais que indicam os parâmetros a serem avaliados nos corpos d'água e seus valores máximos permitidos. A Resolução CONAMA n 357/2005 (complementada e alterada pela Resolução CONAMA n 430/2011) dispõe sobre a classificação dos corpos de águas superficiais e estabelece as condições para o lançamento de efluentes. Nesta Resolução, as águas do Território Nacional são classificadas de acordo com sua salinidade e seus diferentes usos preponderantes, sendo estabelecidos para elas as condições e os padrões de qualidade requeridos.

A Resolução CONAMA $n^{\circ}$ 396/2008 trata do monitoramento da qualidade das águas subterrâneas do Território Nacional, que dispõe sobre o enquadramento, prevenção e controle da poluição destes corpos d'água, estabelecendo valores máximos permitidos de parâmetros com maior ocorrência em águas subterrâneas, de acordo com seus usos preponderantes.

A Legislação Nacional que trata das águas destinadas a consumo humano e seus padrões de potabilidade é a Portaria n².914/2011, estabelecida pelo Ministério da Saúde, que substitui a Portaria $n^{\circ}$ 518/2004. Esta norma estabelece os procedimentos de controle e de vigilância da qualidade da água para consumo humano e seu padrão de potabilidade, indicando valores máximos permitidos de substâncias que representam risco à saúde humana, bem como os planos de amostragem para a análise dos parâmetros estabelecidos para a avaliação da qualidade da água de sistema de abastecimento.

A água é indispensável para o consumo humano, sendo de fundamental importância tê-la à disposição para um abastecimento satisfatório, que atenda aos padrões de potabilidade e que não ofereça riscos à saúde.

Os sedimentos são um importante compartimento que pode ser utilizado como ferramenta para a avaliação da qualidade dos ecossistemas aquáticos. Alguns estudos vêm demonstrando a importância da quantificação dos metais presentes neste compartimento, visto que este, além de ter a capacidade de acumular elementos-traço, também atua como fonte de nutrientes e contaminantes que podem retornar para a coluna d'água diante de alterações nas 
condições físico-químicas da água (LEMES, 2001; ARAIN et al., 2008; BEVILACQUA et al., 2009).

A contínua liberação de compostos químicos para o ambiente, em virtude de atividades humanas, tem resultado em vários níveis de contaminação do meio aquático. Os sedimentos contaminados representam potencial risco à saúde dos organismos aquáticos de água doce, estuários e ambientes marinhos, causando perigo para o ecossistema aquático como um todo (CCME, 1995).

Ao redor do mundo, várias pesquisas mostram altas concentrações de metais, elementos-traço e poluentes orgânicos em sedimentos de ecossistemas aquáticos próximos a áreas industrializadas e urbanizadas. Alguns destes compostos, dentre eles os elementos metálicos, são reconhecidamente tóxicos, sendo considerados possíveis elementos carcinogênicos a humanos, como os elementos As, Be, Cd e Ni (IARC, 2012).

A toxicidade dos metais no sedimento pode ser afetada dependendo da ligação entre os íons metálicos e as partículas constituintes do sedimento, sendo denominados metais ambientalmente disponíveis aqueles que possuem uma associação fraca com o compartimento sedimentar, ou seja, estão fracamente fixados por complexação pela matéria orgânica ou por adsorção com as partículas minerais como areia, silte e argila, podendo ser facilmente rompidos pela biota (BONAl et al., 2009).

O sedimento, por ser um importante indicador de contaminação, tem sido bastante estudado, ganhando notoriedade e constituindo o objeto central de projetos ambientais (JESUS, 2008).

No Brasil, uma das regiões hidrográficas em que há carência de dados de qualidade das águas é a região do Tocantins-Araguaia, em conseqüência da insuficiência das redes de monitoramento das águas (ANA, 2005).

A bacia do Tocantins-Araguaia possui uma área de drenagem de $918.822 \mathrm{~km}^{2}$, abrangendo parte das regiões Centro-Oeste, Norte e Nordeste. Ocupa $11 \%$ do território nacional, incluindo áreas dos estados de Goiás (21,4\% da bacia), Mato Grosso (14,7\% da bacia), Tocantins (30,2\% da bacia), Pará 
( $30,3 \%$ da bacia), Maranhão ( $3,3 \%$ da bacia) e Distrito Federal ( $0,1 \%$ da bacia), totalizando 409 municípios, com o Estado do Tocantins localizado integralmente na região hidrográfica do Tocantins-Araguaia (ANA, 2009).

A região hidrográfica do Tocantins-Araguaia (RHTA) é a mais extensa em termos de área de drenagem integralmente situada em território nacional. Possui um importante papel no desenvolvimento do país em virtude da presença, abundância e utilização dos recursos naturais, sendo palco de um dinâmico processo de desenvolvimento socioeconômico, que tem nos recursos hídricos um dos seus eixos (ANA, 2009). É uma das regiões de relevância em âmbito nacional pela expansão da fronteira agrícola, principalmente com relação ao cultivo de grãos, e pelo grande potencial hidroenergético (ANA, 2005).

Em virtude da importância que esta bacia tem para o Estado do Tocantins e também da carência de dados da qualidade da água da bacia hidrográfica do Tocantins-Araguaia, este estudo está inserido no projeto PROCAD - "Rede Cooperativa de Pesquisa e Formação de Recursos Humanos para a Gestão da Qualidade da Água Visando a Preservação de Recursos Hídricos e sua Biodiversidade no Estado do Tocantins", em parceria com a Universidade Federal do Tocantins, para fornecimento de parâmetros que possam contribuir com o banco de dados do projeto.

Portanto, a avaliação da qualidade dos sedimentos da região hidrográfica do Tocantins-Araguaia é um estudo importante, visto que os dados obtidos podem auxiliar nas futuras tomadas de decisão, servindo de referência para a SANEATINS e, conseqüentemente, para o Governo do Estado do Tocantins, para que assim gerem soluções ambientais que garantam a qualidade de vida da população. 


\section{OBJETIVOS}

\subsection{OBJETIVO GERAL}

Avaliar os níveis de concentração de metais ambientalmente disponíveis em sedimentos provenientes de pontos de captação de água para abastecimento público de Palmas, TO.

\subsection{OBJETIVOS ESPECÍFICOS}

- Realizar caracterização física dos sedimentos quanto ao teor de matéria orgânica e granulometria.

- Validar metodologia analítica para a determinação dos elementos As, $\mathrm{Cd}, \mathrm{Pb}$ e Se em sedimentos por Espectrometria de Absorção Atômica com Atomização Eletrotérmica em Forno de Grafite (GFAAS).

- Realizar estudo comparativo de dois métodos de digestão considerados na literatura como procedimentos analíticos para extração de metais ambientalmente disponíveis.

- Avaliar a qualidade dos sedimentos, quanto à contribuição de metais tóxicos, na fração ambientalmente disponível. 


\section{REVISÃO DA LITERATURA}

\subsection{SEDIMENTO}

\subsubsection{Definição e Constituição}

Os sedimentos aquáticos são constituídos por partículas de diferentes formas, tamanhos e composição química, sendo estas transportadas pela água, ar ou gelo de pontos de origem em ambientes terrestres. Ao entrarem no ambiente aquático, estas partículas são depositadas no fundo de rios (predominantemente em locais de correnteza baixa ou nula), lagos, represas, áreas alagáveis (costeiras ou continentais) e oceanos, levando importantes informações da bacia de drenagem na qual estão inseridos (MUDROCH \& MACKNIGHT, 1994 apud JESUS, 2008).

Segundo Bostelmann (2006), os sedimentos são constituídos basicamente por:

- Água intersticial que preenche os espaços entre as partículas, que equivale a aproximadamente $50 \%$ do volume do sedimento;

- Material inorgânico, rochas, fragmentos de conchas e grãos resultantes da erosão natural do material da crosta terrestre;

- Material orgânico;

- Material de origem antrópica.

Os sedimentos também podem ser definidos como as camadas de partículas minerais e orgânicas, com freqüência finamente granuladas, que se encontram em contato com a parte inferior dos corpos de água natural, como lagos, rios e oceanos (BAIRD, 2002). 


\subsubsection{Importância na Avaliação da Qualidade Ambiental}

Os sedimentos desempenham papel importante na avaliação da qualidade dos ecossistemas aquáticos, por indicar a presença de contaminantes que não permanecem solúveis após seu lançamento em águas superficiais.

A formação dos sedimentos tem sido alterada pela ação do homem, não sendo resultado apenas de processos naturais. O lançamento direto de efluentes industriais e municipais, além da erosão do solo causada pela construção de prédios e rodovias tem transformado o perfil dos sedimentos, tornando-o bem diferente daqueles presentes em ambientes naturais não perturbados. Tal compartimento aquático já não é mais considerado apenas um local de deposição de espécies químicas, mas sim um ambiente ativo que desempenha papel fundamental na redistribuição dessas espécies à biota aquática (BEVILACQUA et al., 2009).

Durante todo o ciclo hidrológico, muito menos do que $1 \%$ dos poluentes permanecem solúveis na água, enquanto que mais de $99 \%$ dos mesmos ficam acumulados nos sedimentos, que são considerados os principais depósitos e carreadores de contaminantes em ambientes aquáticos. Diante de tal importância, a análise de sedimentos tem sido comumente utilizada para se estimar a qualidade dos corpos aquáticos e o índice de poluição das bacias hidrográficas (BARTOLI et al., 2012).

Os sedimentos são o local onde se depositam muitos produtos químicos, especialmente metais tóxicos e compostos orgânicos, como os hidrocarbonetos policíclicos aromáticos (HPAs) e os pesticidas, substâncias estas consideradas tóxicas para a biota. Por esta razão, a proteção da qualidade do compartimento sedimentar é um componente do gerenciamento global da qualidade da água (BAIRD, 2002).

Os íons metálicos são considerados grandes impactantes do ecossistema aquático. Os fenômenos de acúmulo destas espécies nos sedimentos e a sua redisposição para a coluna d'água qualificam o 
compartimento sedimentar como de extrema importância em estudos de impacto ambiental, por registrar em caráter mais permanente, os efeitos da contaminação (BELO et al., 2010).

\subsubsection{Fatores de Mobilização de Metais em Sedimentos}

Os sedimentos atuam como depósitos de metais em ambientes marinhos e de água doce. A capacidade de acúmulo de contaminantes que este compartimento possui, o torna uma das mais importantes ferramentas de avaliação do impacto ambiental em ecossistemas aquáticos (ARAIN et al., 2008).

Segundo Baird (2002), os metais podem ser fixados nos sedimentos por três vias: adsorção, complexação ou precipitação.

a) Adsorção sobre as superfícies das partículas minerais

Uma das formas de fixação dos metais em sedimentos é através da adsorção sobre as superfícies das partículas minerais como areia, silte e argila. De acordo com Lemes (2001), esse fenômeno está relacionado com o tamanho da partícula mineral, sendo observado que, com a diminuição do grão, as concentrações de nutrientes e contaminantes aumentam, fato este que tem feito muitos pesquisadores preferirem trabalhar com a fração de grãos finos do sedimento $(<0,063 \mathrm{~mm})$.

A fração de granulometria mais fina possui maior capacidade de retenção de contaminantes devido às elevadas razões de área e superfície que partículas como argila e pequenos siltes possuem, o que resulta em uma grande capacidade de interação com íons e moléculas diversas, sendo a fração siltoargilosa de sedimentos superficiais, a que contém os principais carreadores geoquímicos tanto de origem natural, quanto antrópica, apresentando, conseqüentemente, as maiores concentrações de metais (FRANKLIN, 2010). 
A Tabela 1 apresenta a classificação granulométrica comumente utilizada para caracterização física de sedimentos, baseada na escala granulométrica de Wentworth (1922) citada por CONAMA (2004).

TABELA 1 - Classificação granulométrica dos sedimentos

\begin{tabular}{ccc}
\hline Classificação & $\begin{array}{c}\mathbf{P h i}^{\star} \\
(\boldsymbol{\Phi})\end{array}$ & $\mathbf{( m m )}$ \\
\hline Areia muito grossa & -1 a 0 & 2 a 1 \\
Areia grossa & 0 a 1 & 1 a 0,5 \\
Areia média & 1 a 2 & 0,5 a 0,25 \\
Areia fina & 2 a 3 & 0,25 a 0,125 \\
Areia muito fina & 3 a 4 & 0,125 a 0,062 \\
Silte & 4 a 8 & 0,062 a 0,00394 \\
Argila & 8 a 12 & 0,00394 a 0,0002 \\
\hline
\end{tabular}

${ }^{*}$ Phi $(\phi)$ : corresponde à unidade de medida do diâmetro da partícula do sedimento

b) Complexação pela matéria orgânica

A principal fonte de matéria orgânica em águas naturais é a descarga de esgotos sanitários, o que se deve ao fato de não haver sistema de tratamento de esgotos na maioria dos municípios brasileiros. Dentre os grupos de substâncias orgânicas encontrados nos esgotos estão proteínas (40 a 60\%), carboidratos (25 a $60 \%$ ) e óleos e graxas (10\%), além de outros compostos orgânicos sintéticos encontrados em menor quantidade como detergentes, pesticidas e fenóis (PIVELI \& KATO, 2005).

A complexação de metais pelas substâncias húmicas das partículas orgânicas, é uma das vias de incorporação destas espécies em sedimentos. Conforme Baird (2002), os materias húmicos têm uma grande afinidade pelos cátions de metais tóxicos, extraindo-os do compartimento aquático por meio de processos de troca iônica. Este processo de complexação ocorre, em grande 
parte, por meio da formação de complexos com os íons metálicos devido à interação destes com os grupos - $\mathrm{COOH}$ dos ácidos húmicos e fúlvicos presentes nas substâncias orgânicas.

A matéria orgânica está intimamente ligada aos elementos $\mathrm{Cu}, \mathrm{Zn}$ e Fe em sedimentos lacustres e ao $\mathrm{Cu}$ em sedimentos de rios. A matéria orgânica tem boa capacidade de adsorver metais tóxicos, podendo concentrar tais elementos no ambiente, impactando-o, ou também pode ser utilizada na remoção destes metais em ambientes contaminados. Uma importante propriedade física da matéria orgânica está associada com a textura fina dos sedimentos, que geralmente contém uma quantidade natural de material húmico derivado das transformações biológicas de plantas e restos de animais. Pelo fato do material húmico ser um dos responsáveis por aumentar a afinidade entre o sedimento e os metais, pode-se dizer que este material pode estar presente como uma discreta partícula ou como uma camada de partículas de argila (FÖRSTNER \& WITTMANN, 1981 apud LEMES, 2001; BONAl et al., 2009).

Segundo Bevilacqua et al. (2009) além do Cu, o Pb também apresenta forte interação com a matéria orgânica, podendo estes ser adsorvidos ou, principalmente, complexados, formando complexos com o material húmico.

c) Reações de precipitação

A precipitação dos metais nos sedimentos pode ocorrer na forma de sulfetos, carbonatos, hidróxidos ou fosfatos (BAIRD, 2002; SANTOS et al., 2008). A toxicidade para os organismos associados ao metal pode variar, mesmo tratando-se de sedimentos diferentes com a mesma concentração total de íons de um metal. Isso se deve, principalmente, pela presença de sulfetos nos sedimentos, os quais controlam a disponibilidade destes compostos. Alguns metais tóxicos, como o $\mathrm{Hg}, \mathrm{Cd}$ e $\mathrm{Pb}$, formam sulfetos muito insolúveis, os quais também podem ser formados por Ni e muitos outros metais (BAIRD, 2002). 


\subsubsection{Fatores de Remobilização de Metais para a Água}

Além da capacidade de acumular elementos-traço, os sedimentos atuam como fonte de nutrientes e contaminantes que podem ser liberados para a coluna d'água por processos de difusão, ressuspensão, dragagem, entre outros (JESUS, 2008).

O estudo de metais tóxicos tem grande importância na avaliação da qualidade de ecossistemas aquáticos pelo fato desses elementos não serem naturalmente degradados, nem permanecerem fixados pelos sedimentos continuamente, podendo retornar para a coluna d'água quando alteradas algumas de suas condições ambientais, tais como $\mathrm{pH}$, potencial redox, salinidade ou presença de quelantes orgânicos (LEMES, 2001; COTTA et al., 2006; SANTOS et al., 2008; BEVILACQUA et al., 2009; FERREIRA et al., 2010; Yu et al., 2010).

a) $\mathrm{pH}$

O aumento da acidez da coluna d'água, geralmente provocado pelo aporte de despejos ácidos de fontes antrópicas e/ou pelas chuvas ácidas pode provocar a remobilização dos metais para a água. Com a queda do $\mathrm{pH}$, pode ocorrer uma solubilização dos carbonatos e hidróxidos, que modifica o processo de dessorção de cátions metálicos devido à competição com os íons $\mathrm{H}^{+}(\mathrm{ROCHA}$ et al., 2004).

b) Potencial redox

O Fe e o Mn são elementos considerados carreadores de metais pelo fato destes poderem ser adsorvidos nos hidróxidos ou óxidos de ferro e manganês (FÖRSTNER \& WITTMANN, 1981 apud LEMES, 2001; SANTOS et al., 2008).

As mudanças do potencial redox, normalmente junto com a diminuição do potencial de oxigênio devido à eutrofização avançada, também são fatores 
importantes, pois acarretam a dissolução parcial ou completa dos hidróxidos de ferro e manganês, levando, conseqüentemente, à liberação dos metais incorporados ou adsorvidos (LEMES, 2001).

c) Salinidade

O aumento da salinidade é outro fator que influencia na remobilização dos metais para a coluna d'água, pois a elevada concentração de sais (cátions de metais alcalinos e alcalino-terrosos) aumenta a competição por sítios de complexação entre estes cátions e os íons metálicos adsorvidos nas partículas sólidas (LEMES, 2001; ROCHA et al., 2004).

d) Presença de quelantes orgânicos

As substâncias orgânicas são capazes tanto de complexar os metais que podem estar adsorvidos nas partículas sólidas, aumentando sua solubilidade, quanto alterar a disponibilidade destes para a vida aquática, fato este que pode ser influenciado pelo aumento do uso de agentes naturais e sintéticos (FÖRSTNER \& WITTMANN, 1981 apud LEMES, 2001).

\subsubsection{Elementos-Traço}

Os elementos-traço são os elementos químicos que ocorrem na natureza, de um modo geral, em pequenas concentrações, não ultrapassando 0,1\% (1000 mg Kg-1). A denominação "elementos-traço" relaciona-se com sua abundância e inclui elementos de diferentes propriedades químicas, podendo ser relacionada tanto para metais quanto não metais (ESTEVES, 2011).

Segundo Lemes (2001) os elementos em nível de traços são aqueles com concentrações que variam entre 0,01 e $100 \mathrm{~g} \mathrm{~L}^{-1}$, enquanto que os ultratraços, são os elementos com concentração abaixo de $0,01 \mu \mathrm{g} \mathrm{L}^{-1}$. 
Alguns elementos-traço como $\mathrm{Mg}, \mathrm{Fe}, \mathrm{Zn}, \mathrm{Mn}, \mathrm{Cu}, \mathrm{Co}, \mathrm{Mo}$ e B são essenciais aos seres vivos, ainda que em pequenas concentrações. Outros elementos, como $\mathrm{Hg}, \mathrm{Pb}, \mathrm{Cd}, \mathrm{Ag}, \mathrm{Cr}$, $\mathrm{Ni}$ e $\mathrm{Sn}$, pelo contrário, não têm nenhuma função biológica conhecida e são geralmente tóxicos a uma grande variedade de organismos. Os elementos-traço essenciais aos organismos podem tornar-se tóxicos, quando em altas concentrações (ESTEVES, 2011).

Os metais e não metais podem estar presentes nos mais variados compartimentos, tais como solo, água, ar, sedimento e organismos vivos, podendo atuar como elementos essenciais (micronutrientes) ou como contaminantes (QUINÁGLIA, 2006).

As características gerais, os usos, as principais fontes de origem no meio ambiente e a toxicidade dos elementos-traço abordados neste estudo e que são freqüentemente citados na literatura são apresentados a seguir.

- Alumínio (Al): considerado o terceiro elemento mais abundante na crosta terrestre. O alumínio e seus sais são usados no tratamento da água, como aditivo alimentar, na fabricação de latas, telhas, papel alumínio, na indústria farmacêutica, etc. Pode atingir a atmosfera como material particulado por meio da suspensão de poeiras dos solos e também da combustão do carvão. Não existem indicações de toxicidade aguda por via oral, apesar da ampla ocorrência em alimentos, água potável e medicamentos (CETESB, 2009).

- Antimônio (Sb): é um metalóide raramente encontrado na natureza. É um elemento usado na tecnologia de semicondutores para detectores infravermelhos, diodos e ligas, usado para aumentar a dureza e força mecânica do chumbo, baterias, armas, maçanetas, soldas, utilizado como camada protetora para inibir a corrosão, entre outros usos. Sua inalação pode provocar alterações cardíacas, renais e hepáticas. É um elemento altamente móvel nos solos, enquanto que quando presente nas águas é rapidamente adsorvido nos sedimentos (QUINÁGLIA, 2006). 
- Arsênio (As): é um metalóide relativamente comum, que pode estar presente na água, ar, solo, plantas e em organismos vivos em concentrações de partes por bilhão a partes por milhão (EISLER, 2000). As fontes de arsênio para o ambiente são decorrentes do uso de pesticidas, de sua emissão durante a mineração e fundição de ouro, chumbo, cobre e níquel (pois ocorre habitualmente nestes minérios), da produção de ferro e aço, e da combustão de carvão, do qual é um contaminante. $O$ arsênio também é um elemento presente em compostos usados na preservação da madeira. Sua ingestão por meio da água, especialmente da subterrânea, é a principal fonte de arsênio para a maioria das pessoas. Em muitos alimentos existem níveis secundários de arsênio e, efetivamente, uma quantidade traço deste elemento é essencial para a boa saúde das pessoas. É um elemento carcinogênico para os seres humanos. Sua inalação e, provavelmente, também ingestão, podem causar câncer de pulmão. A ingestão de arsênio causa câncer de pele e de fígado, podendo causar também, câncer de bexiga e de rins (BAIRD, 2002). O arsênio é encontrado naturalmente na água associado à ambientes geoquímicos como os sedimentos (QUINÁGLIA, 2006).

- Bário (Ba): é um metal utilizado nas indústrias da borracha, têxtil, cerâmica, farmacêutica, entre outras, além de ser utilizado na extração da bauxita. Além disso, seus sais são importantes industrialmente na elaboração de cores, fogos de artifício, fabricação de vidros, inseticidas, etc. É um elemento essencial ao homem e em elevadas concentrações causa efeitos no coração, no sistema nervoso, constrição dos vasos sangüíneos, elevando a pressão arterial, podendo levar rapidamente à morte, dependendo da dose e da solubilidade do sal de bário (CETESB, 2009).

- Berílio (Be): é utilizado em indústrias nucleares como fonte de nêutrons, fabricação de ligas de Cu-Be para uso em contatos elétricos, molas para relógios, eletrodos, interruptores, material utilizado na 
indústria aeroespacial (satélites e mísseis), tubos fosforescentes de televisores e em ligas de alta resistência à tração e à fadiga. $O$ berílio é altamente permeável aos raios- $\mathrm{X}$, sendo transparente às radiações microondas. Seus compostos estão associados com lesões nos pulmões e ossos. Há uma evidência limitada de que se estiver presente na água de abastecimento público, pode ser uma via de risco de câncer (QUINÁGLIA, 2006).

- Boro (B): é um metalóide que ocorre naturalmente em depósitos concentrados do mineral bórax $\left(\mathrm{Na}_{2} \mathrm{~B}_{4} \mathrm{O}_{7} \cdot 10 \mathrm{H}_{2} \mathrm{O}\right)$. As fontes de boro no ambiente são por meio de rejeitos de lavanderia, de produtos agrícolas e fertilizantes, da combustão do carvão, de atividades de mineração e processamento, da produção de vidros e cerâmicas, dentre outras. $\mathrm{O}$ boro é um elemento-traço essencial para o crescimento e desenvolvimento de algumas espécies de plantas, sendo utilizado como micronutriente na agricultura. Elevados níveis naturais de boro no ambiente podem estar associados com sedimentos marinhos, fontes térmicas, grandes depósitos de minerais de boro, água do mar e algumas águas subterrâneas (EISLER, 2000). A intoxicação por boro na forma de bórax causa medo de descer escadas, ladeiras ou rampas, salivação, náuseas, vômitos, cólicas, insuficiência renal com perda de albumina, sangue pela urina, etc. A intoxicação por ácido bórico causa diabetes, frio generalizado, eritema do tronco e membros superiores e edema ao redor dos olhos, etc (QUINÁGLIA, 2006).

- Cádmio (Cd): é um metal relativamente raro na crosta terrestre. É utilizado em galvanoplastia, na produção de pigmentos, na fabricação de estabilizadores de plásticos, além de ser utilizado na indústria eletrônica em baterias cádmio-níquel dos telefones celulares, além de outras baterias e pilhas recarregáveis. A emissão de $\mathrm{Cd}$ para o ambiente ocorre através de fumos e poeiras deste elemento, em meios industriais e de incineração de plásticos e outros materiais que o utilizam como pigmento ou estabilizante, além de ser obtido também através de fertilizantes, queima de combustíveis fósseis e descargas de 
águas residuais urbanas e lamas. Este elemento é um dos metais mais tóxicos, que em concentrações suficientes (de 0,8 a $10 \mu \mathrm{g} \mathrm{L}^{-1}$ ), é tóxico para todas as formas de vida, incluindo microorganismos, plantas maiores, animais e homem (EISLER, 2000). Segundo resumos on line da Agência de Proteção Ambiental dos Estados Unidos (do inglês, United States Environmental Protection Agency - USEPA) a exposição ao cádmio pode causar uma série de efeitos nocivos à saúde. Ingerir algum alimento ou água com elevado nível de cádmio pode irritar severamente ou apenas incomodar o estômago, além de causar vômitos e diarréia. A aspiração de altas concentrações deste metal pode causar graves irritações pulmonares, podendo levar à morte. Entretanto, a maior preocupação está na exposição a baixas doses por longos períodos, que pode danificar os rins. Embora estas doses não causem risco de vida, pode haver formação de pedras nos rins e danos ao esqueleto, podendo ser doloroso e debilitante. $O$ cádmio e alguns de seus compostos são considerados prováveis ou suspeitos carcinogênicos.

- Chumbo $(\mathrm{Pb})$ : é um elemento conhecido desde a Antiguidade, usado na Roma Antiga em recipientes de água, canalização e utensílios domésticos, além também de ser adicionado em vinhos como flavorizante. $\mathrm{O}$ chumbo pode ser encontrado no ambiente sob duas formas iônicas mais estáveis, $\mathrm{Pb}^{2+}$ e $\mathrm{Pb}^{4+}$, porém $\circ \mathrm{Pb}^{2+}$, seus compostos e complexos são os que ocorrem com maior freqüência na natureza, sendo a forma iônica mais tóxica do que a forma de complexos inorgânicos. É um poluente ambiental extremamente tóxico e penetrante (MACÊDO, 2006). O chumbo está presente no ar, no tabaco, nas bebidas e nos alimentos, sendo também utilizado na fabricação de baterias, tintas, esmaltes, inseticidas, vidros, ligas metálicas, entre outros. Sua presença no ambiente ocorre devido à deposição atmosférica ou lixiviação do solo. A ingestão de alimentos e bebidas contaminados é a principal fonte de chumbo para o organismo humano. Sua exposição pode afetar quase todos os órgãos e sistemas 
do corpo, sendo o mais sensível o sistema nervoso, tanto em adultos quanto crianças. A exposição aguda causa sede intensa, sabor metálico, inflamação gastrintestinal, vômitos e diarréias, enquanto que a exposição prolongada causa efeitos renais, cardiovasculares, neurológicos, nos músculos e ossos, entre outros. O chumbo é um elemento cumulativo no organismo, que provoca um envenenamento crônico chamado saturnismo (CETESB, 2009).

- Cobalto (Co): é utilizado na fabricação de ímãs, instrumentos e ferramentas de alta velocidade e de serviço pesado, em ligas de corte, no aço inoxidável e na eletrodeposição de metais. $O$ cobalto radioativo ${ }^{60} \mathrm{Co}$ é útil para radioterapia e como traçador. A intoxicação por este elemento pode causar dores abdominais, vômitos, náuseas, alterações na tireóide e no pâncreas, lesões cardíacas e distúrbios circulatórios. O contato com a pele ou sua inalação pode provocar irritações. É um possível elemento com potencial cancerígeno. Quando insuficiente no organismo, pode causar anemia, falta de apetite, parada do crescimento, irritabilidade e falta de concentração (QUINÁGLIA, 2006).

- Cobre $(\mathrm{Cu})$ : é um metal cujas três principais fontes minerais são a calcocita $\left(\mathrm{Cu}_{2} \mathrm{~S}\right)$, calcopirita $\left(\mathrm{CuFeS}_{2}\right)$ e a malaquita $\left[\mathrm{CuCO}_{3} \mathrm{Cu}(\mathrm{OH})_{2}\right]$ (EISLER, 2000). Ocorre em águas naturais em pequenas concentrações. Maiores teores são decorrentes de sua utilização como algicida, lançamento de despejos industriais (principalmente das atividades de mineração e fundição) e do desgaste de canalização de cobre (LEMES, 2001). O cobre é essencial para diversas funções orgânicas, como a mobilização do ferro para a síntese da hemoglobina, a síntese do hormônio da adrenalina e a formação dos tecidos conjuntivos. Sua deficiência em organismos humanos é caracterizada pela anemia, provocada pela síntese deficiente de hemoglobina, enquanto que seu excesso leva a vômitos, hipotensão, icterícia, coma e até mesmo à morte (MACÊDO, 2006). 
- Cromo (Cr): as principais formas químicas em que aparece são $\mathrm{Cr}(\mathrm{VI})$, considerada tóxica e $\mathrm{Cr}$ (III), considerada nutriente essencial. Os compostos de $\mathrm{Cr}$ (III) são utilizados como pigmentos e curtimento de couro, enquanto que os de $\mathrm{Cr}(\mathrm{VI})$ são largamente empregados em indústrias químicas, especialmente em galvanoplastias, onde a cromeação é um dos revestimentos de peças mais comuns (EISLER, 2000; PIVELI \& KATO, 2005). O Cr (III) é um elemento essencial para o metabolismo da glicose, proteínas e gordura de mamíferos, e os sinais de deficiência em humanos são a perda de peso e a tolerância diminuída à glicose. Já os compostos de $\mathrm{Cr}$ ( $\mathrm{VI})$ são corrosivos, produzindo reações alérgicas na pele logo após o contato, independente da dose. Concentrações elevadas acarretam ulcerações na pele, perfurações no trato respiratório e irritação no trato gastrointestinal (MACÊDO, 2006).

- Ferro $(\mathrm{Fe})$ : é um elemento muito freqüente na crosta terrestre, por isso seus compostos são encontrados em todos os corpos d'água, mesmo que em concentrações muito reduzidas. É um micronutriente indispensável para o metabolismo dos seres vivos (ESTEVES, 2011). $O$ ferro ocorre na natureza na forma elemental $\left(\mathrm{Fe}^{0}\right)$, mas a maior parte ocorre na forma combinada com o oxigênio, silício e enxofre. Quase todas as rochas e solos contêm ao menos traços de ferro. É encontrado em vários alimentos como leite, carnes em geral, gema do ovo, feijão, fígado, germe de trigo, algas marinhas, verduras, levedo e melado. As atividades humanas que liberam ferro para o ambiente são diversas, dentre elas estão as indústrias de aço, ligas em geral, soldas, magnéticos, transformadores elétricos, catálise de amônia, fabricação de máquinas, trilhos e atividades de mineração. Além disso, pode ser disposto no ambiente por meio do uso de lodo de esgoto, liberação de resíduos sólidos sobre superfícies e pelo uso excessivo de fertilizantes. O ferro e seus compostos não são considerados tóxicos, porém quando em doses elevadas podem causar dores abdominais, palidez, cansaço, sonolência, vômitos, diarréias e colapso cardiovascular. $\mathrm{O}$ 
excesso de ferro pode causar fibrose generalizada de órgãos internos, pigmentação bronzeada da pele, diabete e fibrose pancreática. É um elemento considerado essencial para o organismo, sendo o núcleo central da hemoglobina (na forma de $\mathrm{Fe}^{2+}$ ), com $70 \%$ de todo o ferro presente no corpo humano. Os sais de ferro II são recomendados, em quantidades adequadas, para o combate à anemia, cansaço, dores ósseas e nanismo (QUINÁGLIA, 2006).

- Fósforo $(\mathrm{P})$ : é considerado um macronutriente, pois, assim como o nitrogênio, é um dos principais nutrientes para os processos biológicos, sendo exigido em grandes quantidades pelas células. É um elemento que aparece em águas naturais devido, principalmente, às descargas de esgotos sanitários, que apresentam como constituintes majoritários, a matéria orgânica fecal e os detergentes em pó. Além disso, outras fontes antrópicas para o ambiente são os efluentes de indústrias de fertilizantes, pesticidas, químicas em geral, conservas alimentícias, abatedouros, frigoríficos e laticínio, além das águas drenadas em áreas agrícolas e urbanas. O maior problema causado pelo excesso de fósforo no ambiente são os processos de eutrofização das águas naturais (CETESB, 2009).

- Manganês (Mn): é um metal que está presente em quase todos os tipos de solos, ocorrendo naturalmente em águas superficiais e subterrâneas. As fontes antrópicas de manganês para o ambiente decorrem de seu uso nas indústrias de aço, ligas metálicas, baterias, vidros, oxidantes para limpeza, fertilizantes, vernizes, suplementos veterinários, entre outros usos (CETESB, 2009). O manganês é um elemento essencial para o organismo humano, porém a exposição a altas concentrações pode causar efeitos graves. Sua inalação pode acarretar distúrbios mentais e emocionais, além da perda da agilidade em movimentos. A ingestão de água potável contaminada por manganês pode ser a responsável por sintomas de fraqueza, rigidez muscular e tremor das mãos (MACÊDO, 2006). 
- Mercúrio $(\mathrm{Hg})$ : O mercúrio é um metal extremamente tóxico ao homem. É um elemento usado na produção eletrolítica do cloro, em termômetros, barômetros, lâmpadas fluorescentes, equipamentos elétricos, amálgamas e como matéria prima para compostos de mercúrio. No Brasil, é largamente utilizado em garimpos para extração do ouro, uma atividade extremamente impactante ao meio ambiente. As principais fontes antrópicas para o meio aquático são as indústrias cloro-álcali de células de mercúrio, vários processos de mineração e fundição, efluentes de estações de tratamento de esgotos, indústrias de tintas, entre outras. É um elemento tóxico, letal com doses de 3 a 30 gramas. Apresenta efeito cumulativo no organismo, podendo provocar lesões cerebrais. A principal via de exposição é por ingestão de alimentos. A intoxicação aguda pode provocar náuseas, vômitos, dores abdominais, diarréia, danos nos ossos, podendo levar à morte em 10 dias, enquanto que a intoxicação crônica afeta as glândulas salivares, os rins e as funções psicológicas e psicomotoras (CETESB, 2009). metilmercúrio $\left(\mathrm{CH}_{3} \mathrm{Hg}^{+}\right)$é a forma mais perigosa do mercúrio, seguida pelo vapor do elemento. A maior parte do mercúrio presente em seres humanos encontra-se na forma de metilmercúrio, e quase todo o composto procede do peixe que compõe nossa dieta alimentar (BAIRD, 2002).

- Molibdênio (Mo): O molibdênio é considerado um micronutriente essencial para os organismos vivos, que tem papel fundamental na atividade da enzima xantina oxidase, uma flavoproteína Fe-Mo. É um elemento rotineiramente adicionado a solos, plantas e águas, para atingir os efeitos de enriquecimento ou de equilíbrio. O molibdênio é um elemento relativamente raro que é utilizado principalmente nas indústrias de aeronaves e armas. É bastante utilizado também na fabricação de produtos de alta resistência, como nas ligas de aço, na produção de tubos de raios- $X$, catalisadores, pigmentos, reagentes químicos, fertilizantes, entre outros usos. As fontes antrópicas de molibdênio para o ambiente incluem a queima de combustíveis fósseis, 
além das atividades de fundição, mineração e fresagem do aço, cobre e urânio, bem como do molibdênio. É considerado um dos elementostraço essenciais para o organismo humano, podendo ter propriedades anticancerígenas, além de auxiliar na prevenção de cáries dentárias. $\mathrm{O}$ excesso de molibdênio pode causar fraqueza generalizada, fadiga, dor de cabeça, irritabilidade, falta de apetite, dores nas articulações e músculos, perda de peso, pele avermelhada e úmida, tremores das mãos, tontura, entre outros sintomas (EISLER, 2000).

- Níquel (Ni): é um metal utilizado em processos de galvanoplastia, na fabricação de aço inoxidável, na manufatura de baterias $\mathrm{Ni}-\mathrm{Cd}$, moedas, pigmentos, entre outros usos. As fontes antrópicas deste elemento para o ambiente são, principalmente, a queima de combustíveis, além da mineração e fundição do metal, fusão e modelagem de ligas, indústrias de eletrodeposição, fabricação de alimentos, artigos de panificadoras, refrigerantes e sorvetes aromatizados. $O$ efeito adverso mais comum da exposição ao níquel é a reação alérgica, podendo também causar irritação gástrica caso haja ingestão de doses elevadas (CETESB, 2009). O níquel é um elemento essencial, em pequenas doses, para os seres humanos, visto que é responsável pela catálise de um grande número de sistemas enzimáticos, fosfatase, amilase pancreática, etc, reforça a ação da insulina, além de existirem indícios de sua participação nos processos bioquímicos das proteínas e ácidos nucléicos. Sua deficiência pode causar degeneração do fígado, distúrbios no crescimento e reprodução, prejuízo na utilização do ferro e diminuição das concentrações de cálcio e magnésio e aumento das concentrações de cobre e zinco no fêmur. (QUINÁGLIA, 2006).

- Potássio (K): é um elemento encontrado em baixas concentrações nas águas naturais visto que as rochas que o contêm são relativamente resistentes às ações do tempo. As fontes antrópicas de potássio para as águas doces são decorrentes das descargas industriais e de áreas agrícolas, visto que seus compostos são largamente utilizados na 
indústria e em fertilizantes para a agricultura. É um elemento nutricional essencial para a biota aquática (CETESB, 2009).

- Prata $(\mathrm{Ag})$ : é muito utilizada em indústrias fotográficas, operações de fundição, produção de baterias, moedas, jóias, utensílios de cozinha, dentre outros. Na medicina, os sais de prata são utilizados como produtos cáusticos, germicidas, anti-sépticos e adstringentes. A exposição excessiva e prolongada a prata e aos seus sais, seja por contato com a pele, inalação ou ingestão, pode provocar uma doença chamada argiria, caracterizada por causar mudança de cor da pele para uma coloração cinza-azulada (EISLER, 2000).

- Selênio (Se): O selênio é um elemento que apresenta importância bioquímica, tanto como elemento benéfico ou essencial para humanos e algumas espécies de plantas e animais, quanto tóxico, dependendo das concentrações e formas químicas em que está presente no ambiente. Este elemento é liberado para o ambiente em decorrência de atividades humanas, que incluem a queima de combustíveis fósseis e a fundição de metais, bem como por intemperismo de rochas naturais. É considerado um nutriente essencial que constitui parte integrante da enzima glutationa peroxidase, podendo ter papel importante em outros compostos biologicamente ativos, especialmente na vitamina $E$ e nos aminoácidos sulfurados. O selênio pode favorecer ou afetar o crescimento, a sobrevivência e a reprodução de vários organismos vivos, incluindo humanos. Sua deficiência é considerada por alguns pesquisadores como uma ameaça maior para a saúde do que seu envenenamento. A deficiência deste elemento pode levar a uma suscetibilidade ao câncer, artrite, hipertensão, doenças do coração e há possibilidade de doenças periodontais e catarata (EISLER, 2000). Enquanto que seu excesso causa tristeza e melancolia, dores de cabeça, impotência, acne e selenose (queda de cabelo e unha) (QUINÁGLIA, 2006). 
- Sódio $(\mathrm{Na})$ : é um dos elementos mais abundantes na crosta terrestre, sendo encontrado em todas as águas naturais na forma iônica $\mathrm{Na}^{+}$pelo fato de seus sais serem altamente solúveis em água. É encontrado também em plantas e animais por ser um elemento ativo para os organismos vivos. Sua concentração nas águas pode aumentar em decorrência de lançamentos de esgotos domésticos, efluentes industriais e do uso de sais em rodovias para controlar neve e gelo, principalmente em países da América do Norte e Europa. É um elemento comumente medido em águas utilizadas para dessedentação de animais ou para agricultura, particularmente na irrigação, pois quando seu teor eleva-se em certos tipos de solo, sua estrutura pode ser degradada pelo restrito movimento da água e o crescimento das plantas pode ser afetado (CETESB, 2009).

- Titânio (Ti): é um elemento presente em cinzas de carvão e plantas, além de quase sempre presente em rochas ígneas. As fontes antrópicas deste elemento para o ambiente são as indústrias aeroespaciais, ligas Mo-Fe-Mn-Al, estruturas metálicas substituindo o aço, fabricação de tintas, próteses dentárias, pinos de fraturas, pastas de dentes e indústrias de cosméticos. A inalação deste elemento na forma de pó pode causar problemas respiratórios, e alguns de seus compostos orgânicos provocam câncer e ejaculação precoce (QUINÁGLIA, 2006).

- Vanádio (V): é um elemento que pode ser encontrado em baixas concentrações em alguns elementos como feijão de soja, ovos, aveia, azeite, peixes, vários tipos de grãos, maçãs, semente de girassol, entre outros. É um elemento que pode ser liberado para o ambiente por meio de indústrias nucleares e de aviação, fabricação de aço, fabricação de cerâmicas, catalisador na produção de ácido sulfúrico, anilina negra, entre outras. Se for inalado em concentrações altas, pode causar bronquite e pneumonia. Pode causar irritação dos pulmões, garganta, olhos e cavidades nasais, doenças cardiovasculares, inflamação de 
estômago e intestinos, lesões no sistema nervoso central, sangramento do fígado e rins, lesões na pele, dores de cabeça, além de outros efeitos. É um elemento que pode ser encontrado no meio ambiente, especialmente nas algas, plantas, invertebrados, peixes e muitas outras espécies (QUINÁGLIA, 2006).

- Zinco (Zn): é um elemento-traço essencial para os seres humanos, visto que atua na atividade da insulina e de diversos compostos enzimáticos. A carência de zinco pode levar ao atraso no crescimento dos animais e quando ingerido em concentrações muito elevadas, o que é extremamente raro, pode acumular-se em outros tecidos do organismo humano. É utilizado na fabricação de ligas e latão, na galvanização do aço, na borracha como pigmento branco, em suplementos vitamínicos, em protetores solares, desodorantes e xampus, entre outros usos. Concentrações elevadas de zinco podem ocorrer em água de torneira devido à dissolução do metal das tubulações (CETESB, 2009).

\subsubsection{Metais Ambientalmente Disponíveis}

Os metais ambientalmente disponíveis são aqueles que estão associados às frações mais lábeis ou reativas dos sedimentos, podendo ser facilmente liberados diante de alterações nas condições ambientais da coluna d'água. Apesar de nem todos os elementos químicos analisados neste estudo serem metais, pequena parte pertence à classe dos semimetais ( $\mathrm{B}, \mathrm{Si}, \mathrm{As}$ e $\mathrm{Sb}) \mathrm{e}$ à classe dos não metais $(\mathrm{P}$ e Se), por conveniência, neste trabalho, serão todos chamados de metais ambientalmente disponíveis.

Segundo Cotta et al. (2006), as condições ambientais que podem redisponibilizar os metais acumulados em sedimentos de lagos e rios para a coluna d'água são reações de oxirredução, ou processos de ressuspensão de 
origem física (correnteza), biológica (atividade dos organismos que vivem nos sedimentos) ou humanas (dragagem e navegação).

Os metais ambientalmente disponíveis são aqueles que estão comumente ligados aos sedimentos por associações fracas e que podem ser facilmente rompidas pela biota. Estes compostos podem ser de origem natural ou antrópica, e estão associados às fases consideradas mais instáveis e reativas do sedimento, sendo sua determinação de fundamental importância pelo fato de dar uma noção do potencial poluente dos metais contidos no sedimento, além dos índices de contaminação mais recentes (LEMES, 2001; SNAPE et al., 2004).

Os métodos de lixiviação utilizados para solubilizar os metais presentes em matrizes ambientais como em amostras de solos e sedimentos, baseiam-se nas piores condições ambientais, sendo estas capazes de extrair os metais ambientalmente disponíveis, sem atacar a fração detrítica altamente resistente, composta principalmente por óxidos de Al e Si (BOSTELMANN, 2006).

A solubilização das amostras de sedimento é uma etapa fundamental em estudos de quantificação de metais, visto que na maioria das técnicas espectroscópicas, dentre elas a Espectrometria de Absorção Atômica com Atomização Eletrotérmica em Forno de Grafite (GFAAS: Graphite Furnace Atomic Absorption Spectrometry), a Espectrometria de Absorção Atômica com Geração de Vapor Frio (CVAAS: Cold Vapor Atomic Absorption Spectrometry) e a Espectrometria de Emissão Óptica com Plasma Indutivamente Acoplado (ICPOES: Inductively Coupled Plasma Optical Emission Spectrometry), normalmente é utilizada a introdução de soluções, por isso a necessidade da solubilização de amostras sólidas.

Dentre os procedimentos analíticos de tratamento de amostras de sedimento reportados na literatura, estão os métodos de extração seqüencial, em que são utilizados diferentes tipos de ácidos e concentrações, e de extração simples, em que apenas um tipo de ácido é aplicado.

Os métodos analíticos de extração seqüencial ou seletiva são muito utilizados quando o objetivo do estudo é avaliar a distribuição dos metais nas 
diferentes frações que compõem o sedimento, para assim determinar a proporção de metal que está associada a cada fase geoquímica do compartimento. Tais métodos consistem em submeter o sedimento sob condições de extração em etapas cada vez mais energéticas (tipos de reagente, concentração, tempo e temperatura) (BEVILACQUA et al., 2009).

Os procedimentos analíticos desenvolvidos por Tessier et al. e modificados por Förstner são os mais utilizados na literatura (LEMES, 2001). A Tabela 2 resume um método de extração seqüencial utilizado recentemente por Bevilacqua et al. (2009), e que foi baseado nos estudos de Kersten e Förstner (1986, 1987).

TABELA 2 - Esquema de extração seletiva em sedimentos

\begin{tabular}{|c|c|}
\hline Fração & Condições \\
\hline Trocável & Acetato de amônio (pH 7) \\
\hline Ligada a carbonatos & Acetato de sódio $1 \mathrm{M}$ \\
\hline Facilmente redutível & $\mathrm{NH}_{2} \mathrm{OH} . \mathrm{HCl} 0,01 \mathrm{M}(\mathrm{pH} 2)$ \\
\hline Moderadamente redutível & $\mathrm{H}_{2} \mathrm{C}_{2} \mathrm{O}_{4} /\left(\mathrm{NH}_{4}\right)_{2} \mathrm{C}_{2} \mathrm{O}_{4} 0,1 \mathrm{M}(\mathrm{pH} 3)$ \\
\hline Matéria orgânica e sulfetos & $\begin{array}{c}\mathrm{H}_{2} \mathrm{O}_{2} 30 \% \text { em } \mathrm{HNO}_{3} 0,02 \mathrm{M} \text { e acetato de } \\
\text { amônio }\end{array}$ \\
\hline Residual & $\mathrm{HNO}_{3}$ \\
\hline
\end{tabular}

Fonte: BEVILACQUA et al., 2009

Outra forma de solubilização de metais em amostras de sedimento é por meio do método de extração simples, em que um tipo de ácido ou uma mistura de dois ou três ácidos diferentes são utilizados. Esse tipo de solubilização divide-se entre os procedimentos de digestão total e de digestão parcial.

O procedimento de digestão total geralmente utiliza como principal reagente o ácido fluorídrico, considerado um ácido extremamente forte e tóxico. 
De acordo com Aguiar et al. (2007), a digestão total pode incluir uma mistura dos ácidos nítrico, fluorídrico e clorídrico, que é capaz de solubilizar os elementos associados à todas as frações geoquímicas do sedimento, tanto as consideradas frações potencialmente lábeis, quanto à última fração, que está associada à estrutura cristalina dos minerais. Apesar deste tipo de solubilização ser considerado bastante eficiente, é também um método perigoso, pois o ácido fluorídrico é um reagente que requer bastante segurança e prevenção em seu manuseio e descarte.

Já o método de digestão parcial mostra-se eficiente para a extração de metais, em sedimentos, das frações mais facilmente disponíveis (AGUIAR et al., 2007). A extração parcial é considerada por Snape et al. (2004) uma alternativa simples, relativamente segura, que consegue atingir as fases lábeis do sedimento, identificando os metais ambientalmente disponíveis.

Segundo estudos de Yu et al. (2010), quando os metais são encontrados nas frações residuais do sedimento, estes podem ser considerados elementos seguros ambientalmente, enquanto que os metais nas frações não residuais, frações mais reativas do sedimento, estes são instáveis sob as condições ambientais naturais, podendo ser solubilizados diante de certas alterações. A avaliação da concentração total dos metais pode ser considerada insuficiente para a estimativa de um impacto ambiental causado por sedimentos contaminados visto que o comportamento ambiental dos metais depende de suas formas químicas específicas e de seu estado de ligação.

Para Simpson (2005), avaliar os metais na fração ambientalmente disponível do sedimento é o mais importante na avaliação da qualidade deste compartimento, sendo estes elementos os que podem ser facilmente extraídos com ácido diluído frio. Procedimentos de digestão forte, como os que utilizam microondas com água régia ou ácido fluorídrico, não são considerados necessários para a maior parte da avaliação da qualidade de sedimentos.

Os procedimentos de digestão parcial variam entre a utilização de reagentes como água-régia, ácido clorídrico $(\mathrm{HCl})$, ácido nítrico $\left(\mathrm{HNO}_{3}\right)$, além de 
outros, e também entre o uso de aquecimento convencional, aquecimento por fornos de microondas ou extração em temperatura ambiente (extração a frio).

O método de digestão parcial com água-régia é utilizado, por exemplo, por Aguiar et al. (2007), que também fazem uso de aquecimento em banho-maria. Tais autores verificam que é possível caracterizar a geoquímica dos metais em sedimentos marinhos carbonáticos, de forma semelhante a uma digestão total, sendo eficiente por diminuir o tempo de análise e a descarga de efluente laboratorial perigoso, muito reativo e ácido.

A avaliação dos metais ambientalmente disponíveis é fundamental em estudos ambientais porque esta é a fração comumente tóxica para a biota, e que pode causar algum impacto no ecossistema (SNAPE et al., 2004).

A extração parcial ácida de sedimentos é uma ferramenta simples e efetiva, comumente utilizada para avaliar a contaminação, a origem e a disponibilidade de metais em ambientes aquáticos, sendo também importante para avaliar os possíveis riscos decorrentes dos processos de dragagem do material. Já os processos de solubilização total dos sedimentos, por outro lado, tem um significado ecotoxicológico limitado, pois incluem frações em que os metais associados dificilmente são liberados para a coluna d'água ficando disponíveis para os organismos (BETTIOL, et al., 2008).

Snape et al. (2004) consideram o uso de $\mathrm{HCl} 1 \mathrm{M}$ à temperatura ambiente um método eficaz para disponibilizar o material antropogênico, fornecendo uma avaliação mais sensível do contaminante, se comparado com o uso de ácido fluorídrico. Conforme os estudos, o $\mathrm{HCl} 1 \mathrm{M}$ é um reagente adequado pois tem a capacidade tampão suficiente para dissolver carbonatos, ao mesmo tempo que tem um impacto limitado sobre argilas residuais e sulfetos, correspondendo bem com dados ecotoxicológicos. Além disso, muitos guias internacionais de qualidade de sedimento também recomendam o uso do $\mathrm{HCl} 1 \mathrm{M}$ para pesquisas regionais, como ocorre na Austrália e Nova Zelândia.

Townsend et al. (2009) também recomendam o uso de $\mathrm{HCl} 1 \mathrm{M}$, considerado como um poderoso e sensitivo método de extração parcial para 
avaliar a contaminação causada por $\mathrm{Pb}$ em sedimentos marinhos. Segundo os autores, uma digestão total com ácido fluorídrico oferece uma dissolução completa do sedimento, que é capaz de solubilizar tanto os metais de origem antropogênica quanto os de origem geogênica. A análise apenas dos elementos antropogênicos, realizada com o uso de $\mathrm{HCl} 1 \mathrm{M}$, pode fornecer uma avaliação mais sensível do contaminante, oferecendo uma maior discriminação entre sedimentos impactados e não impactados.

Alguns autores fazem uso de ácido clorídrico, porém em concentrações menores. Fiszman et al. (1984) e Lemes (2001) consideram o uso de $\mathrm{HCl} \mathrm{0,1} \mathrm{M}$ uma maneira eficiente de disponibilizar os metais presentes nas fases orgânicas e inorgânicas do sedimento, com um mínimo ataque à matriz. Cotta et al. (2006) também utilizam $\mathrm{HCl}$ 0,1 $\mathrm{M}$ como uma maneira de solubilizar as amostras de sedimento para determinação dos metais ambientalmente disponíveis, enquanto que para a extração dos metais pseudo-totais, é utilizado $\mathrm{HNO}_{3}$ concentrado.

As extrações com ácidos diluídos a frio simulam processos de remoção de metais das frações mais reativas dos sedimentos, sendo uma importante ferramenta para avaliar a mobilidade destes elementos. Esta abordagem é particularmente interessante quando 0 ambiente se encontra fortemente impactado, sendo muito utilizada também para o diagnóstico de ambientes recémcontaminados. $\mathrm{O}$ uso de $\mathrm{HCl}$ 0,1 M é bastante importante para se estimar a fração dos metais lábeis, móveis, ou também considerados ambientalmente disponíveis, além de poder determinar a qualidade de sedimentos (BEVILACQUA et al., 2009).

Quanto ao uso de aquecimento com forno de microondas, o método SW-846-3051A da Agência de Proteção Ambiental dos Estados Unidos - USEPA, objetiva uma digestão parcial usando $\mathrm{HNO}_{3}$ concentrado ou uma mistura de $\mathrm{HNO}_{3}$ e $\mathrm{HCl}$ concentrados, com aquecimento por forno de microondas, sendo este considerado um método de extração dos metais ambientalmente disponíveis por lixiviação natural ou processos biológicos (USEPA, 2007).

Bettiol et al. (2008) comparam o uso de $\mathrm{HCl} 1 \mathrm{M}$ e de $\mathrm{HNO}_{3} 8 \mathrm{M}$ como soluções para extração parcial de sedimentos, e suas aplicações sob temperatura ambiente, aquecimento convencional ou aquecimento por forno de microondas. 
Os autores constataram que a extração com $\mathrm{HCl} 1 \mathrm{M}$ em temperatura ambiente tem uma limitação devido à incompleta solubilização do mineral, que não atinge a fração residual do sedimento, representando uma técnica adequada para identificar os metais de origem antropogênica, bem como para avaliar o potencial de disponibilidade dos metais. A extração com $\mathrm{HNO}_{3} 8 \mathrm{M}$ e aquecimento por forno de microondas foi considerada como uma alternativa para os métodos mais complexos de digestão total, pois fornece uma boa estimativa do teor de metais, produzindo uma eficiente solubilização do sedimento, não atingindo apenas a matriz de silicato do compartimento.

O aquecimento convencional pode ser realizado em chapa ou manta de aquecimento, banho-maria, bloco digestor, estufa, bico de Bunsen, entre outros. Este procedimento é de simples execução, fácil monitoramento e custo operacional relativamente baixo, porém possui várias desvantagens frente ao aquecimento utilizando forno de microondas que são: variação da concentração dos ácidos, quando aquecidos em sistema aberto, maiores riscos de contaminação devido ao contato com o ar, variações na temperatura quando utilizadas chapas ou mantas aquecedoras e, principalmente, perda de alguns elementos voláteis como As, Se e Hg (QUINÁGLIA, 2006).

O uso de fornos de microondas é bastante recomendado como fonte de aquecimento em processos de solubilização de amostras pela alta eficiência de extração e menor tempo requerido (BETTIOL et al., 2008). Sua maior rapidez ocorre pelo fato do calor gerado pelo aquecimento acontecer de dentro da solução para fora, ao contrário do sistema convencional em que primeiramente o recipiente deve ser aquecido e somente depois, a solução ( QUINÁGLIA, 2006).

Pelo fato de existir um amplo leque de reagentes extratores reportados na literatura com a finalidade de extrair parcialmente os metais de amostras de sedimento, neste estudo foi realizada uma comparação entre dois procedimentos diferentes, um adotando $\mathrm{HCl}$ diluído "a frio" e outro utilizando $\mathrm{HNO}_{3}$ concentrado e aquecimento por forno de microondas, sendo este procedimento baseado no método USEPA 3051A, ambos com a finalidade de disponibilizar os metais ambientalmente disponíveis presentes no sedimento. 


\subsubsection{Valores Orientadores da Qualidade de Sedimento}

O sedimento desempenha um papel fundamental na detecção da poluição das águas por metais, podendo indicar a presença e concentração destes compostos. Este compartimento não atua apenas como um ambiente de deposição de espécies químicas, mas também atua ativamente na redistribuição destas espécies à biota aquática. Por meio do sedimento é possível determinar contaminantes que não são naturalmente degradados, nem mesmo permanentemente fixados por ele, podendo ser redisponibilizados para a coluna d'água, dependendo das características físico-químicas do ambiente, afetando, com isso, a qualidade deste meio (BEVILACQUA et al., 2009).

Os ecossistemas aquáticos têm sido alvo de vários níveis de contaminação decorrentes do lançamento de substâncias químicas como conseqüência das atividades humanas. Por integrar uma fonte de poluição, os sedimentos contaminados representam riscos potencialmente significantes para a saúde da biota aquática (CCME, 1995).

Em virtude disto, é de fundamental importância a adoção dos valores orientadores de qualidade de sedimentos - SQGs (do inglês, Sediment Quality Guidelines), que são valores numéricos que fornecem informações a respeito da relação entre os níveis de concentração dos poluentes no sedimento e a probabilidade de efeitos adversos para os organismos expostos a estes contaminantes (SILVÉRIO, 2003).

Os valores orientadores podem ser utilizados como uma avaliação inicial, sendo possível determinar a presença ou não dos contaminantes em níveis tóxicos, além de serem utilizados para identificar áreas contaminadas e contaminantes de interesse em locais específicos (QUINÁGLIA, 2006). Estes valores têm caráter meramente orientador na busca de evidências da presença de contaminantes em concentrações capazes de causar efeitos deletérios, sobretudo com relação à toxicidade para a biota (CETESB, 2006). 
Os valores orientadores da qualidade de sedimentos são fornecidos por vários órgãos ambientais internacionais. Neste estudo os níveis de concentração obtidos foram comparados com os valores estabelecidos pelo órgão ambiental do Canadá, o Conselho Canadense de Ministérios do Meio Ambiente CCME (do inglês Canadian Council of Ministers of the Environment), que fornece valores para metais tóxicos e compostos orgânicos. Na Tabela 3 são apresentados os valores orientadores canadenses para os metais.

TABELA 3 - Valores orientadores utilizados pelo Canadá para metais em sedimentos de água doce (base seca)

\begin{tabular}{ccc}
\hline Metais & $\begin{array}{c}\mathbf{I S Q G} \\
\left(\mathbf{m g ~ K g}^{-1}\right)\end{array}$ & $\begin{array}{c}\mathbf{P E L} \\
\left(\mathbf{m g ~ K g}^{-1}\right)\end{array}$ \\
\hline Arsênio & 5,9 & 17 \\
Cádmio & 0,6 & 3,5 \\
Chumbo & 35 & 91,3 \\
Cobre & 35,7 & 197 \\
Cromo & 37,3 & 90 \\
Mercúrio & 0,17 & 0,486 \\
Zinco & 123 & 315
\end{tabular}

Fonte: CCME, 2002

O CCME estabelece valores orientadores para avaliação da qualidade de sedimento, objetivando a proteção à vida aquática. Neste guia são informados os valores do ISQG (Interim Sediment Quality Guidelines) que representa o valor orientador de referência de qualidade de sedimentos, também designado TEL (Threshold Effect Level), concentração abaixo da qual raramente são esperados efeitos adversos para os organismos, e pelo valor do PEL (Probable Effect Level), que representa a concentração acima da qual é freqüentemente esperado efeito deletério sobre a biota. Na faixa entre TEL e PEL, situam-se os valores onde ocasionalmente espera-se tais efeitos (CCME, 2002; CETESB, 2006). 
No Brasil, a legislação que trata dos critérios para avaliação da qualidade de sedimentos é a Resolução CONAMA n 344/2004, atualizada e revisada pela Resolução CONAMA n 421/2010. Este documento estabelece as diretrizes gerais e procedimentos mínimos para a avaliação do material a ser dragado em águas jurisdicionais brasileiras, sendo material dragado, qualquer material retirado ou deslocado do leito dos corpos d'água decorrente da atividade de dragagem, desde que este material não constitua bem mineral (CONAMA, 2004).

O processo de dragagem relaciona-se com as atividades de escavação ou remoção de solo ou materiais de fundo de hidrovias, portos, canais, lagos, entre outros, que têm como finalidade garantir a implantação e a operação de portos e terminais portuários, além das condições de navegabilidade de corpos hídricos, pela retirada do material depositado, sendo estas atividades, capazes de provocar uma série de mudanças no meio ambiente (QUINÁGLIA, 2006).

A Resolução CONAMA no 344/2004 estabelece três etapas para a avaliação da qualidade do material a ser dragado:

- Caracterização física: inclui a quantidade de material a ser dragado, a distribuição granulométrica (Tabela 1) e o peso específico dos sólidos;

- Caracterização química: deve conter as concentrações de poluentes no sedimento, na fração total, sendo estes os metais tóxicos, os pesticidas organoclorados, os BPCs e os HPAs, além de conter os valores orientadores para carbono orgânico total e nutrientes;

- Caracterização ecotoxicológica: deve ser realizada como uma complementação à caracterização física e química, com a finalidade de avaliar os impactos potenciais à vida aquática, no local proposto para a disposição do material dragado.

Os valores orientadores da Resolução CONAMA n 344/2004 para metais tóxicos e compostos orgânicos são baseados em valores estabelecidos internacionalmente, que inclui aqueles adotados pelo Canadian Council of 
Ministers of the Environment, porém nesta Resolução são adotados os parâmetros Nível 1 e Nível 2, ao invés de TEL e PEL:

- Nível 1: valor abaixo do qual se prevê baixa probabilidade de efeitos adversos à biota;

- Nível 2: valor acima do qual é provável a ocorrência de efeitos adversos à biota.

$\mathrm{Na}$ Tabela 4 são apresentados os valores orientadores estabelecidos para metais tóxicos, adotados na Resolução CONAMA n 344/2004:

TABELA 4 - Valores orientadores utilizados pelo Brasil na Resolução 344/04 para metais em sedimentos (base seca)

\begin{tabular}{ccccc}
\hline \multirow{2}{*}{ Metais } & \multicolumn{2}{c}{ Água Doce } & \multicolumn{2}{c}{ Água Salina - Salobra } \\
\cline { 2 - 5 } & $\begin{array}{c}\text { Nível 1 } \\
\left(\mathbf{m g ~ K g}^{-1}\right)\end{array}$ & $\begin{array}{c}\text { Nível 2 } \\
\left(\mathbf{m g ~ K g}^{-1}\right)\end{array}$ & $\begin{array}{c}\text { Nível 1 } \\
\left(\mathbf{m g ~ K g}^{-1}\right)\end{array}$ & $\begin{array}{c}\text { Nível 2 } \\
\left(\mathbf{m g ~ K g}^{-1}\right)\end{array}$ \\
\hline Arsênio & 5,9 & 17 & 8,2 & 70 \\
Cádmio & 0,6 & 3,5 & 1,2 & 9,6 \\
Chumbo & 35 & 91,3 & 46,7 & 218 \\
Cobre & 35,7 & 197 & 34 & 270 \\
Cromo & 37,3 & 90 & 81 & 370 \\
Mercúrio & 0,17 & 0,486 & 0,15 & 0,71 \\
Níquel & 18 & 35,9 & 20,9 & 51,6 \\
Zinco & 123 & 315 & 150 & 410 \\
\hline
\end{tabular}

A CETESB, Companhia de Tecnologia de Saneamento Ambiental do Estado de São Paulo, também possui um guia com critérios para avaliação da qualidade dos sedimentos. Os valores estabelecidos neste documento também são baseados naqueles adotados pelo Canadá, porém foi realizado um 
refinamento do diagnóstico químico em cinco classes de qualidade para cada contaminante, delimitadas pelos valores de TEL e PEL:

- ÓTIMA: concentração inferior a TEL;

- BOA: faixa entre TEL, inclusive, e a concentração correspondente a $50 \%$ da distância entre TEL e PEL, somado a TEL;

- REGULAR: faixa superior a 50\% da distância entre TEL e PEL, somado a TEL e inferior a PEL;

- RUIM: faixa entre PEL, inclusive, e a concentração correspondente a 1,5 multiplicado de seu próprio valor;

- PÉSSIMA: acima de 1,5 x PEL.

Através desta nova classificação adotada pela CETESB, é possível considerar a pior situação dentro da série de contaminantes analisados, quando as concentrações encontradas superam significativamente o valor de PEL (em mais de 50\%). Assim, em termos biológicos, um único contaminante em concentração elevada seria suficiente para causar dano a uma população. $\mathrm{Na}$ Tabela 5 é apresentada a classificação adotada para metais (CETESB, 2010).

TABELA 5 - Classificação de contaminantes em sedimento de água doce estabelecida pela CETESB a partir do TEL e PEL

\begin{tabular}{cccccc}
\hline QUALIDADE & $\begin{array}{c}\text { ÓTIMA } \\
\left(\mathbf{m g ~ K g}^{-1}\right)\end{array}$ & $\begin{array}{c}\text { BOA } \\
\left(\mathbf{m g ~ K g}^{-1}\right)\end{array}$ & $\begin{array}{c}\text { REGULAR } \\
\left(\mathbf{m g ~ K g}^{-1}\right)\end{array}$ & $\begin{array}{c}\text { RUIM } \\
\left(\mathbf{m g ~ K g}^{-1}\right)\end{array}$ & $\begin{array}{c}\text { PÉSSIMA } \\
\left(\mathbf{m g ~ K g}^{-1}\right)\end{array}$ \\
\hline $\mathrm{As}$ & $<5,9$ & $\geq 5,9-11,5$ & $>11,5-<17,0$ & $17,0-25,5$ & $>25,5$ \\
$\mathrm{Cd}$ & $<0,6$ & $\geq 0,6-2,1$ & $>2,1-<3,5$ & $3,5-5,3$ & $>5,3$ \\
$\mathrm{~Pb}$ & $<35,0$ & $\geq 35,0-63,2$ & $>63,2-<91,3$ & $91,3-137,0$ & $>137,0$ \\
$\mathrm{Cu}$ & $<35,7$ & $\geq 35,7-116,4$ & $>116,4-<197,0$ & $197,0-295,5$ & $>295,5$ \\
$\mathrm{Cr}$ & $<37,3$ & $\geq 37,3-63,7$ & $>63,7-<90,0$ & $90,0-135,0$ & $>135,0$ \\
$\mathrm{Hg}$ & $<0,17$ & $\geq 0,17-0,328$ & $>0,328-<0,486$ & $0,486-0,729$ & $>0,729$ \\
$\mathrm{Ni}$ & $<18,0$ & $\geq 18,0-27,0$ & $>27,0-<36,0$ & $36,0-54,0$ & $>54,0$ \\
$\mathrm{Zn}$ & $<123$ & $\geq 123-219$ & $>219-<315$ & $315-473$ & $>473$ \\
\hline
\end{tabular}




\subsection{TÉCNICAS ANALÍTICAS}

A espectrometria atômica é uma ferramenta muito importante para a determinação de metais e elementos-traço em matrizes de interesse ambiental. $\mathrm{Na}$ espectrometria atômica, as concentrações dos analitos são determinadas pela medida da absorção ou da emissão da radiação em determinados comprimentos de onda característicos dos átomos dos elementos, podendo-se determinar tais concentrações na faixa de partes por milhão $\left(\mathrm{mg} \mathrm{L}^{-1}\right)$ até partes por trilhão $\left(n \mathrm{~L} \mathrm{~L}^{-1}\right)$ (HARRIS, 2005).

A espectrometria atômica é muito utilizada em virtude de sua alta sensibilidade, de sua capacidade em distinguir um elemento de outro em uma amostra complexa, da possibilidade da análise de vários elementos simultaneamente e pela facilidade de várias amostras serem analisadas automaticamente (HARRIS, 2005).

As técnicas espectroscópicas comumente utilizadas são: análise por ativação neutrônica (AAN), espectrometria de absorção atômica com chama (FAAS), espectrometria de absorção atômica com atomização eletrotérmica em forno de grafite (GFAAS), espectrometria de absorção atômica com geração de vapor frio (CVAAS), espectrometria de emissão óptica com plasma indutivamente acoplado (ICPOES) e espectrometria de massas com plasma indutivamente acoplado (ICPMS) (QUINÁGLIA, 2006).

\subsubsection{Espectrometria de Absorção Atômica com Atomização Eletrotérmica em Forno de Grafite (GFAAS)}

A espectrometria de absorção atômica baseia-se no princípio de que todos os átomos dos elementos metálicos em seu estado fundamental absorvem energia em comprimentos de onda específicos.

As medidas quantitativas em absorção atômica ocorrem da seguinte maneira: um feixe de luz de comprimento de onda ressonante de intensidade 
inicial $I_{0}$ incide no compartimento do atomizador no qual se encontram os átomos no estado fundamental. A intensidade inicial $I_{0}$ decresce para uma intensidade reduzida I, devido à absorção da energia radiante pelos átomos do elemento analisado, sendo esta intensidade final transmitida para o detector. A quantidade de luz absorvida é determinada por comparação entre $\mathrm{I}_{0}$ e I, sendo denominada "transmitância", a razão entre a intensidade final e a intensidade inicial da radiação incidente na amostra (PERKIN ELMER, 1993; LAJUNEN \& PERÄMÄKI, 2004).

$$
T=\frac{I}{I_{0}}
$$

A medida da absorção é um complemento da medida da transmitância, podendo ser calculada matematicamente por meio da equação:

$$
A=\log \frac{I_{0}}{I}=\log \frac{1}{T}
$$

A absorbância é um termo mais conveniente para caracterizar a absorção da luz em espectrometria de absorção atômica, a qual é quantificada seguindo uma relação linear com a concentração, definida pela lei de LambertBeer:

$$
A=a b c
$$

na qual "A" é a absorbância, "a" é o coeficiente de absorção, "b" é o comprimento do caminho óptico e "c" é a concentração das espécies analisadas.

A determinação quantitativa pela espectrometria de absorção atômica ocorre com a medida da quantidade de absorção pelo analito em um comprimento de onda específico. Os princípios da quantificação da absorção atômica seguem a lei de Lambert-Beer, em que o aumento da absorbância (medida como a diminuição da transmitância) tem uma relação linear com a concentração dos átomos no estado fundamental (LAGALANTE, 2004). 
A espectrometria de absorção atômica com atomização eletrotérmica em forno de grafite consiste na medida da absorção da intensidade da radiação eletromagnética, proveniente de uma fonte de luz, por átomos gasosos no estado fundamental, que são obtidos com o uso de um forno de grafite como atomizador (KRUG et al., 2001).

O espectrômetro de absorção atômica com forno de grafite é um equipamento que permite a análise quantitativa de elementos metálicos. Conforme mostrado na figura 1 , seus componentes básicos são:

- Fonte de radiação: têm a função de emitir luz no mesmo comprimento de onda em que ocorre a absorção pelo átomo do elemento de interesse. Na maioria dos espectrômetros de absorção atômica a fonte de luz utilizada é a lâmpada de catodo oco ( $\mathrm{HCL}$ ). Também são utilizadas lâmpadas de descarga sem eletrodos (EDL);

- Forno de grafite: atomizador que cria a população de átomos no estado fundamental;

- Monocromador: utilizado para isolar a luz no comprimento de onda característico do elemento de qualquer outra radiação emitida pela lâmpada. É um filtro ajustável que seleciona uma região específica e estreita do espectro para transmiti-la ao detector, rejeitando todas as demais linhas fora dessa região. Para isso, são utilizados um prisma ou uma rede de difração, que decompõem o feixe de radiação em discretos comprimentos de onda, com diferentes ângulos, assim, na fenda de saída é possível selecionar apenas a linha de comprimento de onda desejado;

- Detector: dispositivo sensível à luz que detecta o sinal proveniente do monocromador. O sinal é convertido em concentração ou absorbância por um microcomputador interfaceado ao equipamento. 


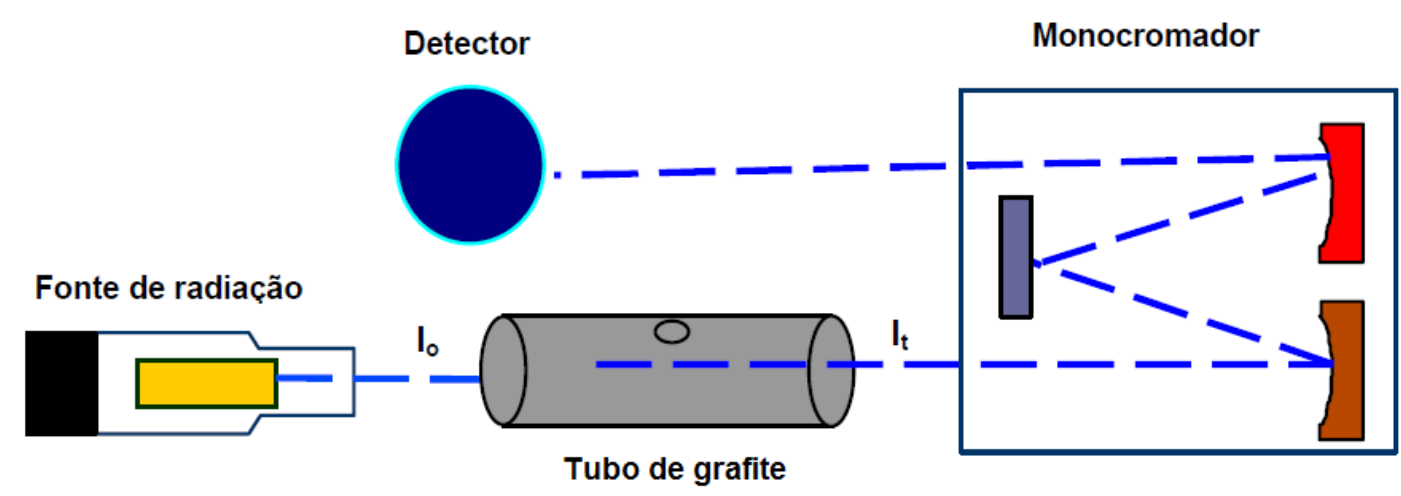

FIGURA 1 - Esquema de um espectrômetro de absorção atômica com forno de grafite de óptica seqüencial (QUINÁGLIA, 2006)

A espectrometria de absorção atômica com forno de grafite é uma técnica amplamente utilizada para a determinação de elementos metálicos em amostras de interesse ambiental. Dentre suas vantagens estão (PERKIN ELMER, 1993):

- Limites de detecção que alcançam a ordem de $n g \mathrm{~L}^{-1}$ para a maioria dos elementos;

- Atomização da amostra realizada em um período curto, em torno de 5 segundos;

- Pequenos volumes de amostras que variam de 10 a $50 \mu \mathrm{L}$;

- Amostradores automáticos que tornam a operação mais autônoma;

- Ampla aplicabilidade, que inclui vários tipos de amostras como água, solo, sedimento, efluente, urina, sangue, dentre outras.

As principais desvantagens desta técnica são o longo tempo de análise e o fato de ser monoelementar (DANTAS, 1999).

Nos equipamentos que utilizam forno de grafite, um volume da solução da amostra é inserido e depositado em um tubo de grafite. A amostra é então submetida a um programa de temperatura em que, inicialmente, há remoção do 
solvente e de constituintes voláteis da amostra até chegar ao processo de atomização, que ocorre rapidamente. $\mathrm{O}$ sinal detectado leva à formação de um pico proporcional à massa do analito na amostra (WELZ \& SPERLING, 1999).

O programa de aquecimento utilizado em fornos de grafite para a atomização correta da amostra inclui basicamente quatro etapas:

- Secagem: para remoção do solvente e de ácidos voláteis;

- Pirólise: para queima da matéria orgânica e/ou outros constituintes voláteis da amostra, a fim de deixar o analito em uma matriz menos complexa, livre de interferentes. É considerada a etapa mais crítica do programa, pois para que a maior quantidade dos componentes da matriz seja volatilizada, a temperatura deve ser mantida o mais alto possível, porém a temperatura aplicável depende da volatilidade do analito, para assim, não ocorrer perdas e este ficar retido no tubo quantitativamente;

- Atomização: para formar os átomos do analito de interesse, por meio do fornecimento de energia térmica, e medir a absorção atômica;

- Limpeza: para eliminar os constituintes menos voláteis da amostra e remover qualquer resíduo condensado nas partes mais frias do tubo.

Um procedimento analítico realizado durante as análises por GFAAS é a modificação química, freqüentemente necessária para remover interferência de matriz. Os modificadores químicos também permitem a não ocorrência de picos múltiplos devido à presença de determinado elemento em mais de uma espécie, visto que cada espécie tem uma razão de atomização única. Estas substâncias convertem o analito em uma espécie comum podendo eliminar o problema. Outra função dos modificadores químicos é estabilizar o analito a fim de permitir uma temperatura de pirólise maior ou tornar a matriz mais volátil para uma pirólise mais efetiva (DANTAS, 1999).

A modificação efetiva do analito ou da matriz reduz grandemente o número de interferências espectrais causadas por absorção da fonte de radiação 
por elementos com linhas atômicas concomitantes ou espalhamento da radiação por partículas não volatilizadas da matriz (DANTAS, 1999).

O uso de modificadores químicos têm se tornado importante para a obtenção de análises livres de interferentes. $O$ modificador químico freqüentemente utilizado é uma mistura de nitrato de paládio com nitrato de magnésio, sendo considerado um modificador universal para mais de 20 analitos (DOBROWOLSKI, 2010).

Nas técnicas de espectrometria de absorção atômica a absorção ocorre em comprimentos de onda específicos, que são característicos de cada elemento químico. Na teoria, qualquer absorção que ocorre é atribuída à presença de átomos do analito, sendo o grau de absorção, função da densidade populacional dos átomos. Na prática, entretanto, o sinal analítico pode ter a interferência de outros meios que não são absorção atômica.

A absorção de fundo ou background é um termo geral utilizado para descrever os efeitos combinados de fenômenos como a absorção molecular, que ocorre quando o aquecimento não é suficiente para decompor todos os componentes da amostra e as moléculas remanescentes absorvem luz, podendo gerar um espectro que se sobrepõe à linha analítica proveniente da concentração do elemento de interesse. Outro fenômeno responsável por tal interferência é o espalhamento de luz, que pode ocorrer quando há altas concentrações de sólidos dissolvidos na amostra, que, em casos em que o aquecimento não é suficiente para decompor todos os compostos da amostra, tais partículas podem permanecer em algumas áreas do forno, podendo refletir e espalhar luz.

A técnica considerada mais eficiente para correção de todos os tipos de absorção de fundo que podem aparecer em absorção atômica com atomização em forno de grafite é a correção baseada no efeito Zeeman (LEPRI et al., 2010).

O efeito Zeeman é o deslocamento dos níveis de energia dos átomos e moléculas devido à presença de um campo magnético. Para a utilização da técnica com efeito Zeeman, o campo magnético intenso é ligado e desligado alternadamente. A amostra e a radiação de fundo são observadas quando o 
campo está desligado, porém apenas a radiação de fundo é observada quando o campo está ligado. Assim, a diferença entre os dois sinais é o sinal corrigido (HARRIS, 2005).

\subsubsection{Espectrometria de Absorção Atômica com Geração de Vapor Frio (CVAAS)}

A espectrometria de absorção atômica com geração de vapor frio baseia-se nos mesmos princípios da absorção atômica, ou seja, absorção da radiação eletromagnética por átomos no estado fundamental. A principal diferença que existe com relação às outras técnicas de absorção atômica é a de que esta técnica é específica para determinação do elemento mercúrio, pelo fato do mercúrio ser o único elemento que, em seu estado fundamental, apresenta-se na forma de vapor em temperatura ambiente $\left(20^{\circ} \mathrm{C}-14 \mathrm{mg} \mathrm{m}^{-3}\right.$ ) (QUINÁGLIA, 2006).

A análise de mercúrio é um caso particular de absorção atômica em que o atomizador presente no equipamento não é utilizado para gerar átomos no estado fundamental. O mercúrio é reduzido previamente a mercúrio elementar e o vapor monoatômico é conduzido ao compartimento da amostra, que, neste caso, funciona apenas como uma célula de absorção (GUILHEN, 2009).

Na técnica de geração de vapor frio, o mercúrio presente na amostra é quimicamente reduzido a mercúrio elementar por reação química de redução utilizando-se fortes agentes redutores, como cloreto estanoso ou borohidreto de sódio, em um sistema reacional fechado. O mercúrio elementar volátil gerado é transportado para a cela de absorção por meio de um fluxo de gás (em geral, argônio ou nitrogênio), na qual ocorre a absorção atômica. Algumas células são levemente aquecidas para evitar a condensação de água (PERKIN ELMER, 1993; QUINÁGLIA, 2006).

A espectrometria de absorção atômica com geração de vapor frio possui sensibilidade e seletividade adequadas para a determinação de 
quantidades muito pequenas de mercúrio em amostras de interesse ambiental (na ordem de traços e ultra-traços) (QUINÁGLIA, 2006; GUILHEN, 2009).

\subsubsection{Espectrometria de Emissão Óptica com Plasma Indutivamente Acoplado (ICP-OES)}

A espectrometria de emissão óptica ou atômica baseia-se no fenômeno de emissão de luz por átomos ou íons excitados. O processo ocorre quando uma energia elétrica ou térmica suficiente está disponível para excitar os átomos ou íons dos elementos para um nível de energia instável. Imediatamente, os elétrons em estado excitado sofrem relaxação e retornam para o estado fundamental emitindo luz (fótons), com comprimentos de onda característicos dos elementos presentes na amostra. A intensidade da linha de emissão é proporcional, portanto, à concentração do elemento analisado. Os componentes básicos da técnica são similares aos usados em espectrometria de absorção atômica, com a diferença que não é necessária a utilização de uma fonte de luz primária. Um dos componentes mais críticos para instrumentos de emissão atômica é a fonte de atomização, pois esta deve fornecer energia suficiente para excitação e atomização dos átomos (PERKIN ELMER, 2004).

A fonte de energia utilizada em espectrometria de emissão óptica é um plasma de argônio, um gás altamente ionizado, estável e quimicamente inerte, que chega a temperaturas próximas a $10.000 \mathrm{~K}$, com temperaturas usuais entre 5.500 e $8.000 \mathrm{~K}$, que permitem a completa atomização de elementos da amostra, minimizando interferências químicas (PERKIN ELMER, 2004).

O plasma é uma nuvem de gás fortemente ionizado, composto por elétrons, íons e partículas neutras. O plasma com acoplamento indutivo é formado em uma tocha de quartzo, constituída por três tubos concêntricos com entradas de gás independentes (Figura 2). Entre o tubo exterior e o tubo intermediário flui um fluxo de argônio tangencialmente, chamado gás refrigerante ou gás do plasma, utilizado para formar o plasma e refrigerar a tocha, prevenindo 0 
aquecimento. O tubo intermediário carrega o gás argônio auxiliar a cerca de 1,0 L $\mathrm{min}^{-1}$, sendo este fluxo ionizado por meio de uma bobina Tesla. O tubo central é chamado de gás de arraste e, serve para conduzir a amostra, na forma de um aerosol formado previamente por processo de nebulização, para dentro do plasma (DANTAS, 1999; LEMES, 2001).

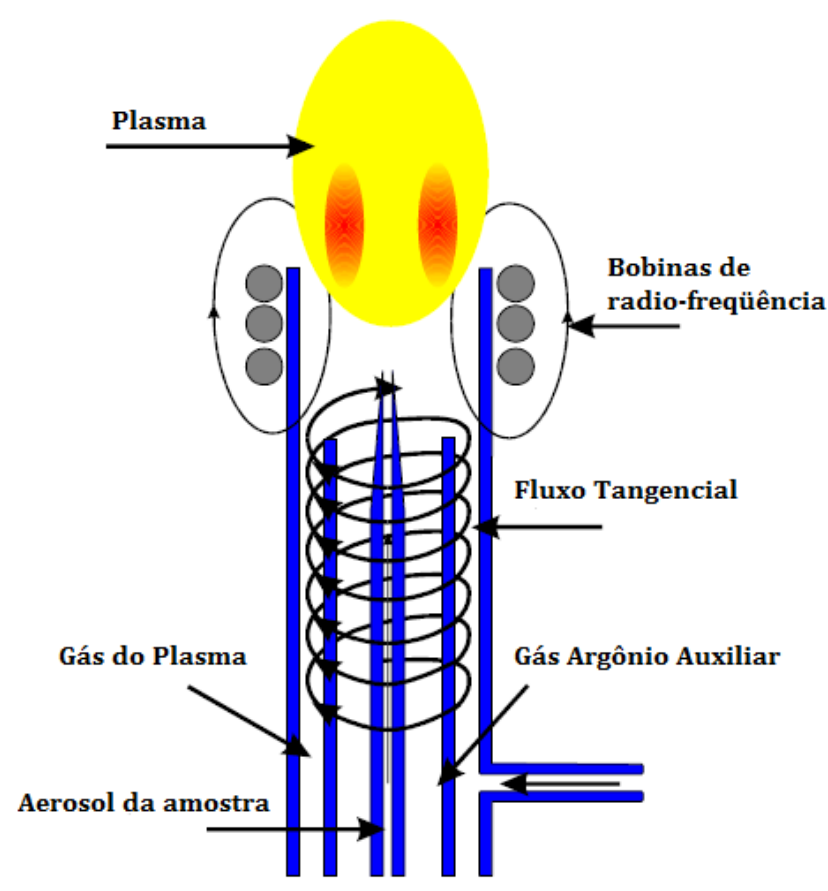

FIGURA 2 - Esquema da tocha em espectrômetro de emissão óptica com plasma indutivamente acoplado (MANNING \& GROW, 1997)

O plasma é dividido em quatro zonas: a região de indução, na qual ocorre a transferência de energia indutiva da bobina ao plasma; a zona de préaquecimento, onde ocorre a dessolvatação da amostra seguida pela vaporização e atomização; a zona de radiação normal, onde ocorre, predominantemente, excitação e ionização; e a zona analítica normal, região do plasma em que usualmente são medidas as emissões do analito (DANTAS, 1999). 
A espectrometria de emissão óptica com plasma indutivamente acoplado é bastante utilizada em análises ambientais. Segundo Lemes (2001), esta técnica é requerida devido às suas características gerais:

- É uma técnica multielementar rápida que permite a determinação simultânea dos constituintes maiores, menores e traços;

- Apesar de não possuir uma sensibilidade muito baixa para elementos comumente analisados, como $\mathrm{Cu}, \mathrm{Cd}, \mathrm{Ni}, \mathrm{Pb}$ e $\mathrm{Zn}$, é uma técnica bastante sensível para elementos metálicos refratários, como $\mathrm{V}$ e $\mathrm{Be}$, bem como para alguns elementos não-metálicos, como $B$ e $P$.

$\mathrm{Na}$ espectrometria de emissão óptica com plasma indutivamente acoplado podem aparecer as interferências espectrais, que são controladas pela seleção de um comprimento de onda alternativo, e as interferências físicas, relacionadas com o transporte da amostra, que são amenizadas com o uso de padrões internos ou por compatibilização de matriz, sem prejuízo dos resultados analíticos (QUINÁGLIA, 2006).

Na Tabela 6 são apresentados os limites de detecção $\left(e m \mu \mathrm{g} \mathrm{L}^{-1}\right)$ das principais técnicas analíticas de espectrometria atômica utilizadas para análises de amostras ambientais. 
TABELA 6 - Limites de detecção $\left(\mu g \mathrm{~L}^{-1}\right)$ para técnicas de espectrometria atômica

\begin{tabular}{|c|c|c|c|c|c|}
\hline Elemento & FAAS & Hg/HGAAS & GFAAS & ICP-OES & ICP-MS \\
\hline $\mathrm{Ag}$ & 1,5 & & 0,005 & 0,6 & 0,002 \\
\hline $\mathrm{Al}$ & 45 & & 0,1 & 1 & 0,005 \\
\hline As & 150 & 0,03 & 0,05 & 2 & 0,0006 \\
\hline B & 1000 & & 20 & 1 & 0,003 \\
\hline $\mathrm{Ba}$ & 15 & & 0,35 & 0,03 & 0,00002 \\
\hline $\mathrm{Be}$ & 1,5 & & 0,008 & 0,09 & 0,003 \\
\hline $\mathrm{Ca}$ & 1,5 & & 0,01 & 0,05 & 0,0002 \\
\hline $\mathrm{Cd}$ & 0,8 & & 0,002 & 0,1 & 0,00009 \\
\hline Co & 9 & & 0,15 & 0,2 & 0,0009 \\
\hline $\mathrm{Cr}$ & 3 & & 0,004 & 0,2 & 0,0002 \\
\hline $\mathrm{Cu}$ & 1,5 & & 0,014 & 0,4 & 0,0002 \\
\hline $\mathrm{Fe}$ & 5 & & 0,06 & 0,1 & 0,0003 \\
\hline $\mathrm{Hg}$ & 300 & 0,009 & 0,6 & 1 & 0,016 \\
\hline K & 3 & & 0,005 & 1 & 0,0002 \\
\hline $\mathrm{Li}$ & 0,8 & & 0,06 & 0,3 & 0,001 \\
\hline $\mathrm{Mg}$ & 0,15 & & 0,004 & 0,04 & 0,0003 \\
\hline $\mathrm{Mn}$ & 1,5 & & 0,005 & 0,1 & 0,00007 \\
\hline Mo & 45 & & 0,03 & 0,5 & 0,001 \\
\hline $\mathrm{Na}$ & 0,3 & & 0,005 & 0,5 & 0,0003 \\
\hline $\mathrm{Ni}$ & 6 & & 0,07 & 0,5 & 0,0004 \\
\hline$P$ & 75000 & & 130 & 4 & 0,1 \\
\hline $\mathrm{Pb}$ & 15 & & 0,05 & 1 & 0,00004 \\
\hline $\mathrm{Sb}$ & 45 & 0,15 & 0,05 & 2 & 0,0009 \\
\hline Sc & 30 & & & 0,1 & 0,004 \\
\hline $\mathrm{Se}$ & 100 & 0,03 & 0,05 & 4 & 0,0007 \\
\hline $\mathrm{Si}$ & 90 & & 1,0 & 10 & 0,03 \\
\hline $\mathrm{Ti}$ & 75 & & 0,35 & 0,4 & 0,003 \\
\hline V & 60 & & 0,1 & 0,5 & 0,0005 \\
\hline $\mathrm{Zn}$ & 1,5 & & 0,02 & 0,2 & 0,0003 \\
\hline
\end{tabular}




\subsubsection{Validação de Metodologia Analítica}

A validação é um processo realizado para a obtenção da credibilidade de um método analítico, para assim ser demonstrado que, nas condições em que é praticado pelo laboratório, tem as características necessárias para serem obtidos resultados com a qualidade exigida. Os parâmetros de validação são indicadores quantitativos do bom desempenho das metodologias, sendo alguns dos mais descritos na literatura: curva analítica, linearidade, limites de detecção e quantificação, precisão e exatidão (RIBEIRO et al., 2008).

\section{a) Curva analítica e linearidade}

A curva analítica representa graficamente a relação entre a resposta obtida (y) e a concentração do analito (x), estabelecida pela calibração. Em métodos de espectrometria atômica, a relação $A=a b c$ (equação 3 ) é bastante explorada na construção da curva analítica.

A linearidade pode ser analisada pelo gráfico da resposta obtida (absorção) em função da concentração do analito, e verificada a partir da equação da regressão linear (INMETRO, 2010).

O coeficiente de correlação linear ( $r$ ), também conhecido por coeficiente de correlação linear de Pearson, é um modo de verificar a adequação do ajuste da curva, sendo estimado como a razão da covariância entre a concentração (x) e o sinal analítico (y), pelo produto dos desvios-padrão de x e y, conforme representado na equação 4 (RIBEIRO et al., 2008).

$$
r=\frac{S_{x y}}{\left(s_{x}\right)\left(s_{y}\right)}
$$

Portanto, tem-se que:

$$
r=\frac{\sum\left(x_{i}-\bar{x}\right)\left(y_{i}-\bar{y}\right)}{\sqrt{\left(\sum\left(x_{i}-\bar{x}\right)^{2} \sum\left(y_{i}-\bar{y}\right)^{2}\right)}}
$$


O coeficiente de correlação linear é uma medida do grau de associação entre as duas variáveis, que varia de -1 a 1 , e quanto mais próximo de -1 ou de 1 , maior será a associação linear entre x e y. Segundo a ANVISA (2003), um valor de $r$ igual a 0,99 é recomendado, já o INMETRO (2003) indica um valor superior a 0,90 .

b) Faixa de trabalho

É a faixa de concentração do analito na qual o método será aplicado. Como limite inferior, normalmente são estipulados os valores dos limites de detecção e quantificação do método, e, no limite superior, os fatores limitantes dependem do sistema de resposta do equipamento de medição e da necessidade das análises.

c) Limite de quantificação

O limite de quantificação (LQ) é a menor concentração de analito que pode ser quantificada com um nível de precisão e veracidade aceitável, sob as condições experimentais adotadas (INMETRO, 2003).

d) Limite de detecção

É a menor concentração do analito que pode ser detectada pelo método, sendo um parâmetro fundamental quando são realizadas medidas em amostras com níveis baixos do analito (INMETRO, 2010).

O limite de detecção pode ser definido como a concentração mínima de uma substância medida e declarada com $95 \%$ ou $99 \%$ de confiança de que a concentração do analito é maior que zero (INMETRO, 2003).

$\mathrm{Na}$ validação de metodologias, é normalmente suficiente fornecer o limite de deteç̧ão no nível em que a deteç̧ão do analito começa a ficar problemática, ou seja, "Branco + 3s" e " $0+3 s$ ", considerando a análise de sete ou 
mais amostras de branco e de brancos com adição, respectivamente (INMETRO, 2003).

O desvio padrão (s) para uma série de "n" replicatas, é calculado como:

$$
s=\sqrt{\frac{\sum\left(x_{i}-\vec{x}\right)^{2}}{(n-1)}}
$$

O limite de detecção do método pode ser calculado com base no desvio padrão (s) obtido para as 7 replicatas da menor concentração aceitável do analito (limite de quantificação), conforme equação 7 :

$$
L D=t . s
$$

em que: $s$ corresponde ao desvio padrão e $t$ corresponde ao $t$ de Student, que no caso de 7 alíquotas (com 7-1 = 6 graus de liberdade) e para 99\% de confiança, equivale a 3,143 .

\section{e) Exatidão}

A exatidão reflete a proximidade entre 0 resultado de um ensaio e 0 valor de referência considerado verdadeiro. Quando aplicada a uma série de resultados de ensaio, causa uma combinação de erros aleatórios e sistemáticos, a tendência, podendo esta ser expressa como recuperação analítica (valor observado/valor esperado) para assim estabelecer a rastreabilidade dos padrões reconhecidos (INMETRO, 2003).

A avaliação da exatidão pode ser feita de várias maneiras, sendo os processos mais usuais: uso de materiais de referência, participação em comparações interlaboratoriais e realização de ensaios de recuperação (INMETRO, 2003). 
Os materiais de referência certificados devem, sempre que possível, fazer parte do processo de validação, visto que vêm acompanhados por um certificado contendo os valores de concentração, ou outra grandeza, para cada parâmetro e suas respectivas incertezas associadas (INMETRO, 2003).

Segundo BRITO et al. (2003), o estudo da recuperação é considerado o método mais utilizado para avaliar a exatidão de processos analíticos. A recuperação é calculada segundo a equação:

$$
R(\%)=\frac{\bar{C}}{C_{M R C}} \cdot 100
$$

onde: $\bar{C}$ é a média das recuperações obtidas para $\mathrm{n}$ repetições e $C_{M R C}$ é a concentração verdadeira.

Para um dos métodos de tratamento de amostra utilizados no presente estudo, o USEPA $3051 \mathrm{~A}$, os critérios de aceitabilidade de recuperação são $75 \%<$ $\mathrm{R}<125 \%$ (BOSTELMANN, 2006).

\section{f) Precisão}

A precisão, de um modo geral, avalia a dispersão dos resultados entre ensaios independentes, repetidos de uma mesma amostra, amostras semelhantes ou padrões, em condições definidas, sendo usualmente expressa pelo desvio padrão (equação 6) ou desvio padrão relativo (equação 9) (INMETRO, 2003).

$$
D P R \%=\frac{s}{\bar{x}} \cdot 100
$$

onde $s$ é o desvio padrão e $\bar{x}$ é o valor médio do número total de medidas.

Uma relação entre concentração do analito e precisão (através do DPR\%) é apresentada na Tabela 7. 
TABELA 7 - Relação entre a concentração do analito e a precisão esperada

\begin{tabular}{cc}
\hline Unidade & DPR (\%) \\
\hline $100 \%$ & 1,3 \\
$10 \%$ & 2,8 \\
$1 \%$ & 2,7 \\
$0,1 \%$ & 3,7 \\
$100 \mathrm{ppm}$ & 5,3 \\
$10 \mathrm{ppm}$ & 7,3 \\
$1 \mathrm{ppm}$ & 11 \\
$100 \mathrm{ppb}$ & 15 \\
$10 \mathrm{ppb}$ & 21 \\
$1 \mathrm{ppb}$ & 30 \\
\hline
\end{tabular}

Fonte: GUILHEN, 2009

A determinação da precisão pode ser feita em três níveis: repetibilidade, precisão intermediária e reprodutibilidade. A repetibilidade expressa a precisão quando os resultados são obtidos dentro do próprio laboratório, pelo mesmo analista e pelo mesmo instrumento usado sob as mesmas condições, sendo as repetições, realizadas no menor espaço de tempo possível. Já a precisão intermediária é utilizada para definir a precisão quando as medidas são realizadas por diferentes analistas, ou em diferentes dias, ou por equipamentos diferentes, enquanto que a reprodutibilidade verifica o desempenho de seus métodos por meio de comparação interlaboratorial (RIBEIRO et al., 2008). 


\section{3. ÁREA DE ESTUDO}

As bacias hidrográficas são compostas por diferentes subsistemas (sub-bacias, microbacias, calha, planície de inundação, terraços, encostas e lagos). Uma bacia hidrográfica normalmente possui limites diferentes dos limites administrativos, podendo ser considerada como uma célula básica da análise ambiental, que permite conhecer e avaliar os diversos componentes e os processos de interações que nela ocorrem. A adoção desta unidade fundamental inclui implicitamente a visão sistêmica e integrada do ambiente (MARQUES, 2011).

A Política Nacional de Recursos Hídricos, na Lei Federal n 9.433/1997 considera bacia hidrográfica como uma unidade territorial de gestão dos recursos hídricos.

Segundo Bostelmann (2006) uma bacia hidrográfica é uma área drenada parcial ou totalmente por um ou vários cursos d'água. Atualmente o território nacional é divido em 12 regiões hidrográficas, conforme apresentadas na Figura 3 (ANA, 2009). 


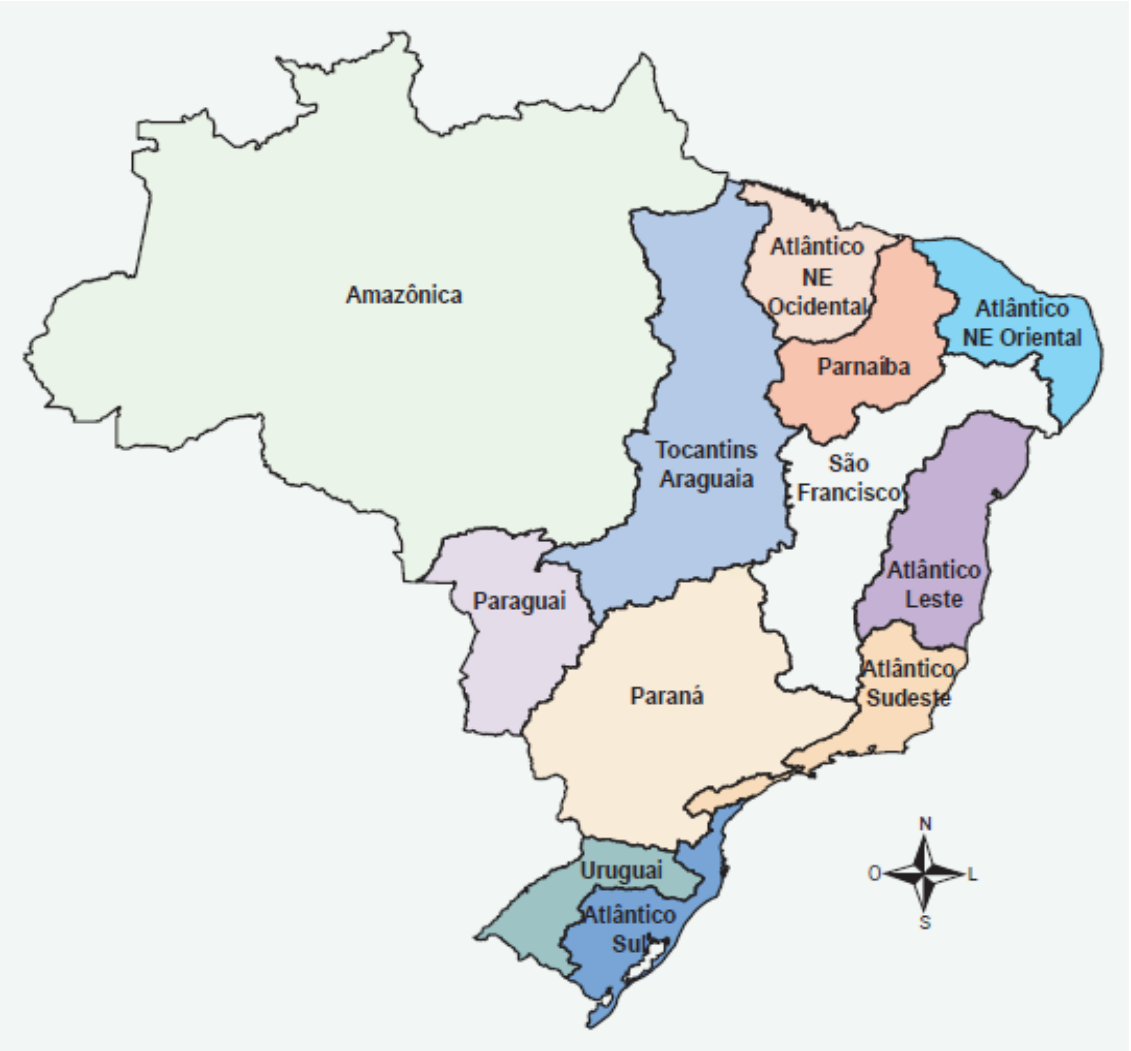

FIGURA 3 - Regiões hidrográficas do Brasil (ANA, 2005)

A bacia hidrográfica do Tocantins-Araguaia localiza-se entre os paralelos sul $0^{\circ} 30^{\prime}$ e $18^{\circ} 05^{\prime}$ e os meridianos de longitude oeste $45^{\circ} 45^{\prime}$ e $56^{\circ} 20^{\prime}$ '. Possui uma configuração alongada com sentido Sul-Norte, seguindo a direção predominante dos cursos d'água principais, os rios Tocantins e Araguaia, que se unem na parte setentrional da região, a partir de onde é denominado apenas de rio Tocantins, que segue até desaguar na Baía da llha de Marajó (ANA, 2009).

As principais fontes de contaminação dos corpos d'água desta região estão distribuídas entre o lançamento de esgotos domésticos, a construção de hidrelétricas, o assoreamento, o uso inadequado de fertilizantes e agrotóxicos, e de forma mais pontual, a atividade industrial (frigoríficos, laticínios, curtumes, mineração e siderurgia) (ANA, 2009).

A caracterização da área de estudo é realizada nos itens a seguir: 


\subsubsection{Sistemas Hidrográficos}

Os pontos amostrados estão distribuídos nos sistemas hidrográficos:

- Araguaia (Bacia do Rio do Côco): P3 (Córrego Côco);

- Tocantins (Bacia do Rio Tocantins): P1 (Córrego São João), P6 (Córrego Água Fria), P8 (Córrego Brejo Comprido), P20 (Córrego Roncador), P21 (Rio Taquaruçu Grande) e P30 (Córrego Água Suja).

Estes pontos foram selecionados em virtude da utilização das águas para abastecimento público das cidades de Palmas, Paraíso do Tocantins e Porto Nacional.

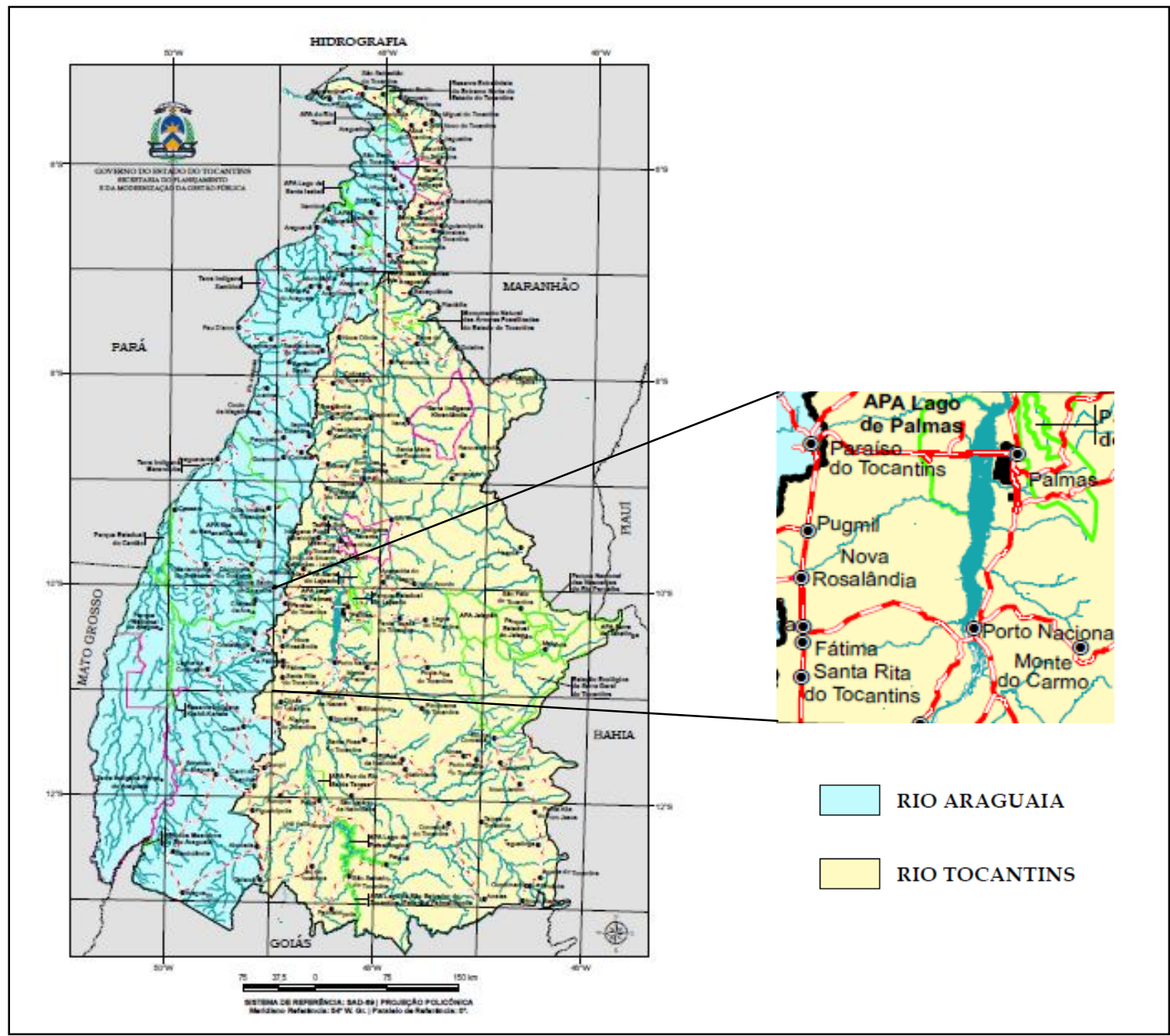

FIGURA 4 - Sistemas hidrográficos da região em estudo (TOCANTINS, 2012) 


\subsubsection{Pedologia}

Os solos que apresentam maior evidência na região em que os pontos foram coletados são:

- Latossolos Vermelho-Amarelados (LVA): P1 (Córrego São João), P6 (Córrego Água Fria), P8 (Córrego Brejo Comprido), P21 (Rio Taquaruçu Grande) e P30 (Córrego Água Suja). São considerados solos muito profundos, bem a acentuadamente drenados, muito permeáveis e porosos, em avançado estágio de intemperização. É uma classe de solos do tipo ácidos e álicos (toxidez alumínica), que necessitam de calagem para a sua correção;

- Plintossolos Pétricos (FF): P3 (Córrego Côco) e P20 (Córrego Roncador). São solos com restrição à percolação da água, que apresentam plintização ou horizonte petroplíntico (ALENCAR, 2011).

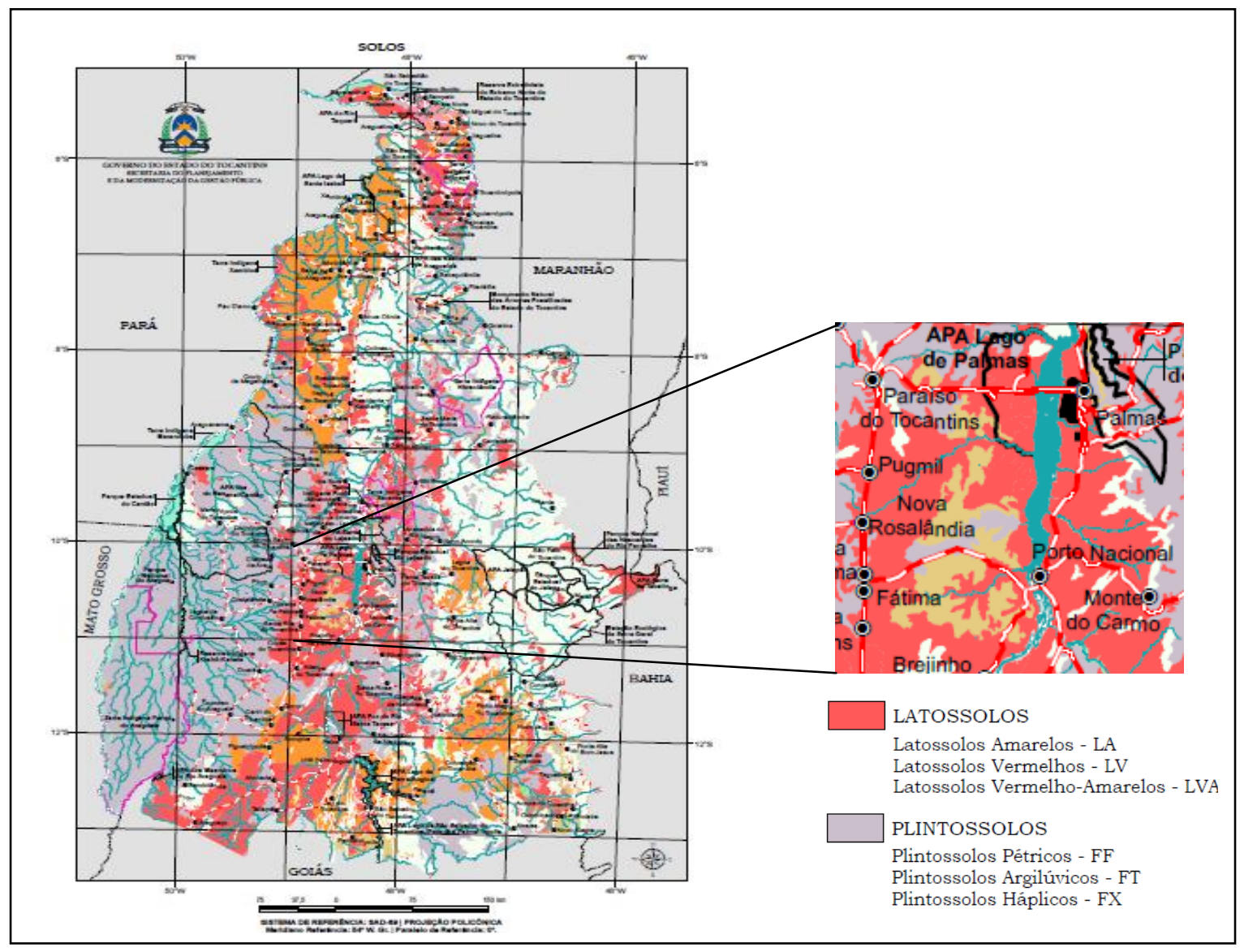

FIGURA 5 - Pedologia da região em estudo (TOCANTINS, 2012) 


\subsubsection{Clima}

O clima da região hidrográfica do Tocantins-Araguaia é tropical, com temperatura média anual de $26^{\circ} \mathrm{C}$, e dois períodos climáticos bem definidos: 0 chuvoso, de outubro a abril, com mais de $90 \%$ de precipitação, com a existência de alguns dias secos entre janeiro e fevereiro; e o seco, de maio a setembro, com baixa umidade relativa do ar (MMA, 2006b).

Na região dos pontos amostrados há o predomínio do clima C2wA'a", clima úmido subúmido com moderada deficiência hídrica no inverno, evapotranspiração potencial média anual de $1.500 \mathrm{~mm}$, distribuindo-se no verão em torno de $420 \mathrm{~mm}$ ao longo dos três meses consecutivos com temperatura mais elevada (TOCANTINS, 2012).

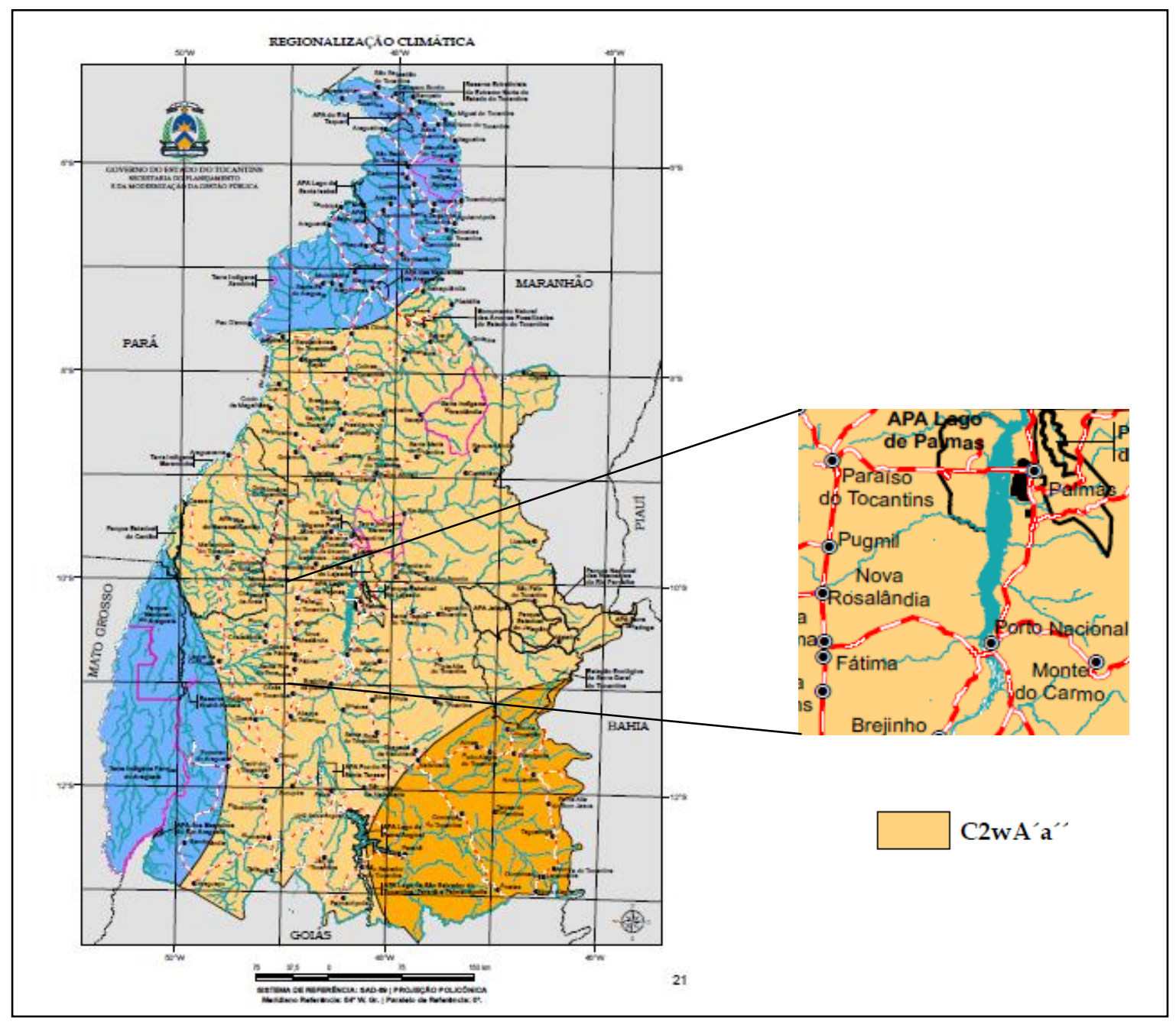

FIGURA 6 - Clima da região em estudo (TOCANTINS, 2012) 


\subsubsection{Geologia}

Os pontos amostrados na região hidrográfica do Tocantins-Araguaia estão localizados em três tipos de ambientes geológicos:

- Bacias Sedimentares: P1 (Córrego São João), P6 (Córrego Água Fria), P8 (Córrego Brejo Comprido), P20 (Córrego Roncador) e P21 (Rio Taquaruçu Grande);

- Embasamentos de Estilos Complexos: P3 (Córrego Côco);

- Depósitos Sedimentares Inconsolidados: P30 (Córrego Água Suja).

As Bacias Sedimentares, ambientes em que encontram-se a maioria dos locais estudados, são constituídas por um grupo de rochas provenientes do Paleozóico/Mesozóico, que são preenchidas por sedimentos clásticos e químicos e por extensos derrames de basalto. Estas bacias são intracratônicas, do tipo sinéclise, relativamente pouco movimentadas do ponto de vista tectônico, ressaltando-se os falhamentos verticais em suas bordas. As Coberturas Sedimentares Recentes são bem representadas na porção centro-oeste da região hidrográfica, sendo encontradas no alto curso do rio Xingu e llha do Bananal, e também na porção norte da região, nas calhas dos rios Araguaia e Tocantins, tratando-se de sedimentos detríticos freqüentemente inconsolidados (MMA, 2006b). 


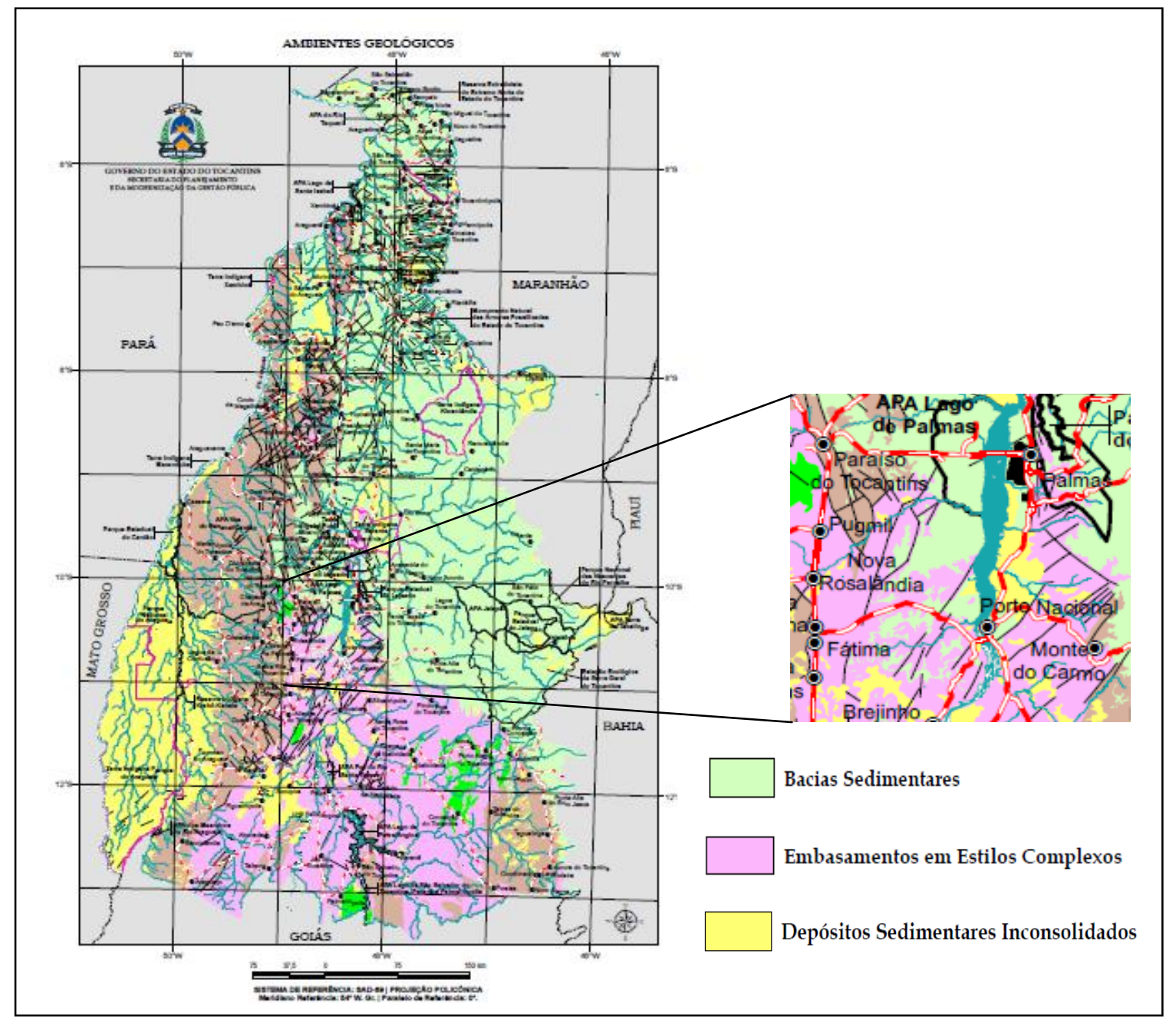

FIGURA 7 - Geologia da região em estudo (TOCANTINS, 2012)

\subsubsection{Geomorfologia}

$\mathrm{Na}$ região hidrográfica do Tocantins-Araguaia são identificadas seis macro unidades geomorfológicas: Planícies, Depressões, Tabuleiros, Patamares, Chapadas e Planaltos. Os pontos coletados estão situados em planaltos e depressões:

- Planalto Dissecado do Tocantins: P20 (Córrego Roncador);

- Depressão do Médio Tocantins: P6 (Córrego Água Fria), P8 (Córrego Brejo Comprido), P21 (Rio Taquaruçu Grande); 
- Depressão de Cristalândia: P3 (Córrego Côco);

- Depressão do Alto Tocantins: P1 (Córrego São João) e P30 (Córrego Água Suja).

As depressões estão associadas às bacias sedimentares, faixas de dobramentos e ao embasamento cristalino, representando quase um terço da região. Os planaltos representam áreas alçadas em relação às depressões circundantes. Os Planaltos Residuais do Araguaia-Tocantins posicionam-se de maneira alongada na direção norte-sul, tendo como expressão a Serra do Estrondo (MMA, 2006b).

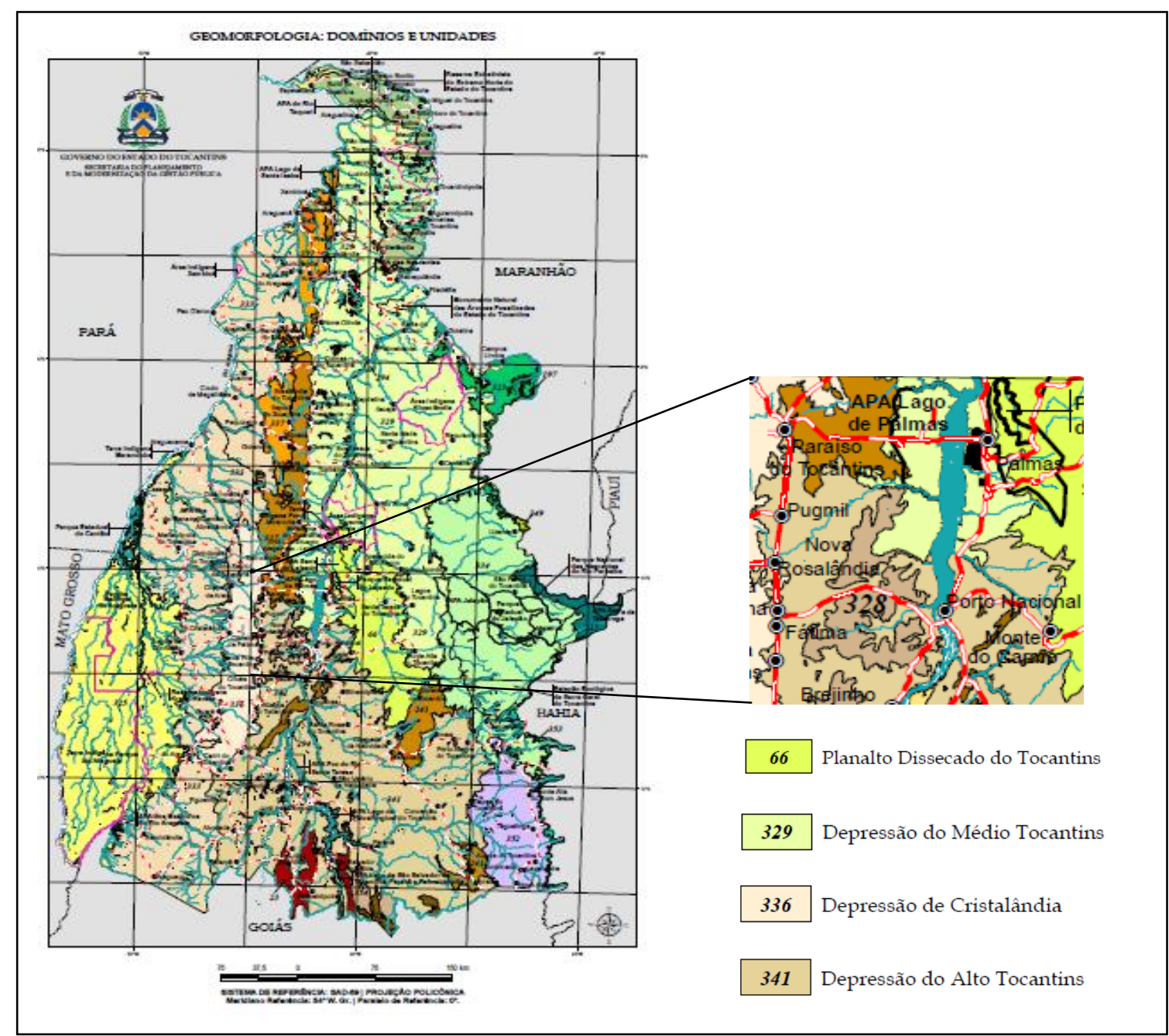

FIGURA 8 - Geomorfologia da região em estudo (TOCANTINS, 2012) 


\section{PARTE EXPERIMENTAL}

\subsection{COLETA DAS AMOSTRAS DE SEDIMENTO}

As amostras foram coletadas no mês de outubro de 2011, sendo este mês caracterizado como um período de transição entre a estação seca e a chuvosa. A coleta foi realizada em 7 pontos da região hidrográfica do TocantinsAraguaia, pontos utilizados para captação de água para abastecimento público das cidades de Palmas (pontos 06, 08, 20 e 21), Paraíso do Tocantins (ponto 03) e Porto Nacional (pontos 01 e 30), no Estado do Tocantins, todas abastecidas pela SANEATINS, companhia distribuidora de água do estado.

Na Figura 9 é apresentado um mapa com a localização geográfica dos pontos de coleta. Os detalhes desta localização são descritos na Tabela 8.

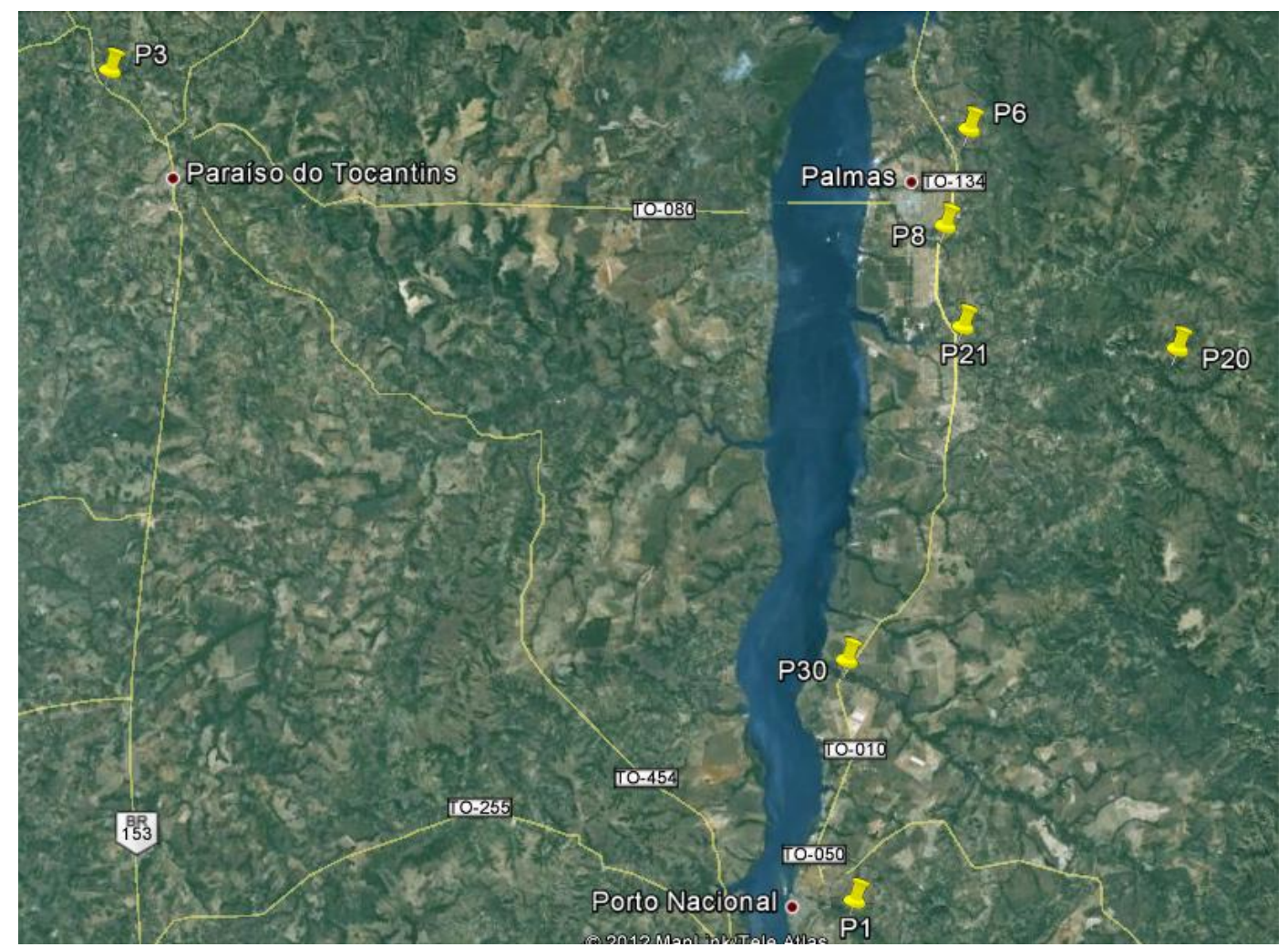

FIGURA 9 - Mapa com a localização geográfica dos pontos de coleta 
TABELA 8 - Localização dos pontos de coleta

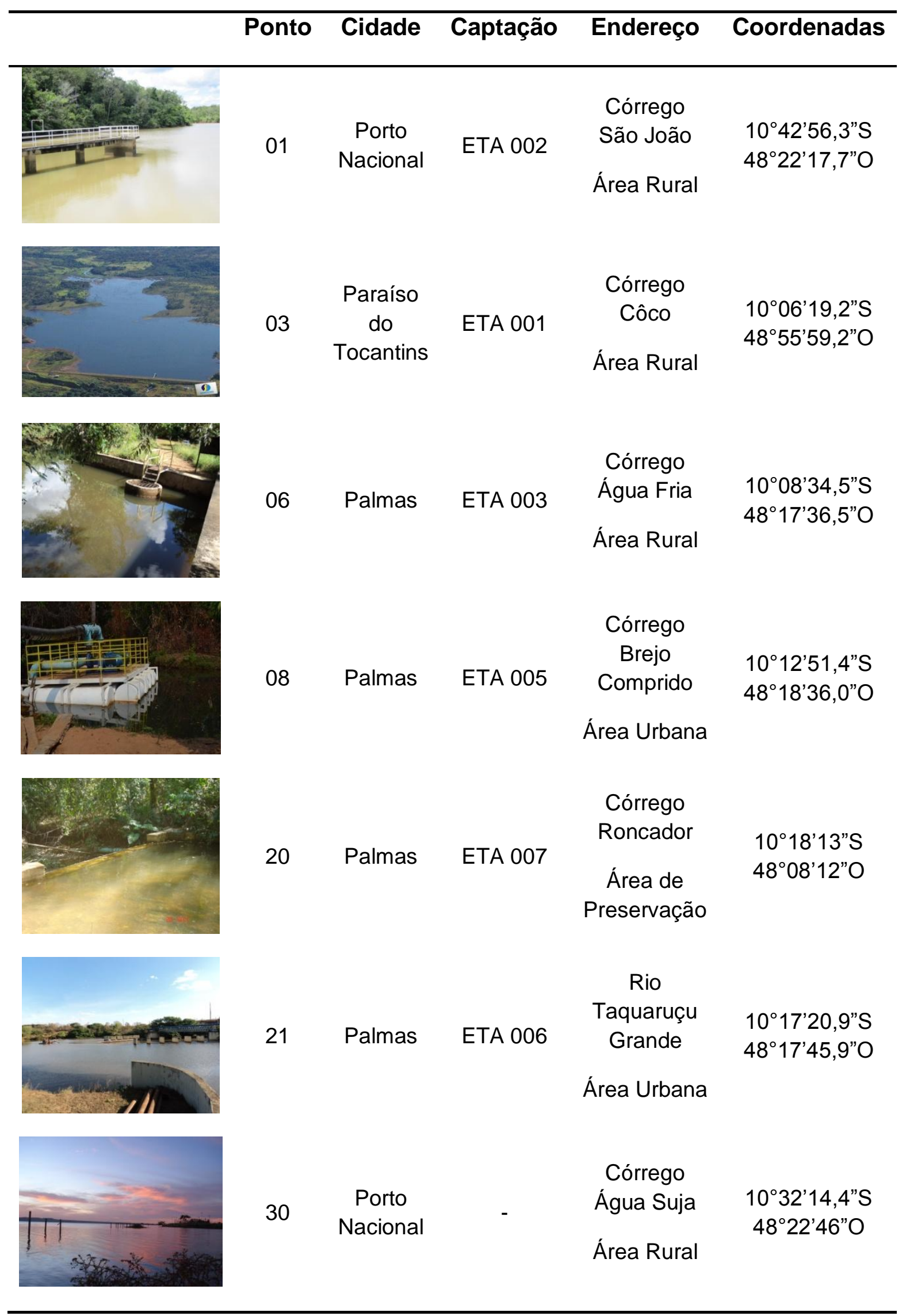


A coleta das amostras foi realizada com o auxílio da draga de Petersen (Figura 10), um instrumento capaz de escavar ("morder") substratos grossos devido ao seu peso elevado e sistema de alavanca. A draga de Petersen possui um sistema de braços armados em pantógrafo que, quando tensionados, mantém aberta a caçamba por meio de uma trava. Quando o instrumento entra em contato com o solo, a tensão desaparece e libera a trava. $O$ fechamento do pegador somente ocorre quando o cabo é novamente tracionado para a retirada do instrumento da água, permitindo a coleta do sedimento. É um equipamento que requer cuidado em seu manuseio por não possuir travas de segurança (CETESB, 2011).

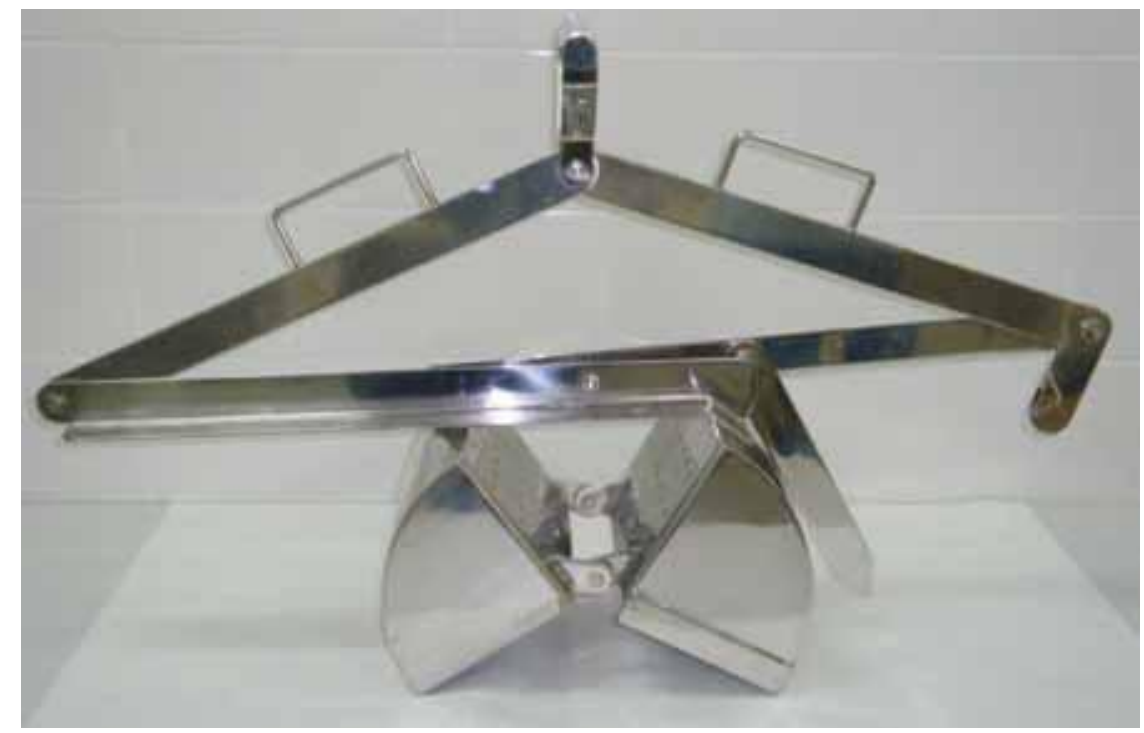

FIGURA 10 - Draga de Petersen (CETESB, 2011)

Após a coleta, as amostras foram acondicionadas em sacos plásticos e resfriadas para serem transportadas até o laboratório, onde permaneceram sob refrigeração até a etapa seguinte. 


\subsection{PRÉ-TRATAMENTO DAS AMOSTRAS DE SEDIMENTO}

As amostras de sedimento foram distribuídas uniformemente em bandejas de vidro pyrex, as quais foram levadas para estufa de circulação de ar modelo $320 \mathrm{E}$, da FANEM, onde permaneceram por 24 horas a $60^{\circ} \mathrm{C}$, temperatura em que, segundo Lemes (2001), não há perdas dos metais presentes no sedimento por meio de arraste pelo vapor de água.

As amostras, previamente secas, foram maceradas em almofariz de ágata, visando sua homogeneização. Durante o processo de maceramento, alguns resíduos vegetais visíveis, como galhos e folhas, foram retirados com uma pinça. Com o intuito de estudar apenas as frações mais finas do sedimento, as amostras foram, então, peneiradas em peneira de aço inox com abertura de malha de 0,250 $\mathrm{mm}$ e armazenadas em pequenos sacos plásticos.

Posteriormente foi realizada a solubilização das amostras de sedimento a fim de extrair os metais ambientalmente disponíveis. Para fim de estudo comparativo, foram utilizados dois métodos de digestão ácida reportados na literatura:

\subsubsection{Digestão com $\mathrm{HNO}_{3} 8 \mathrm{M}$ e Aquecimento em Equipamento Microondas}

Este processo foi estabelecido com base no método número 3051A da Agência de Proteção Ambiental dos Estados Unidos - USEPA (USEPA 3051A, 2007) em que foi utilizado como fonte de calor o equipamento microondas Modelo DGT 100 Plus da marca Provecto Analítica. Pelo fato deste equipamento microondas não dispor de retorno de temperatura da amostra, utilizou-se uma adaptação do método, visto que o mesmo especifica que as amostras sejam aquecidas a temperatura de $(175 \pm 5)^{\circ} \mathrm{C}$ por cerca de 10 minutos. Foi então utilizada uma programação que faz uso de potência, no lugar de temperatura, programação esta que é utilizada no laboratório para este tipo de processo e que atende às especificações do método 3051A da USEPA. Inicialmente as amostras 
de sedimento foram secas em estufa de secagem modelo 315 SE, da FANEM, em temperatura de $105-110^{\circ} \mathrm{C}$, por 2 horas. Em seguida, cerca de $0,2 \mathrm{~g}$ de sedimento foi transferido para o frasco reacional Hostaflon ${ }^{\circledR}$, que é transparente às microondas e tem resistência às altas temperaturas e pressão, sendo então adicionados $10 \mathrm{~mL}$ de $\mathrm{HNO}_{3} 8 \mathrm{M}$. A amostra foi levada ao forno de microondas e, após o término da programação de aquecimento (Tabela 9) e posterior resfriamento, a solução foi transferida para balão volumétrico de $50 \mathrm{~mL}$ e seu volume foi completado com água tipo I obtida com o purificador de água EASYpure RF da Barnstead. A amostra foi então filtrada com papel de filtro de filtração lenta, e armazenada em frascos de polietileno, sendo mantida sob refrigeração até a análise dos metais de interesse.

TABELA 9 - Programa de aquecimento utilizado no equipamento microondas (indicação do tempo e potência nominal aplicada)

\begin{tabular}{ccc}
\hline Passo & $\begin{array}{c}\text { Tempo } \\
\text { (minutos) }\end{array}$ & $\begin{array}{c}\text { Potência } \\
\text { (Watts) }\end{array}$ \\
\hline 1 & 5 & 500 \\
2 & 1 & 0 \\
3 & 5 & 500 \\
4 & 2 & 0 \\
5 & 5 & 500 \\
\hline
\end{tabular}

Observação: A aplicação de 0 Watts de potência significa tempo de resfriamento, utilizado para evitar superaquecimento das amostras e elevação demasiada da pressão dentro das células de digestão, e assim, trabalhar em faixa segura de temperatura e pressão. Para que a solubilização das amostras seja efetiva faz-se necessária uma repetição de 5 vezes da programação acima.

\subsubsection{Digestão com $\mathrm{HCl} 0,1 \mathrm{M}$ e Agitação em Temperatura Ambiente}

Cerca de $0,2 \mathrm{~g}$ de sedimento foi pesado em papel manteiga, sendo este transferido para um frasco erlenmeyer, no qual foram adicionados $10 \mathrm{~mL}$ de 
$\mathrm{HCl}$ 0,1 M. A mistura foi submetida a uma agitação constante em agitador mecânico da Ética modelo 430, a $150 \mathrm{rpm}$, em temperatura ambiente, por $2 \mathrm{~h}$. Após a lixiviação ácida, a solução foi transferida para balão volumétrico de $50 \mathrm{~mL}$, e o volume aferido com água tipo I. Finalmente, a amostra foi filtrada em papel de filtro de filtração lenta, armazenada em frascos de polietileno e mantida em geladeira até as análises requeridas.

\subsection{CARACTERIZAÇÃO FíSICA DO SEDIMENTO}

\subsubsection{Determinação do teor de matéria orgânica}

A análise da matéria orgânica é uma parte fundamental de estudos de contaminação de águas naturais, visto que tem a capacidade de adsorver os metais tóxicos, tornando o compartimento mais contaminado, havendo, portanto, importante relação entre o teor de matéria orgânica e a concentração de metais tóxicos em sedimentos aquáticos.

A determinação do teor de matéria orgânica foi realizada seguindo a norma da ABNT, NBR 13600, a qual baseia-se na determinação do teor de matéria orgânica por combustão, sendo um método de quantificação da fração de sólidos voláteis (correspondentes à porção orgânica da amostra) em altas temperaturas.

Cerca de $50 \mathrm{~g}$ da amostra de sedimento (seca a $60^{\circ} \mathrm{C}$; fração total) foram transferidos para cadinho de porcelana previamente tarado, o qual foi levado para estufa de secagem modelo $315 \mathrm{SE}$, da FANEM, em temperatura de $105-110^{\circ} \mathrm{C}$, onde permaneceu por 24 horas. Após resfriamento da amostra e posterior pesagem, o cadinho contendo a amostra foi colocado em mufla da ELETROlab, modelo $901 / 3$ e, a temperatura foi aumentada gradualmente até atingir $(440 \pm 5)^{\circ} \mathrm{C}$. A amostra permaneceu em mufla por 12 horas, ou seja, até sua queima total. Novamente, após resfriamento da amostra, fez-se a pesagem 
do conjunto, sendo o ensaio finalizado com os cálculos necessários indicados na norma (ABNT, 1996).

\subsubsection{Análise granulométrica}

A determinação da distribuição granulométrica em sedimentos é realizada devido ao grau de efeito que o tamanho das partículas tem na adsorção e retenção dos metais tóxicos na superfície do sedimento.

Esta análise foi realizada baseando-se no método da Cetesb, L6.160 (CETESB, 1995) em que um conjunto de 7 peneiras da Bertel com aberturas diferentes que variam entre $2,000 \mathrm{~mm}$ a $0,063 \mathrm{~mm}$ (Tabela 10), um dispositivo vibratório e uma balança semi-analítica são utilizados. Uma massa de $100 \mathrm{~g}$ de amostra (seca a $60^{\circ} \mathrm{C}$; fração total) foi transferida para o conjunto de peneiras, sendo colocada na peneira superior (abertura de $2 \mathrm{~mm}$ ). A tampa do conjunto foi colocada e em seguida, o sistema foi deixado no dispositivo vibratório por 15 minutos em rotação de $8 \mathrm{rpm}$. Após este tempo, pesou-se cada peneira individualmente para a obtenção da massa de cada fração granulométrica.

TABELA 10 - Numeração das peneiras da Bertel e suas respectivas aberturas (em $\mathrm{mm}$ )

\begin{tabular}{cc}
\hline $\mathbf{n}^{\circ}$ ABNT & $(\mathbf{m m})$ \\
\hline 10 & 2,000 \\
18 & 1,000 \\
35 & 0,500 \\
60 & 0,250 \\
120 & 0,125 \\
230 & 0,063 \\
fundo & não retido \\
\hline
\end{tabular}




\subsection{DETERMINAÇÃO DE METAIS NAS AMOSTRAS DE SEDIMENTO}

A quantificação dos metais e elementos-traço foi realizada nos Laboratórios do Centro de Química e Meio Ambiente - CQMA do IPEN-CNEN/SP, podendo-se considerar os resultados com a qualidade exigida, visto que estes laboratórios possuem o Sistema de Qualidade Implantado - ISO-IEC-17025, recebem auditoria regularmente por um Sistema Integrado de Qualidade do IPEN, e fazem parte de Programas Interlaboratoriais, de Testes de Proficiência e do Programa Brasileiro de Metrologia Química (COTRIM, 2006).

As análises foram realizadas por meio das técnicas: Espectrometria de Absorção Atômica com Atomização Eletrotérmica em Forno de Grafite (GFAAS: Graphite Furnace Atomic Absorption Spectrometry), Espectrometria de Absorção Atômica com Geração de Vapor Frio (CVAAS: Cold Vapor Atomic Absorption Spectrometry) e Espectrometria de Emissão Óptica com Plasma Indutivamente Acoplado (ICP-OES: Inductively Coupled Plasma Optical Emission Spectrometry). Os elementos analisados por cada técnica estão descritos na Tabela 11.

TABELA 11 - Resumo das técnicas utilizadas para a determinação dos metais ambientalmente disponíveis nas amostras de sedimento

\begin{tabular}{|c|c|c|c|c|}
\hline Técnica & Descrição & Elementos & Ajustes & Validação \\
\hline GFAAS & $\begin{array}{c}\text { Espectrometria de } \\
\text { Absorção Atômica } \\
\text { com Forno de } \\
\text { Grafite }\end{array}$ & As, $\mathrm{Cd}, \mathrm{Pb}, \mathrm{Se}$ & $\begin{array}{c}\text { Otimização das } \\
\text { temperaturas de } \\
\text { pirólise e } \\
\text { atomização para } \\
\text { cada elemento e } \\
\text { matriz }\end{array}$ & Necessário \\
\hline CVAAS & $\begin{array}{c}\text { Espectrometria de } \\
\text { Absorção Atômica } \\
\text { com Geração de } \\
\text { Vapor Frio }\end{array}$ & $\mathrm{Hg}$ & $\begin{array}{l}\text { Uso de solução } \\
\text { no tratamento } \\
\text { das amostras } \\
\text { para redução do } \\
\text { elemento }\end{array}$ & $\begin{array}{c}\text { Metodologia já } \\
\text { validada } \\
\text { (GUILHEN, 2009) }\end{array}$ \\
\hline $\begin{array}{l}\text { ICP } \\
\text { OES }\end{array}$ & $\begin{array}{l}\text { Espectrometria de } \\
\text { Emissão Óptica } \\
\text { com Plasma } \\
\text { Indutivamente } \\
\text { Acoplado }\end{array}$ & $\begin{array}{c}\mathrm{Ag}, \mathrm{Al}, \mathrm{B}, \mathrm{Ba}, \mathrm{Be} \\
\mathrm{Ca}, \mathrm{Co}, \mathrm{Cr}, \mathrm{Cu} \\
\mathrm{Fe}, \mathrm{K}, \mathrm{Li}, \mathrm{Mg}, \mathrm{Mn}, \\
\mathrm{Mo}, \mathrm{Na}, \mathrm{Ni}, \mathrm{P}, \mathrm{Sb} \\
\mathrm{Sc}, \mathrm{Si}, \mathrm{Ti}, \mathrm{V}, \mathrm{Zn}\end{array}$ & $\begin{array}{l}\text { Uso de linhas de } \\
\text { emissão com } \\
\text { menor } \\
\text { interferência para } \\
\text { cada elemento }\end{array}$ & $\begin{array}{c}\text { Metodologia já } \\
\text { validada } \\
\text { (COTRIM, 2006) }\end{array}$ \\
\hline
\end{tabular}




\subsubsection{Espectrometria de Absorção Atômica com Atomização Eletrotérmica em Forno de Grafite (GFAAS)}

A determinação da concentração de $\mathrm{As}, \mathrm{Cd}, \mathrm{Pb}$ e Se em amostras de sedimento foi realizada num espectrômetro de absorção atômica da Perkin Elmer modelo AAnalyst 800 acoplado a um forno de grafite modelo HGA 400 da Perkin Elmer com aquecimento transversal e corretor Zeeman.

$\mathrm{Na}$ Tabela 12 estão descritas as condições operacionais e os parâmetros instrumentais do sistema.

TABELA 12 - Condições operacionais do forno de grafite THGA

\begin{tabular}{cccccc}
\hline Etapas & Secagem & Secagem & Pirólise & Atomização & Limpeza \\
\hline $\begin{array}{c}\text { Temperatura } \\
\left({ }^{\circ} \mathrm{C}\right)\end{array}$ & 110 & 130 & variável & variável & 2450 \\
$\begin{array}{c}\text { Rampa de } \\
\text { Aquecimento } \\
(\mathrm{s})\end{array}$ & 1 & 15 & 10 & 0 & 1 \\
$\begin{array}{c}\text { Tempo de } \\
\text { Isoterma } \\
(\mathrm{s})\end{array}$ & 30 & 30 & 20 & 5 & 3 \\
$\begin{array}{c}\text { Fluxo Interno } \\
\text { de Gás } \\
\left(\mathrm{mL} \text { min }{ }^{-1}\right)\end{array}$ & 250 & 250 & 250 & 0 & 250 \\
\hline
\end{tabular}

Para a obtenção de uma maior sensibilidade na determinação de qualquer elemento, as temperaturas das etapas de pirólise e atomização têm de ser otimizadas previamente. A otimização da temperatura de pirólise para cada elemento foi realizada fixando-se a temperatura de atomização (cada elemento possui uma temperatura pré-estabelecida pelo equipamento) e variando a de pirólise. Uma vez estabelecida a temperatura de pirólise, determinou-se a 
temperatura de atomização, da mesma maneira, fixando-se a temperatura de pirólise pré-estabelecida pelo equipamento.

A otimização das temperaturas de pirólise e atomização foi realizada utilizando solução padrão da Merck de cada elemento de interesse e soluções do material de referência certificado Buffalo River Sediment SRM 8704 digerido, proveniente dos dois processos de digestão utilizados no estudo. Esta etapa é bastante importante para verificar a influência da matriz sobre as temperaturas de pirólise e atomização dos elementos estudados.

A concentração de cada elemento analisado é obtida por meio da interpolação da absorbância em uma curva analítica construída previamente com uma solução padrão, sendo a relação absorbância e concentração, uma relação linear que segue a Lei de Lambert-Beer. Para a construção desta curva, utilizouse uma solução padrão obtida por meio de diluição de um padrão misto da Perkin Elmer em $\mathrm{HNO}_{3} 0,2 \%$.

Foi utilizado modificador químico $\mathrm{Pd} / \mathrm{Mg}\left(\mathrm{NO}_{3}\right)_{2}$ tanto nas curvas analíticas quanto nas análises das amostras, sendo sua massa de 0,005 mg de $\mathrm{Pd}\left(\mathrm{NO}_{3}\right)_{2}$ e $0,003 \mathrm{mg}$ de $\mathrm{Mg}\left(\mathrm{NO}_{3}\right)_{2}$.

A fim de controlar a qualidade dos resultados analíticos, foi utilizado, durante as análises, um material de referência certificado do NIST, o SRM 1643e Trace Elements in Water, além das determinações terem sido realizadas em duplicata.

\subsubsection{Validação da Metodologia Analítica}

Foi realizada a validação da metodologia analítica para a determinação de $\mathrm{As}, \mathrm{Cd}, \mathrm{Pb}$ e Se em amostras de sedimento por meio da técnica de GFAAS. Os parâmetros selecionados para a avaliação do método foram: curva analítica e linearidade, faixa de trabalho, limites de detecção e quantificação, exatidão e precisão. 
A solução padrão utilizada para a construção da curva analítica foi obtida por meio de diluição de um padrão misto da Perkin Elmer em $\mathrm{HNO}_{3}$ 0,2\%. A curva foi construída com cinco concentrações distintas diferentes de zero, além do branco.

Para a determinação do $L Q$ normalmente são feitas adições de concentrações específicas do analito ao branco da amostra, porém neste caso utilizou-se soluções padrões da Merck de cada elemento de interesse, devido às dificuldades em se obter o branco das amostras de sedimento. Então para cada analito estudado, foram preparadas soluções com concentrações variadas, inferiores à concentração do primeiro ponto da curva analítica, com o número de replicatas independentes a cada nível de concentração correspondente a 7 , sendo adotada como aceitável uma precisão ou DPR\% de 10\%.

O material de referência certificado utilizado para avaliação da exatidão do método analítico foi do NIST, o SRM 8704 (Buffalo River Sediment), que possui valores certificados para $\mathrm{As}, \mathrm{Cd}$ e $\mathrm{Pb}$ e valor não certificado para Se. Este material de referência foi previamente digerido pelos dois procedimentos de digestão em estudo, e os valores obtidos pelo laboratório foram comparados com os valores fornecidos pelo material de referência certificado, para assim ser determinada a recuperação da metodologia analítica.

No presente estudo, o desvio padrão relativo foi calculado em todas as análises, sendo considerado como aceitável durante todo o processo, DPR\% em torno de $10 \%$.

\subsubsection{Espectrometria de Absorção Atômica com Geração de Vapor Frio (CVAAS)}

A determinação da concentração de $\mathrm{Hg}$ nas amostras de sedimento foi realizada num espectrômetro de absorção atômica da Perkin Elmer modelo AAnalyst 800 acoplado a um sistema de injeção em fluxo FIAS 400 com gerador 
de vapor frio, também da Perkin Elmer. Foram utilizadas soluções de $\mathrm{KMnO}_{4}$ para oxidação de todas as espécies, e $\mathrm{NaBH}_{4}$, para redução das mesmas.

Foi utilizada uma programação analítica pré-estabelecida e já certificada para análise de mercúrio em amostras ambientais, sendo utilizado o método da curva analítica na determinação da concentração de mercúrio, através do uso de uma solução padrão monoelementar da Merck.

Na Tabela 13 é apresentada a faixa de concentração e o limite de quantificação estabelecido para o método.

TABELA 13 - Faixa de concentração e limite de quantificação para determinação de Hg por CVAAS

\begin{tabular}{ccc}
\hline Elemento & $\begin{array}{c}\text { Faixa de } \\
\text { Concentração } \\
\left(\mathbf{m g ~ L}^{-1}\right)\end{array}$ & $\begin{array}{c}\text { Limite de } \\
\text { Quantificação } \\
\left(\mathbf{m g ~ L}^{-1}\right)\end{array}$ \\
\hline $\mathrm{Hg}$ & $0,0008-0,006$ & 0,0008 \\
\hline
\end{tabular}

Fonte: COTRIM, 2006

\subsubsection{Espectrometria de Emissão Óptica com Plasma Indutivamente Acoplado (ICP-OES)}

A determinação de 24 elementos (Ag, Al, B, Ba, Be, Ca, Co, Cr, Cu, Fe, $\mathrm{K}, \mathrm{Li}, \mathrm{Mg}, \mathrm{Mn}, \mathrm{Mo}, \mathrm{Na}, \mathrm{Ni}, \mathrm{P}, \mathrm{Sb}, \mathrm{Sc}, \mathrm{Si}, \mathrm{Ti}, \mathrm{V}, \mathrm{Zn}$ ) nas amostras de sedimento foi realizada utilizando-se o equipamento Spectro Flame M 120 E - Spectro, com tocha axial, o qual possui uma programação com recursos suficientes a fim de permitir uma escolha criteriosa das linhas de emissão a serem utilizadas para cada elemento.

As análises foram realizadas utilizando-se programas analíticos préestabelecidos e já certificados pelo laboratório, os quais empregam o método da curva analítica para determinação dos elementos, sendo esta produzida por meio 
de soluções padrão multielementares. As condições operacionais do sistema são resumidas na Tabela 14.

TABELA 14 - Condições operacionais do sistema (ICP-OES)

\begin{tabular}{cc}
\hline Parâmetros Operacionais & Condições \\
\hline Potência do Plasma & $1200 \mathrm{~W}$ \\
Gás Refrigerante $(\mathrm{Ar})$ & $28 \mathrm{~L} \mathrm{~min}^{-1}$ \\
Gás Auxiliar & $1,5 \mathrm{~L} \mathrm{~min}^{-1}$ \\
Pressão do Nebulizador & $2,8 \mathrm{bar}$ \\
Fluxo de amostra & $1,5 \mathrm{~mL} \mathrm{~min}^{-1}$ \\
\hline
\end{tabular}

Com o objetivo de controlar a qualidade dos resultados analíticos, a análise das amostras foi realizada em triplicata, além disso, foi realizado um controle de qualidade analítico baseado em análises diárias de soluções padrão.

$\mathrm{Na}$ Tabela 15 estão descritos a linha de emissão, a faixa de concentração e o limite de quantificação estabelecidos para cada elemento quantificado pelo método, para as análises das amostras de sedimento. 
TABELA 15 - Linhas de emissão, faixas de concentração e limites de quantificação utilizados na análise de sedimentos por ICP-OES

\begin{tabular}{|c|c|c|c|}
\hline Elemento & $\begin{array}{c}\text { Linhas de } \\
\text { Emissão } \\
\text { (nm) }\end{array}$ & $\begin{array}{c}\text { Faixa de } \\
\text { Concentração } \\
\left(\mathrm{mg} \mathrm{L}^{-1}\right)\end{array}$ & $\begin{array}{c}\text { Limite de } \\
\text { Quantificação } \\
\left(\mathrm{mg} \mathrm{L}^{-1}\right)\end{array}$ \\
\hline $\mathrm{Ag}$ & 328,068 & $0,10-1,20$ & 0,10 \\
\hline $\mathrm{Al}$ & 257,510 & $0,50-600$ & 0,50 \\
\hline$B$ & 249,773 & $0,10-1,20$ & 0,10 \\
\hline $\mathrm{Ba}$ & 455,403 & $0,01-12,0$ & 0,01 \\
\hline $\mathrm{Be}$ & 313,042 & $0,01-1,20$ & 0,01 \\
\hline $\mathrm{Ca}$ & 318,128 & $1,00-300$ & 1,00 \\
\hline Co & 228,616 & $0,02-1,20$ & 0,02 \\
\hline $\mathrm{Cr}$ & 267,716 & $0,02-12,0$ & 0,02 \\
\hline $\mathrm{Cu}$ & 327,396 & $0,02-120$ & 0,02 \\
\hline $\mathrm{Fe}$ & 273,074 & $1,00-600$ & 1,00 \\
\hline $\mathrm{K}$ & 766,491 & $0,10-120$ & 0,10 \\
\hline $\mathrm{Li}$ & 670,784 & $0,01-1,20$ & 0,01 \\
\hline $\mathrm{Mg}$ & 279,079 & $0,05-300$ & 0,05 \\
\hline $\mathrm{Mn}$ & 280,106 & $0,05-60,0$ & 0,05 \\
\hline Mo & 386,411 & $0,10-12,0$ & 0,10 \\
\hline $\mathrm{Na}$ & 589,592 & $0,50-300$ & 0,50 \\
\hline $\mathrm{Ni}$ & 341,476 & $0,50-120$ & 0,50 \\
\hline$P$ & 177,500 & $0,05-12,0$ & 0,05 \\
\hline $\mathrm{Sb}$ & 206,833 & $0,05-12,0$ & 0,05 \\
\hline Sc & 335,373 & $0,02-1,20$ & 0,02 \\
\hline $\mathrm{Si}$ & 288,158 & $1,00-24,0$ & 1,00 \\
\hline $\mathrm{Ti}$ & 391,346 & $0,10-120$ & 0,10 \\
\hline V & 292,464 & $0,03-12,0$ & 0,03 \\
\hline $\mathrm{Zn}$ & 213,856 & $0,02-1,20$ & 0,02 \\
\hline
\end{tabular}




\subsubsection{Tratamento Estatístico dos Dados - Análise Multivariada}

A análise multivariada está relacionada com um conjunto de métodos estatísticos que torna possível a análise simultânea de mais de duas variáveis. $\mathrm{A}$ fim de obter-se um melhor entendimento da base de dados obtida, foram utilizadas duas técnicas de análise multivariada, a análise fatorial e a análise de conglomerados (clusters analysis). Para isso, foi utilizado o programa estatístico Statistica 8.0 (STATSOFT).

\subsubsection{Análise Fatorial}

A análise fatorial é uma técnica multivariada que considera simultaneamente todas as variáveis e que avalia as inter-relações existentes entre cada uma delas, buscando a sumarização dos dados. Esta técnica tem por objetivo encontrar um meio de condensar a informação contida nas variáveis originais em um conjunto menor de variáveis estatísticas (fatores) com uma perda mínima de informação (CORRAR et al., 2007).

A análise fatorial com extração dos componentes principais foi realizada submetendo a matriz à rotação Varimax (onde o valor de corte é igual a 1). Para o tratamento estatístico foram considerados os resultados das análises dos metais ambientalmente disponíveis nas amostras de sedimento, bem como os dados obtidos de matéria orgânica e granulometria, considerando para esta apenas as porcentagens resultantes de fração $<0,250 \mathrm{~mm}$.

\subsubsection{Análise de Conglomerados (Clusters Analysis)}

A análise de conglomerados é uma técnica multivariada cuja finalidade primária é agregar objetos com base nas características que eles possuem, 
formando grupos por meio da análise das semelhanças e diferenças existentes entre suas características (CORRAR et al., 2007).

Para esta análise foi utilizado o procedimento single linkage, também chamado de abordagem do vizinho mais próximo, método baseado na distância mínima entre os objetos. Para medir a similaridade ou dissimilaridade entre as variáveis foram adotadas as distâncias euclideanas, assim, as menores distâncias indicam maior similaridade.

Com a mesma base de dados utilizada na análise fatorial, foi realizada a análise de conglomerados. Neste caso, foram gerados dendogramas para identificar as similaridades e dissimilaridades entre os pontos de amostragem e entre as variáveis analisadas. 


\section{RESULTADOS E DISCUSSÃO}

Os dados obtidos neste estudo foram trabalhados a fim de:

- Determinar o teor de matéria orgânica e a distribuição granulométrica dos sedimentos coletados para obter informações de alguns dos fatores que podem influenciar na mobilização dos contaminantes no compartimento;

- Validar metodologia analítica para determinação de metais em sedimentos pela técnica GFAAS;

- Comparar métodos de solubilização de amostras de sedimento de modo a verificar aquele mais adequado para a avaliação de metais ambientalmente disponíveis;

- Realizar uma avaliação da qualidade da água do sistema hidrográfico Tocantins-Araguaia, quanto à contribuição de metais tóxicos na fração ambientalmente disponível de sedimentos.

\subsection{CARACTERIZAÇÃO FíSICA DO SEDIMENTO}

\subsubsection{Teor de Matéria Orgânica}

A determinação do teor de matéria orgânica é uma ferramenta importante neste tipo de estudo, visto que alguns pesquisadores relatam a existência de uma relação entre o teor de matéria orgânica e a concentração de elementos-traço em sedimentos aquáticos (LEMES, 2001; BAIRD, 2002; BONAI et al., 2009; BELO et al., 2010; FRANKLIN et al., 2012). 
$\mathrm{Na}$ Tabela 16 são apresentados os valores determinados para matéria orgânica nos sedimentos coletados.

TABELA 16 - Resultado da matéria orgânica (em \%)

\begin{tabular}{|c|c|}
\hline Ponto & Matéria Orgânica (\%) \\
\hline 01 & $4,74 \pm 0,56$ \\
\hline 03 & $14,19 \pm 0,43$ \\
\hline 06 & $5,64 \pm 0,07$ \\
\hline 08 & $1,42 \pm 0,09$ \\
\hline 20 & $2,77 \pm 0,08$ \\
\hline 21 & $3,74 \pm 0,04$ \\
\hline 30 & $3,47 \pm 0,29$ \\
\hline
\end{tabular}

Os valores obtidos mostram que os sedimentos analisados são de natureza mineral, com moderado conteúdo de matéria orgânica, visto que, com exceção do sedimento coletado no ponto 03 , todos os outros pontos apresentaram menos de $10 \%$ de matéria orgânica em peso seco (BONAl et al., 2009; BELO et al., 2010).

O teor de matéria orgânica é um fator que pode promover a retenção dos metais. As partículas orgânicas podem mobilizar de 1 a 10\% (peso seco) de $\mathrm{Ag}, \mathrm{Co}, \mathrm{Cu}, \mathrm{Fe}, \mathrm{Pb}, \mathrm{Mn}, \mathrm{Mo}, \mathrm{Ni}, \mathrm{V}$ e $\mathrm{Zn}$, o que demonstra que os ácidos húmicos e fúlvicos, atuando como agentes complexantes, são grandes responsáveis pelo enriquecimento de metais em sedimentos (Lemes, 2001).

Segundo Bonai et al. (2009), a matéria orgânica tem boa capacidade de retenção de metais tóxicos, concentrando tais elementos no ambiente, o que pode acarretar no impacto do meio, ou também pode auxiliar na remoção destes metais em ambientes contaminados. 
Pela análise dos resultados apresentados na Tabela 16 é possível perceber que o sedimento do ponto 03 é o único que apresenta um teor de matéria orgânica acima de 10\%. Este ponto está localizado no Córrego Côco, na zona rural do município de Paraíso do Tocantins, a $10 \mathrm{~km}$ da cidade. Ao redor do local de coleta existem pequenas propriedades onde são realizadas as atividades de agricultura e pecuária, fato que pode ter sido relevante para o teor de matéria orgânica encontrado, visto que em tais atividades são muito utilizados compostos orgânicos sintéticos, como pesticidas e fertilizantes, além da contribuição da vegetação local.

\subsubsection{Granulometria}

A análise granulométrica é outra ferramenta que se relaciona com a incorporação de metais em sedimentos devido à fixação destas espécies por adsorção sobre as superfícies minerais do sedimento, como areia, silte e argila.

Muitos estudos sobre análise granulométrica têm demonstrado significante relação entre a concentração de metais e o tamanho das partículas do sedimento. Estes trabalhos demonstram que normalmente partículas mais finas contêm as maiores concentrações de metais, sendo estes elementos incorporados, principalmente, às frações minerais silte e argila $(<0,063 \mathrm{~mm})$ (QUINÁGLIA, 2006).

Segundo Franklin (2010), a fração de granulometria mais fina possui maior capacidade de retenção de contaminantes devido às suas elevadas razões de área e superfície, o que acarretam em uma grande capacidade de interação da fração silto-argilosa com íons e moléculas diversas.

$\mathrm{Na}$ Tabela 17 são apresentadas as porcentagens das frações dos sedimentos coletados, com a distribuição granulométrica realizada baseando-se na escala de Wentworth. 
TABELA 17 - Resultado das frações granulométricas (em \%) obtidas em cada amostra de sedimento

\begin{tabular}{cccccccc}
\hline Ponto & $\begin{array}{c}\text { Seixos e } \\
\text { Grânulos } \\
(\%)\end{array}$ & $\begin{array}{c}\text { Areia Muito } \\
\text { Grossa } \\
(\%)\end{array}$ & $\begin{array}{c}\text { Areia } \\
\text { Grossa } \\
(\%)\end{array}$ & $\begin{array}{c}\text { Areia } \\
\text { Média } \\
(\%)\end{array}$ & $\begin{array}{c}\text { Areia } \\
\text { Fina } \\
(\%)\end{array}$ & $\begin{array}{c}\text { Areia } \\
\text { Muito Fina } \\
(\%)\end{array}$ & $\begin{array}{c}\text { Silte e } \\
\text { Argila } \\
(\%)\end{array}$ \\
\hline 01 & 32,67 & 15,51 & 11,19 & 11,17 & 17,81 & 8,91 & 2,74 \\
03 & 9,02 & 22,49 & 19,84 & 15,72 & 18,44 & 12,31 & 2,17 \\
06 & 5,14 & 6,22 & 6,05 & 10,08 & 38,41 & 25,40 & 8,71 \\
08 & 1,07 & 1,84 & 7,89 & 35,63 & 39,43 & 9,31 & 4,83 \\
20 & 37,29 & 14,99 & 19,37 & 18,71 & 6,99 & 1,65 & 0,99 \\
21 & 7,06 & 5,74 & 10,83 & 25,29 & 16,50 & 25,77 & 8,81 \\
30 & 29,98 & 10,61 & 9,88 & 17,93 & 20,64 & 8,39 & 2,57 \\
\hline $\mathrm{n}=2$ & & & & & & &
\end{tabular}

Analisando a tabela acima, é possível perceber que os sedimentos coletados são de predominância arenosa, visto que em todos os pontos os sedimentos apresentaram uma fração areia $>60 \%$. Com exceção dos pontos 06 (Córrego Água Fria) e 21 (Rio Taquaruçu Grande), os outros pontos possuem no máximo $5 \%$ de granulometria silte e argila.

A granulometria mais arenosa pode ser resultado de coletas em regiões mais superficiais do compartimento aquático. De acordo com Bevilacqua et al. (2009), os sedimentos de granulometria mais fina (silte e argila) se acumulam em áreas mais profundas de ambientes aquáticos.

A porcentagem da fração silte e argila, mesmo nos pontos onde sua porcentagem situou-se em torno de $9,0 \%$, pode ser considerada baixa, se comparada com outros estudos em que tal porcentagem ultrapassa $60 \%$. Nos estudos de Franklin et al. (2012), por exemplo, que foram realizados na região do reservatório Rio Grande, estado de São Paulo, a característica dos sedimentos é bem diferente, apresentando textura predominantemente argilosa. Conforme o autor, o alto teor de finos, e portanto, a presença de uma grande área superficial, 
leva à uma maior capacidade de adsorção tanto de matéria orgânica, quanto de metais.

Os moderados conteúdos de matéria orgânica encontrados nos sedimentos da região podem estar relacionados com a composição de predominância arenosa do compartimento analisado. Como as partículas de areia possuem menores razões de área e superfície, estas têm menor capacidade de adsorção tanto de matéria orgânica quanto de contaminantes.

\subsection{ESTUDO COMPARATIVO DOS MÉTODOS DE DIGESTÃO}

A comparação entre os métodos de digestão utilizados no presente estudo foi verificada para os elementos $\mathrm{As}, \mathrm{Cd}, \mathrm{Pb}$ e Se, utilizando-se a técnica Espectrometria de Absorção Atômica com Atomização Eletrotérmica em Forno de Grafite (GFAAS). Para iniciar tal estudo, foi necessário primeiramente verificar as temperaturas de pirólise e atomização para cada elemento nas diversas matrizes, a fim de obter-se uma maior sensibilidade durante as análises.

\subsubsection{Otimização das Temperaturas de Pirólise e Atomização}

As etapas de pirólise e atomização são de grande importância na técnica de absorção atômica com forno de grafite, pois eliminam a maior parte da matriz e atomizam o analito na forma de uma nuvem atômica para absorção da radiação característica. $\mathrm{Na}$ Tabela 18 são apresentadas as temperaturas obtidas nas diferentes matrizes. 
TABELA 18 - Temperaturas ótimas $\left(\mathrm{em}^{\circ} \mathrm{C}\right)$ obtidas para a pirólise e a atomização dos elementos em estudo, para cada matriz analisada

\begin{tabular}{cccccc}
\hline Solução & Etapa & As & Cd & Pb & Se \\
& Pirólise & 1200 & 400 & 1000 & 1200 \\
Padrão & Atomização & 2100 & 1300 & 1800 & 1800 \\
& Pirólise & 1200 & 600 & 900 & 1200 \\
SRM 8704 digerido & Atomização & 2300 & 1100 & 1400 & 2400 \\
$\left(\mathrm{HNO}_{3}\right.$ e microondas $)$ & Pirólise & 1500 & 300 & 300 & 1200 \\
SRM 8704 digerido & Atomização & 2200 & 1100 & 1500 & 1900 \\
(HCl e agitação) & & & & &
\end{tabular}

Com estes resultados verifica-se que há uma grande influência das diferentes matrizes sobre as temperaturas de pirólise e atomização para os elementos em estudo. Observa-se que para $\mathrm{As}, \mathrm{Cd}$ e $\mathrm{Pb}$ ocorrem variações nas duas etapas. Para o elemento As a temperatura de pirólise obtida varia de 1200 a $1500{ }^{\circ} \mathrm{C}$, enquanto que a temperatura de atomização está entre 2100 e $2300{ }^{\circ} \mathrm{C}$. O Cd apresenta uma temperatura de pirólise entre 300 e $600{ }^{\circ} \mathrm{C}$, e uma temperatura de atomização de 1100 ou $1300{ }^{\circ} \mathrm{C}$, enquanto que o $\mathrm{Pb}$ apresenta temperaturas de pirólise e atomização diferentes em todas as matrizes estudadas. Para o Se tal variação é observada apenas na temperatura de atomização, que varia entre 1800 e $2400^{\circ} \mathrm{C}$, enquanto que sua temperatura de pirólise é constante nas diferentes matrizes.

Diante de tantas variações, torna-se fundamental o uso destas condições otimizadas durante as análises posteriores.

\subsubsection{Validação da Metodologia}

Pelo fato do laboratório não dispor de uma metodologia validada para este estudo, foi necessário validá-la. Os parâmetros selecionados para avaliar o desempenho da metodologia empregada foram: curva analítica, linearidade, faixa de trabalho, limites de quantificação e detecção, recuperação e precisão. $\mathrm{Na}$ 
Tabela 19 são apresentados alguns dos resultados obtidos com a validação da metodologia.

TABELA 19 - Faixa de trabalho, linearidade e limites de quantificação e detecção obtidos para a determinação dos metais por GFAAS

\begin{tabular}{ccccc}
\hline Elemento & $\begin{array}{c}\text { Faixa de } \\
\text { trabalho } \\
\left(\mu \mathrm{L} \mathrm{L}^{-1}\right)\end{array}$ & Linearidade & $\begin{array}{c}\text { Limite de } \\
\text { Detecção } \\
\left(\mu \mathrm{L} \mathrm{L}^{-1}\right)\end{array}$ & $\begin{array}{c}\text { Limite de } \\
\text { Quantificação } \\
\left(\mu \mathrm{g} \mathrm{L}^{-1}\right)\end{array}$ \\
\hline $\mathrm{As}$ & $0-100$ & 0,9999 & 0,44 & 1,5 \\
$\mathrm{Cd}$ & $0-5$ & 0,9998 & 0,01 & 0,1 \\
$\mathrm{~Pb}$ & $0-100$ & 0,9997 & 0,30 & 1,5 \\
$\mathrm{Se}$ & $0-100$ & 0,9997 & 0,38 & 2,0 \\
\hline
\end{tabular}

Analisando-se a Tabela 19 é possível verificar que todas as curvas analíticas construídas tiveram um coeficiente de correlação linear superior a 0,999 . Tal valor é considerado suficiente, visto que a ANVISA (2003), recomenda um valor de $r$ igual a 0,99, enquanto que o INMETRO (2003) indica um valor superior a 0,90 .

O limite de quantificação obtido para cada elemento foi adotado como a menor concentração de analito que pôde ser quantificada, aceitando-se como nível de precisão, 10\%. Já o limite de deteç̧ão foi calculado com base no desvio padrão das 7 replicatas da menor concentração aceitável do analito (limite de quantificação).

No presente estudo foram realizados dois processos de digestão de sedimento objetivando a extração dos metais ambientalmente disponíveis. O primeiro método, considerado pela Agência de Proteção Ambiental dos Estados Unidos (USEPA) um meio de extrair os metais ambientalmente disponíveis por lixiviação natural ou processos biológicos, empregou $\mathrm{HNO}_{3}$ concentrado e aquecimento por meio de forno de microondas. O segundo método, que visa um mínimo ataque à matriz, utilizou $\mathrm{HCl} 0,1 \mathrm{M}$ e agitação em temperatura ambiente. 
Para avaliar a recuperação dos dois processos de solubilização de amostras de sedimento, foi utilizado o material certificado do NIST, SRM 8704, que fornece valores certificados e não certificados para vários elementos em sedimento de rio. É importante lembrar que estes valores certificados e não certificados são fornecidos para uma solubilização total das amostras de sedimento, podendo ser feita uma análise do nível de recuperação que cada método de digestão parcial estudado fornece. Nas Tabelas 20 e 21 são apresentados os resultados obtidos para os dois métodos de digestão utilizados no estudo.

TABELA 20 - Valores de recuperação e desvio padrão relativo obtidos na solubilização do material de referência certificado SRM 8704 utilizando o método USEPA $3051 \mathrm{~A}$

\begin{tabular}{ccccc}
\hline Elemento & $\begin{array}{c}\text { Valor Certificado* } \\
\left(\boldsymbol{\mu \mathbf { g ~ g ~ } ^ { - 1 } )}\right.\end{array}$ & $\begin{array}{c}\text { Valor Encontrado } \\
\left(\boldsymbol{\mu \mathbf { g ~ g } ^ { - 1 } )}\right.\end{array}$ & $\begin{array}{c}\text { DPR } \\
(\%)\end{array}$ & $\begin{array}{c}\text { Recuperação } \\
(\%)\end{array}$ \\
\hline As & 23,4 & $19,4 \pm 0,2$ & 1,2 & 82,9 \\
$\mathrm{Cd}$ & 3,45 & $3,1 \pm 0,2$ & 6,5 & 89,9 \\
$\mathrm{~Pb}$ & 161 & $134,1 \pm 6,5$ & 4,8 & 83,3 \\
$\mathrm{Se}$ & $1,1^{\star *}$ & $0,95 \pm 0,03$ & 3,2 & 86,4 \\
\hline
\end{tabular}

$\mathrm{n}=7$

* Valores certificados para a abertura total do material de referência SRM 8704 Buffalo River Sediment;

${ }^{* *}$ Valor não certificado 
TABELA 21 - Valores de recuperação e desvio padrão relativo obtidos na solubilização do material de referência certificado SRM 8704 utilizando $\mathrm{HCl}$ 0,1 $\mathrm{M}$ e agitação em temperatura ambiente

\begin{tabular}{ccccc}
\hline Elemento & $\begin{array}{c}\text { Valor Certificado* } \\
\left(\mu \mathbf{g ~ g}^{-1}\right)\end{array}$ & $\begin{array}{c}\text { Valor Encontrado } \\
\left(\mu \mathbf{g ~ g}^{-1}\right)\end{array}$ & $\begin{array}{c}\text { DPR } \\
(\%)\end{array}$ & $\begin{array}{c}\text { Recuperação } \\
(\%)\end{array}$ \\
\hline As & 23,4 & $7,2 \pm 0,1$ & 1,4 & 30,8 \\
$\mathrm{Cd}$ & 3,45 & $2,44 \pm 0,05$ & 2,0 & 70,7 \\
$\mathrm{~Pb}$ & 161 & $77,8 \pm 3,6$ & 4,6 & 48,3 \\
$\mathrm{Se}$ & $1,1^{* *}$ & - & - \\
\hline $\begin{array}{l}\text { * } \\
\text { Valores certificados para a abertura total do material de referência SRM 8704 Buffalo } \\
\text { River Sediment; } \\
* * \text { Valor não certificado }\end{array}$ &
\end{tabular}

Por meio dos resultados obtidos nas Tabelas 20 e 21, observa-se que o método de extração com $\mathrm{HCl} 0,1 \mathrm{M}$ realmente é bem mais brando que o método com $\mathrm{HNO}_{3} 8 \mathrm{M}$ e microondas. Como observado por Bettiol et al. (2008) a extração com $\mathrm{HCl}$ diluído em temperatura ambiente é uma técnica simples e adequada para avaliar a fração de metais de origem antropogênica, enquanto que o processo com $\mathrm{HNO}_{3}$ concentrado e aquecimento em forno de microondas, é uma alternativa para os métodos mais complexos de digestão total, não sendo suficiente para digerir apenas a matriz de silicato dos sedimentos. Apesar de ambos serem considerados procedimentos analíticos para extração de metais ambientalmente disponíveis, nota-se uma recuperação muito mais baixa no processo que utiliza $\mathrm{HCl} \mathrm{0,1} \mathrm{M}$, o que se deve, provavelmente, ao fato da solubilização ser realizada por um ácido diluído a frio, ocorrendo processo inverso no método com $\mathrm{HNO}_{3} 8 \mathrm{M}$, que utiliza ácido concentrado e aquecimento em forno de microondas.

Além da recuperação mais baixa, observa-se também que o procedimento com $\mathrm{HCl}$ 0,1 $\mathrm{M}$ não é eficiente para recuperar Se, tal fato pode estar relacionado com a forte interação entre o elemento e a matriz mineralógica dos sedimentos. Além disso, alguns sais se selênio, como o $\mathrm{SeS}_{2}$, não são 
decompostos em presença de ácido clorídrico, ao contrário do que ocorre em meio de água-régia ou ácido nítrico, sendo um fato relevante para a não recuperação do elemento no meio lixiviante considerado.

A recuperação obtida para o processo de solubilização baseado no método USEPA 3051A está dentro dos critérios de aceitabilidade de recuperação estabelecidos pela USEPA, visto que os valores para todos os elementos estão dentro da faixa de aceitabilidade $(75 \%<R<125 \%)$. Já para o processo utilizando $\mathrm{HCl} 0,1 \mathrm{M}$ a frio, pode-se considerá-lo eficaz, visto que determina os metais mais fracamente ligados, àqueles associados às fases mais instáveis e reativas no sedimento.

A precisão da metodologia analítica foi determinada pelo cálculo do desvio padrão relativo para uma série de medições sucessivas dos analitos durante o processo de validação. Todas as análises realizadas obtiveram um DPR\% menor que $10 \%$, valores que estão dentro dos limites de aceitabilidade estabelecidos pelo processo, podendo a metodologia, ser então, considerada precisa.

\subsubsection{Análise de Metais}

Nas Figuras 11, 12, 13 e 14 são apresentados os resultados obtidos para $\mathrm{As}, \mathrm{Cd}, \mathrm{Pb}$ e Se em amostras provenientes dos dois métodos de digestão de sedimento considerados no estudo. 


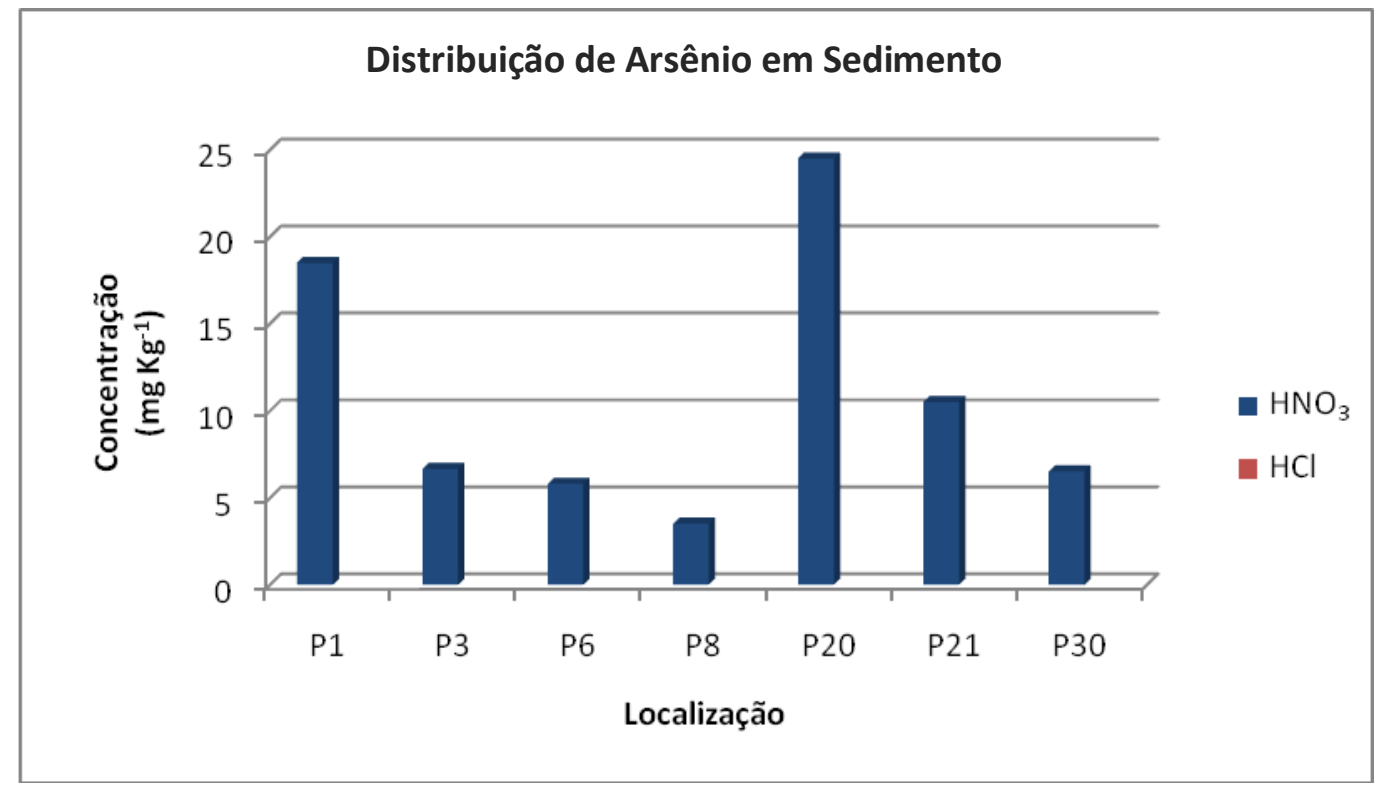

FIGURA 11 - Distribuição de As nas amostras de sedimento solubilizadas nos pontos de coleta da região hidrográfica do Tocantins-Araguaia

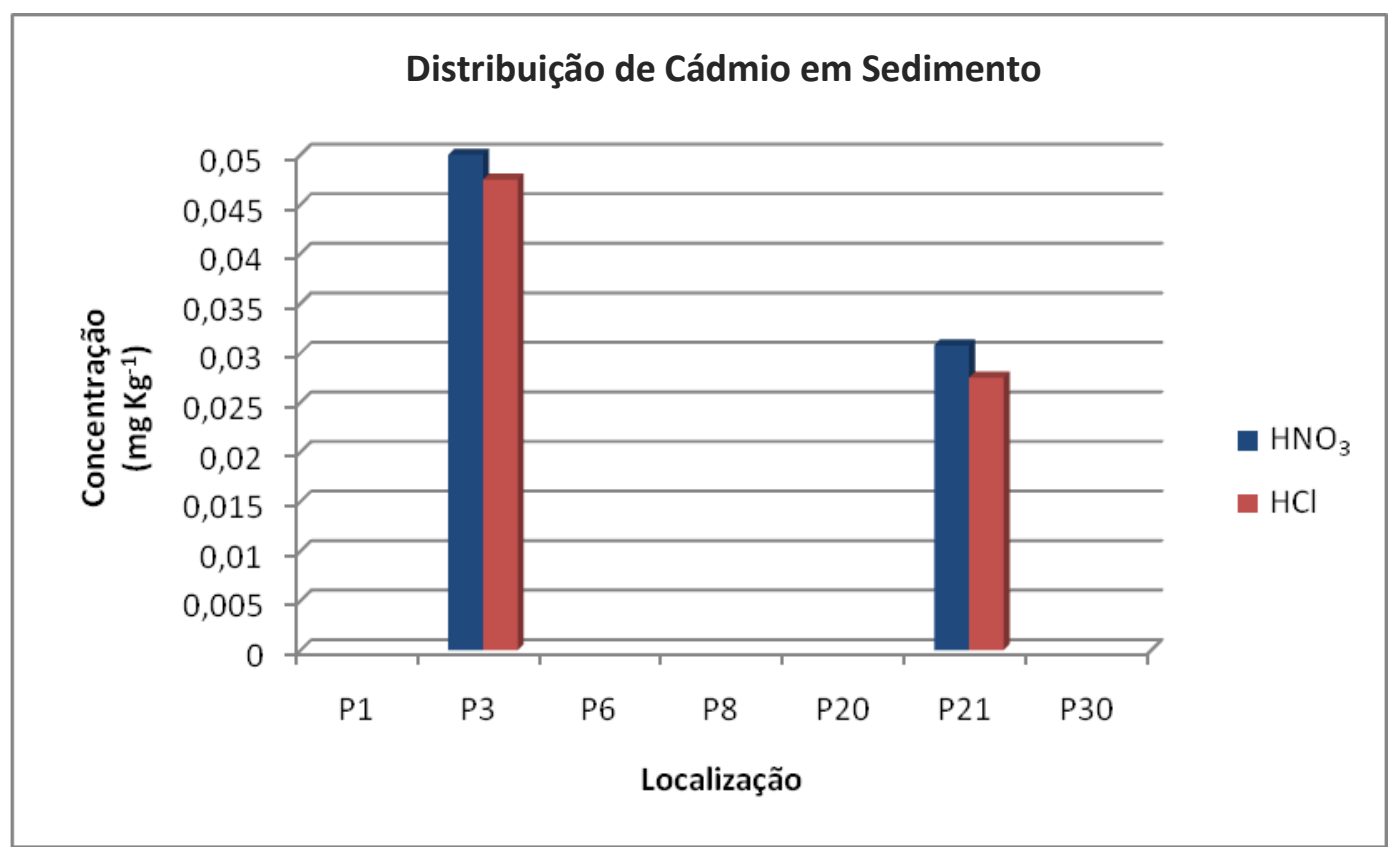

FIGURA 12 - Distribuição de Cd nas amostras de sedimento solubilizadas nos pontos de coleta da região hidrográfica do Tocantins-Araguaia 


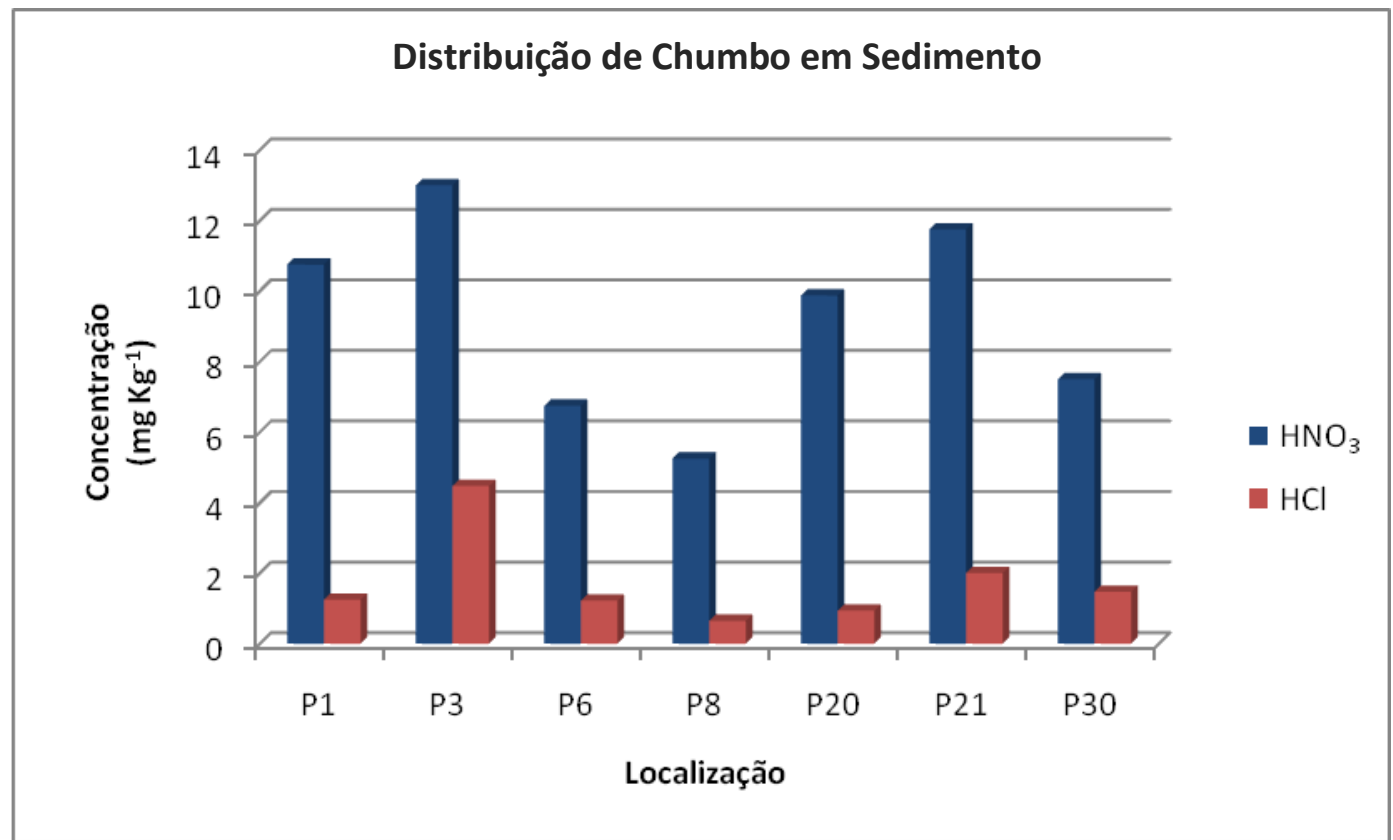

FIGURA 13 - Distribuição de $\mathrm{Pb}$ nas amostras de sedimento solubilizadas nos pontos de coleta da região hidrográfica do Tocantins-Araguaia

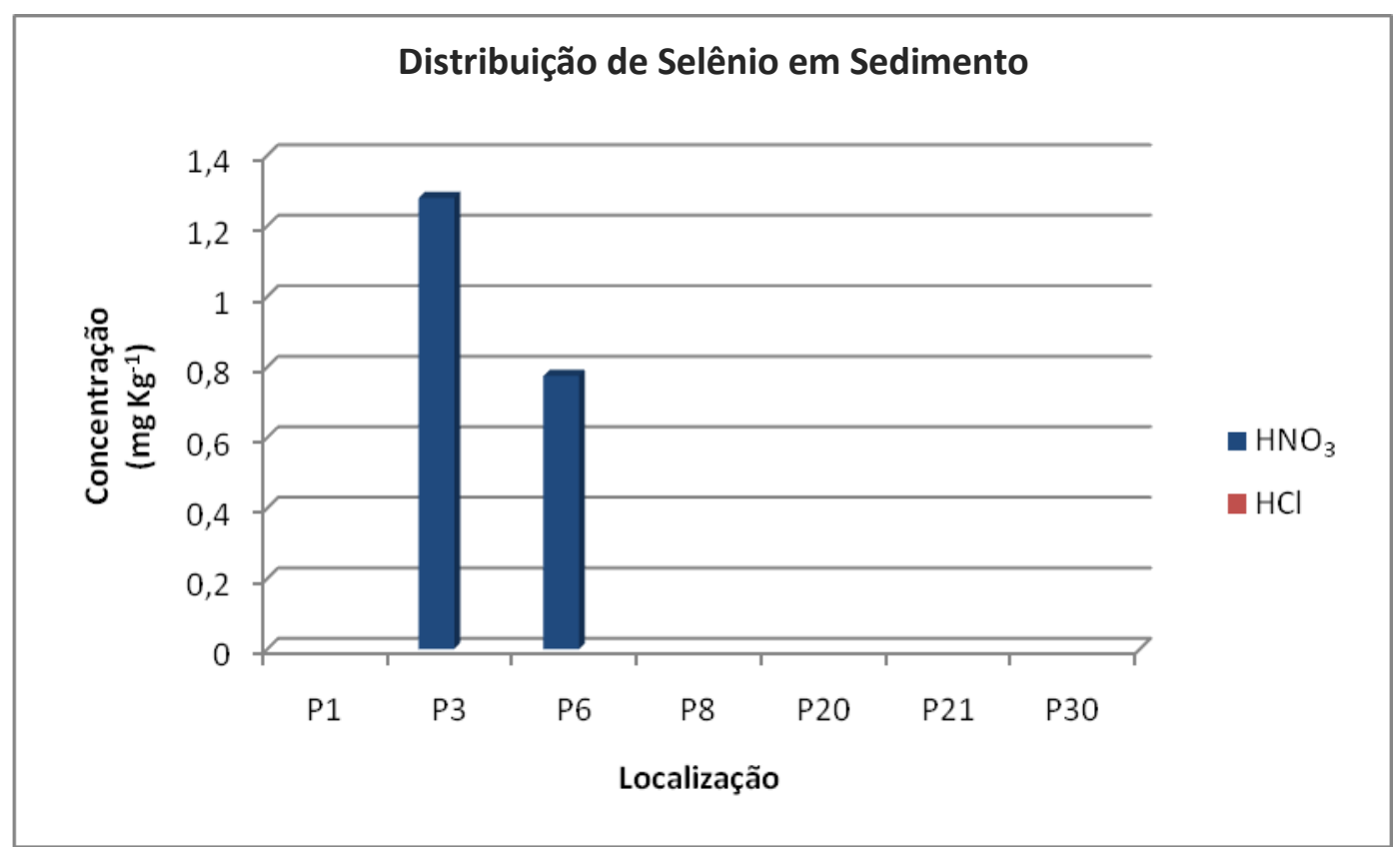

FIGURA 14 - Distribuição de Se nas amostras de sedimento solubilizadas nos pontos de coleta da região hidrográfica do Tocantins-Araguaia 
Analisando as Figuras 11, 12, 13 e 14 é possível observar que o processo de digestão que utiliza $\mathrm{HNO}_{3}$ concentrado é mais eficaz, visto que extrai maiores concentrações dos metais em estudo, enquanto que o método que utiliza $\mathrm{HCl}$ diluído é mais sensível, adequado para avaliar os metais ambientalmente disponíveis, podendo-se notar que, em alguns pontos, com este segundo método, os metais nem chegam a ser recuperados. As concentrações obtidas pelo procedimento de digestão com $\mathrm{HNO}_{3}$ concentrado e aquecimento em forno de microondas foram superiores aos resultados determinados pelo método de digestão com $\mathrm{HCl}$ diluído a frio. Esses resultados já eram esperados e corroboram tanto com a validação realizada para esta metodologia, como também com a literatura (BETTIOL et al., 2008).

Observa-se a distribuição do elemento As em todos os pontos coletados, porém apenas com o método de digestão com $\mathrm{HNO}_{3}$, enquanto que o $\mathrm{Pb}$ é o único elemento encontrado em todos os pontos e em todas as condições utilizadas. O Se é encontrado apenas nos pontos 3 (Córrego Côco) e 6 (Córrego Água Fria), e, como esperado, não foi recuperado com a extração utilizando $\mathrm{HCl}$ diluído.

Para o Cd, destaca-se os pontos 03 (Córrego Côco) e 21 (Rio Taquaruçu Grande) em que o elemento é encontrado nas duas condições avaliadas.

Observando os resultados obtidos de distribuição dos elementos em sedimento e os valores encontrados para recuperação dos elementos na validação da metodologia, pode-se concluir que a extração com $\mathrm{HNO}_{3}$ concentrado é um processo que obtém uma solubilização quase total do sedimento, podendo-se observar na Tabela 20 que tais valores ultrapassam $80 \%$ de recuperação. Porém tais condições podem ser consideradas muito drásticas para ocorrerem no ambiente naturalmente ou por conseqüência de atividades humanas, visto que a concentração do ácido é muito alta, $8 \mathrm{M}$, além de serem utilizadas altas temperaturas e pressões dentro do forno de microondas. Já as condições utilizadas no método de extração mais brando, estas já podem ocorrer com maior facilidade na natureza, visto que o processo é realizado com um ácido 
diluído em temperatura ambiente, podendo ser considerado um método mais adequado para solubilização dos metais ambientalmente disponíveis.

\subsection{ESTUDO DA AVALIAÇÃO DA QUALIDADE DO SEDIMENTO}

\subsubsection{Variação da Concentração dos Metais Ambientalmente Disponíveis}

Este estudo teve como objetivo fazer uma análise da qualidade dos sedimentos coletados, quanto à contribuição dos metais ambientalmente disponíveis. Para tal estudo foi utilizada a digestão parcial dos sedimentos com $\mathrm{HCl}$ 0,1 $\mathrm{M}$ e agitação em temperatura ambiente, que, apesar de não ser um método normatizado pela USEPA, pode ser considerado como um processo que se aproxima do que se pode encontrar na natureza, e portanto, aquele utilizado nos laboratórios do CQMA, onde as análises foram realizadas.

Foram escolhidos 29 elementos para este estudo, para assim realizar uma avaliação ampla da qualidade do compartimento analisado. Os elementos determinados foram: Ag, Al, As, B, Ba, Be, Ca, Cd, Co, Cr, Cu, Fe, Hg, K, Li, Mg, $\mathrm{Mn}, \mathrm{Mo}, \mathrm{Na}, \mathrm{Ni}, \mathrm{P}, \mathrm{Pb}, \mathrm{Sb}, \mathrm{Sc}, \mathrm{Se}, \mathrm{Si}, \mathrm{Ti}, \mathrm{V}$ e $\mathrm{Zn}$. Nas próximas figuras são apresentados apenas os elementos que tiveram concentrações acima de seus limites de quantificação nas técnicas apropriadas. 


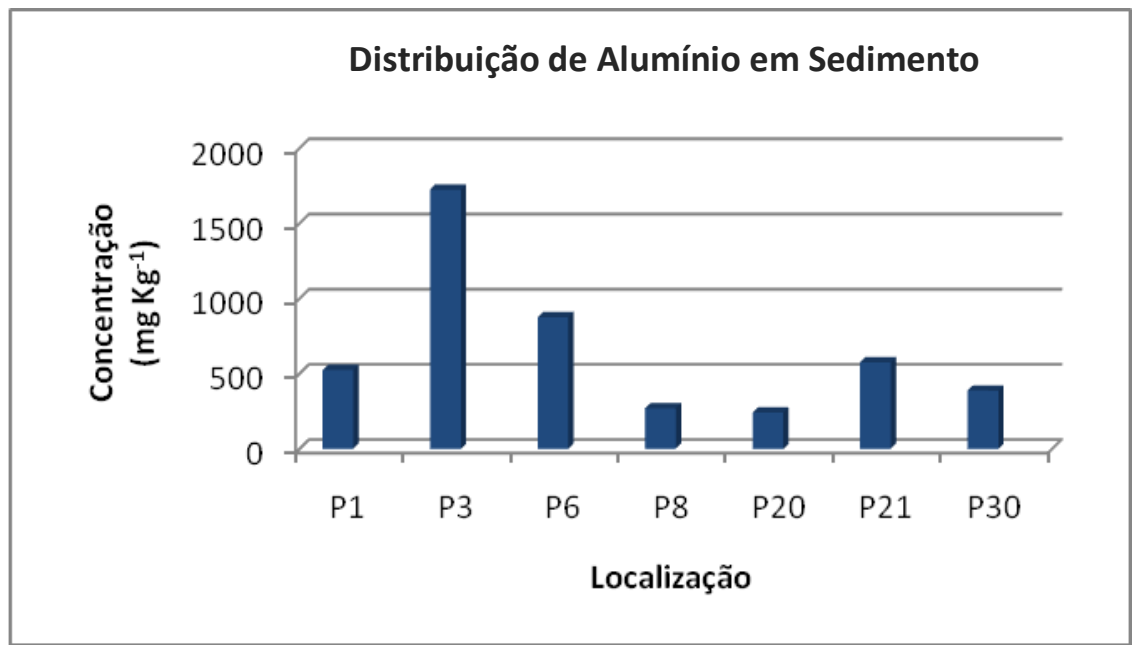

FIGURA 15 - Distribuição de Al nos sedimentos nos pontos de coleta

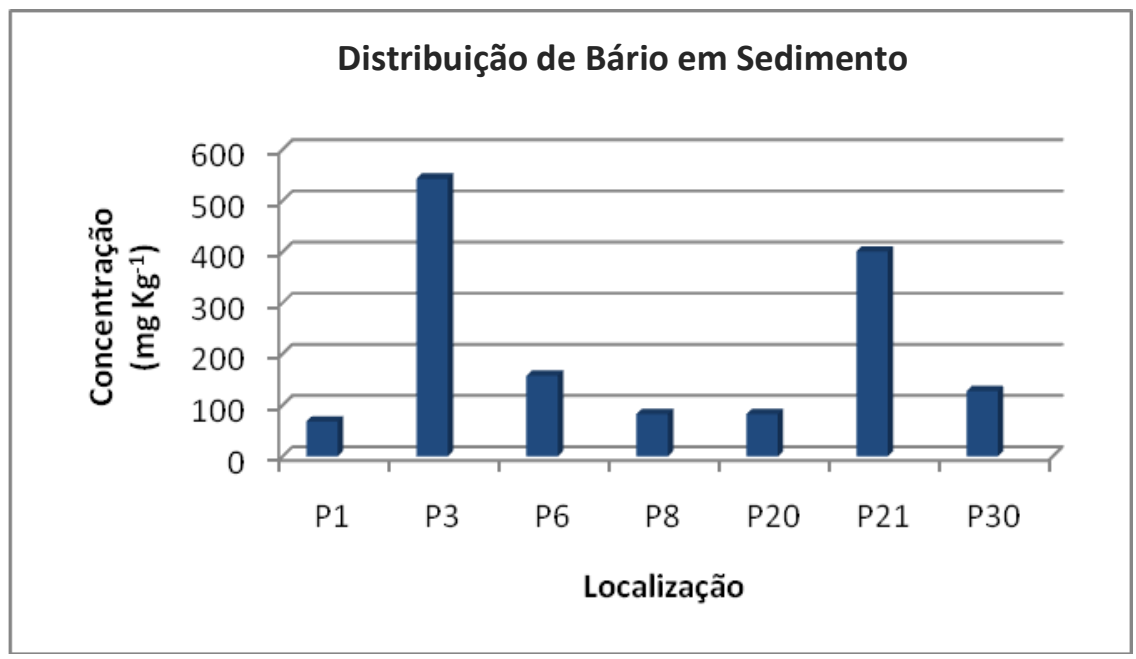

FIGURA 16 - Distribuição de Ba nos sedimentos nos pontos de coleta

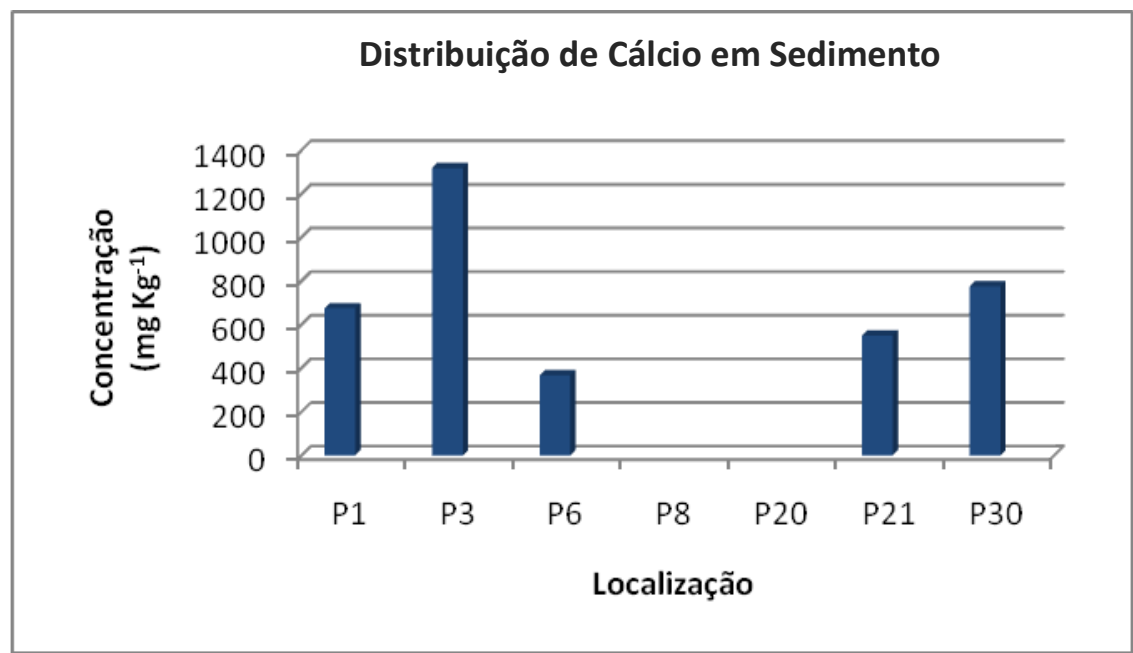

FIGURA 17 - Distribuição de Ca nos sedimentos nos pontos de coleta 


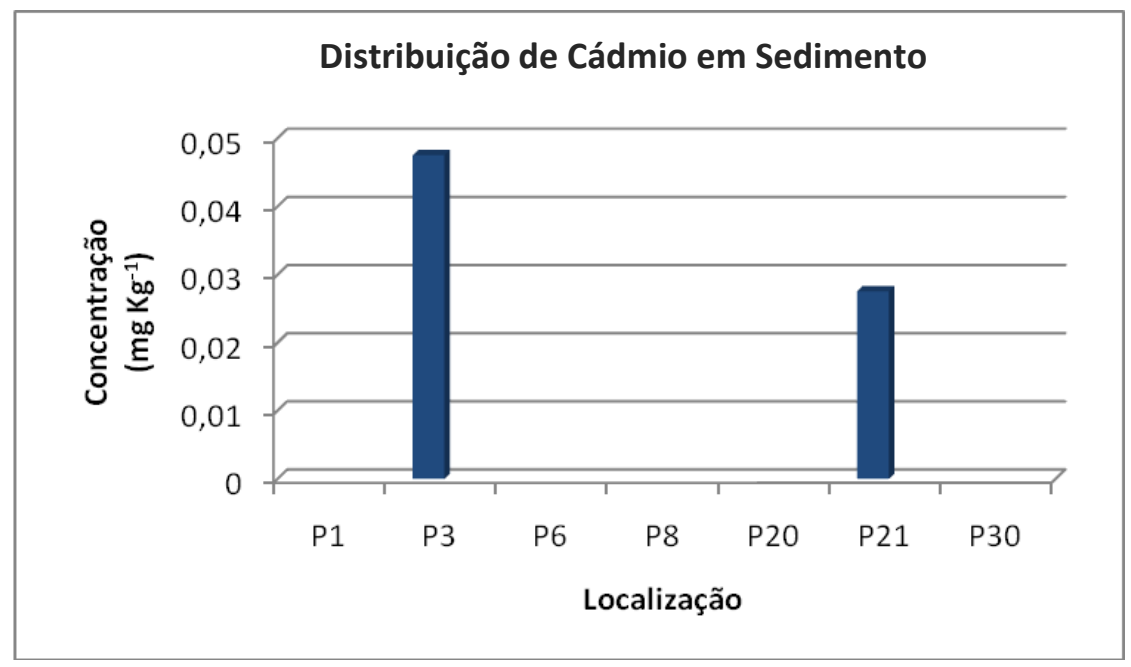

FIGURA 18 - Distribuição de Cd nos sedimentos nos pontos de coleta

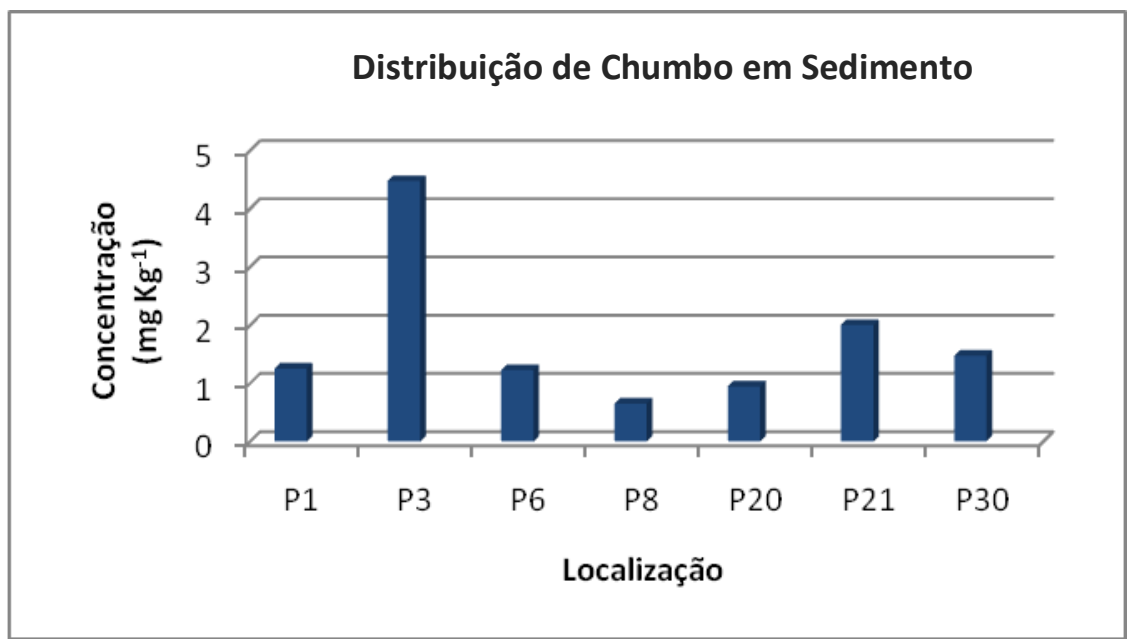

FIGURA 19 - Distribuição de Pb nos sedimentos nos pontos de coleta

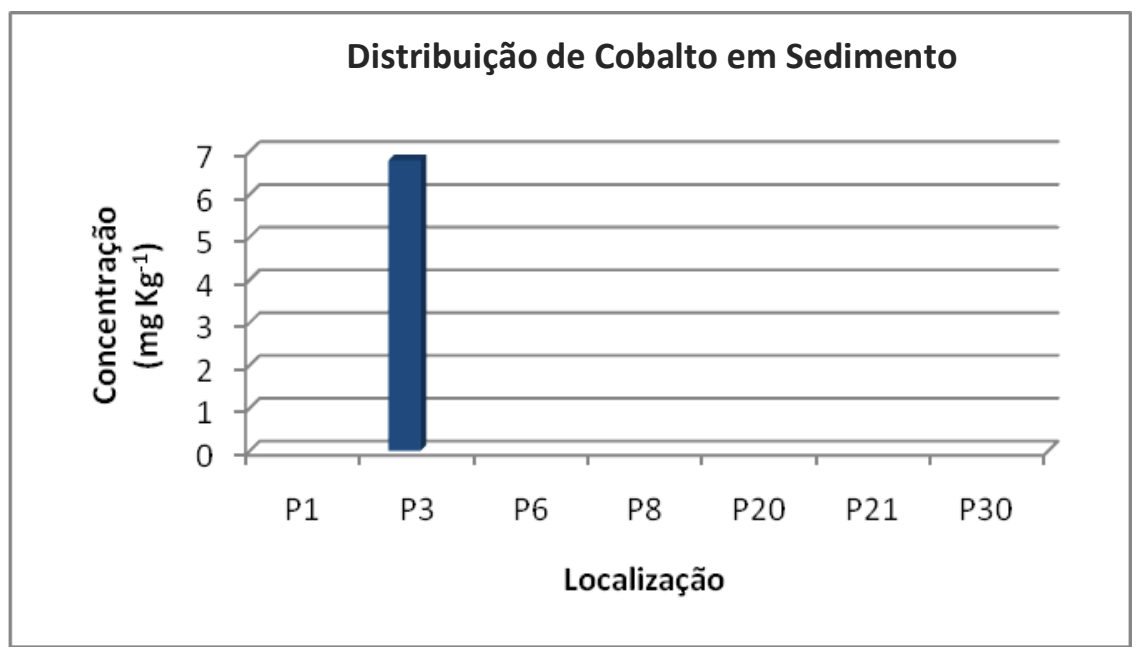

FIGURA 20 - Distribuição de Co nos sedimentos nos pontos de coleta 


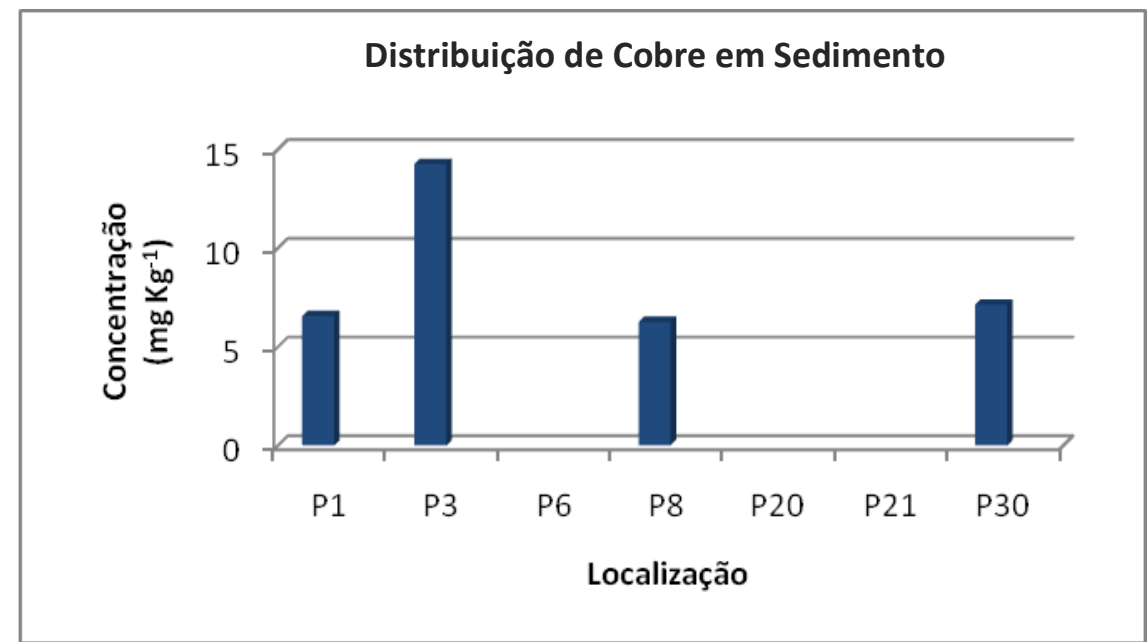

FIGURA 21 - Distribuição de Cu nos sedimentos nos pontos de coleta

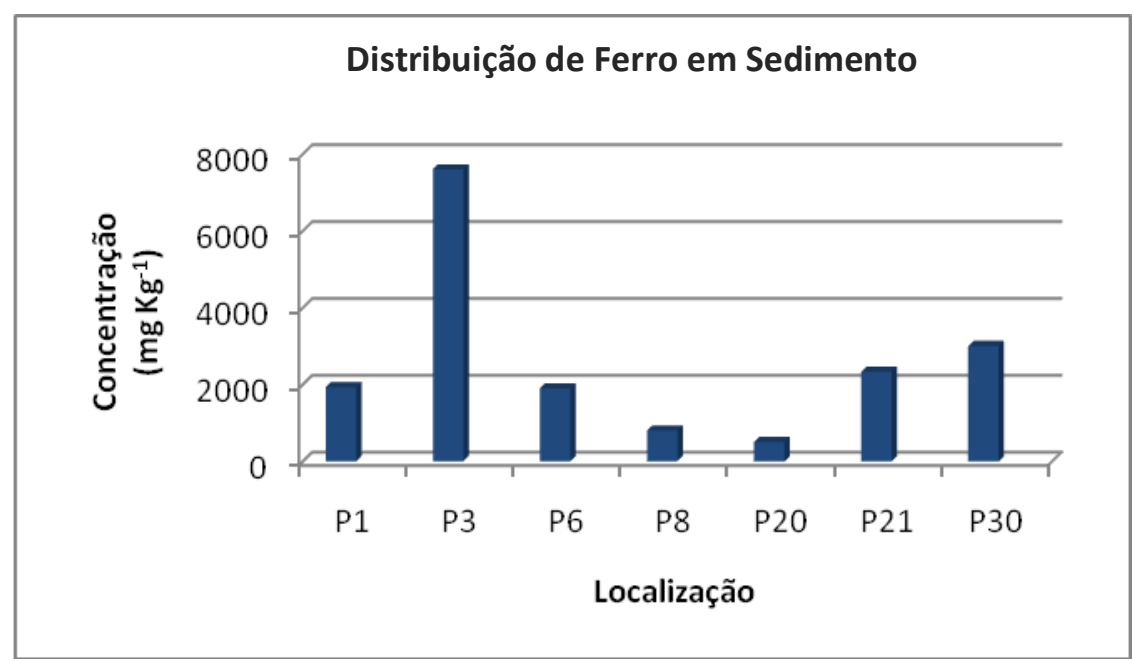

FIGURA 22 - Distribuição de Fe nos sedimentos nos pontos de coleta

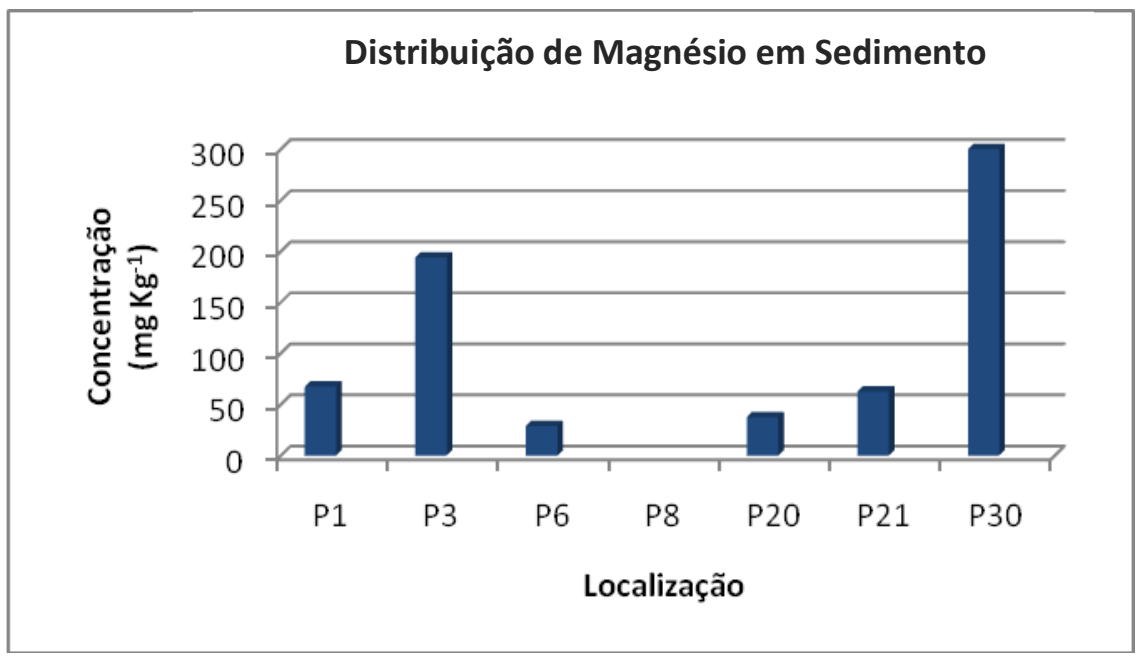

FIGURA 23 - Distribuição de Mg nos sedimentos nos pontos de coleta 


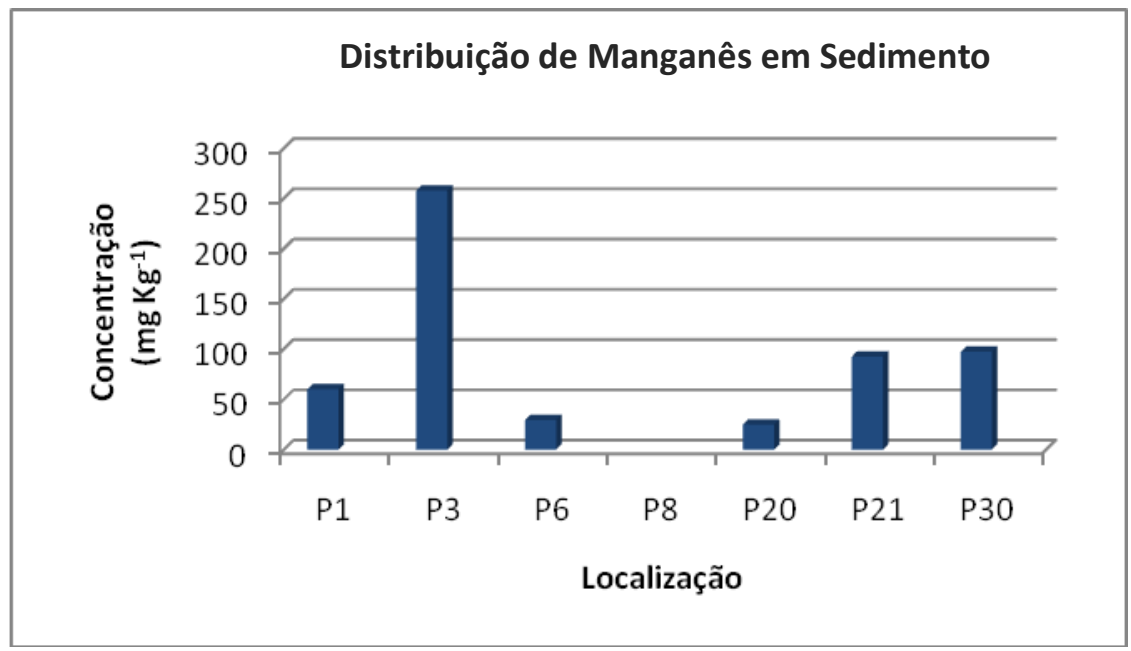

FIGURA 24 - Distribuição de Mn nos sedimentos nos pontos de coleta

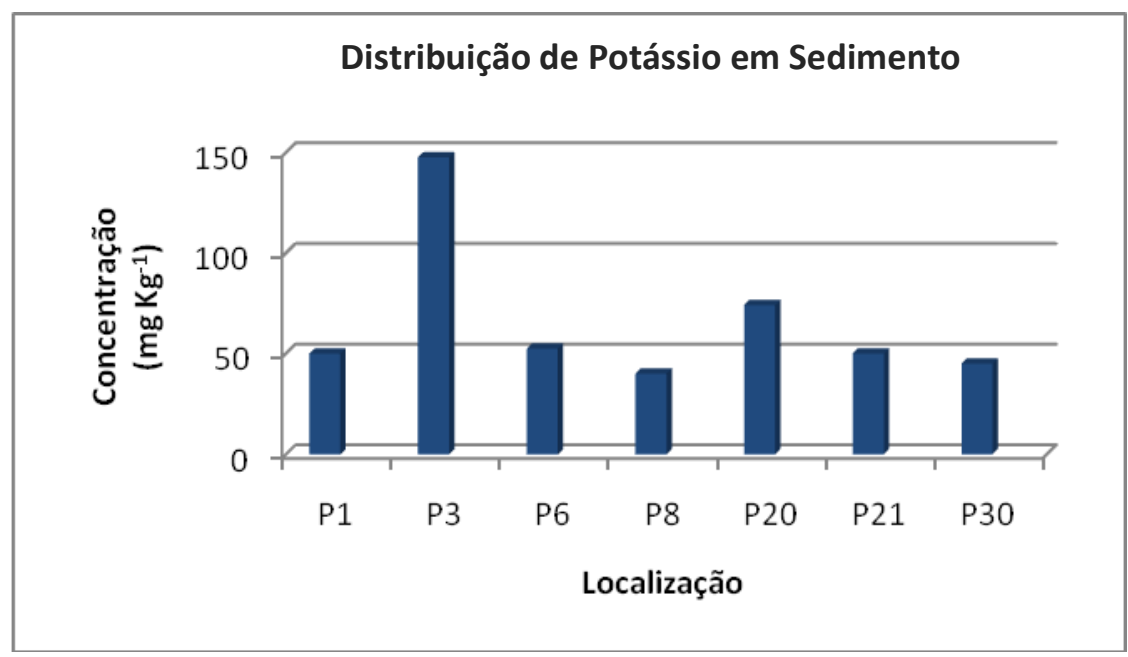

FIGURA 25 - Distribuição de K nos sedimentos nos pontos de coleta

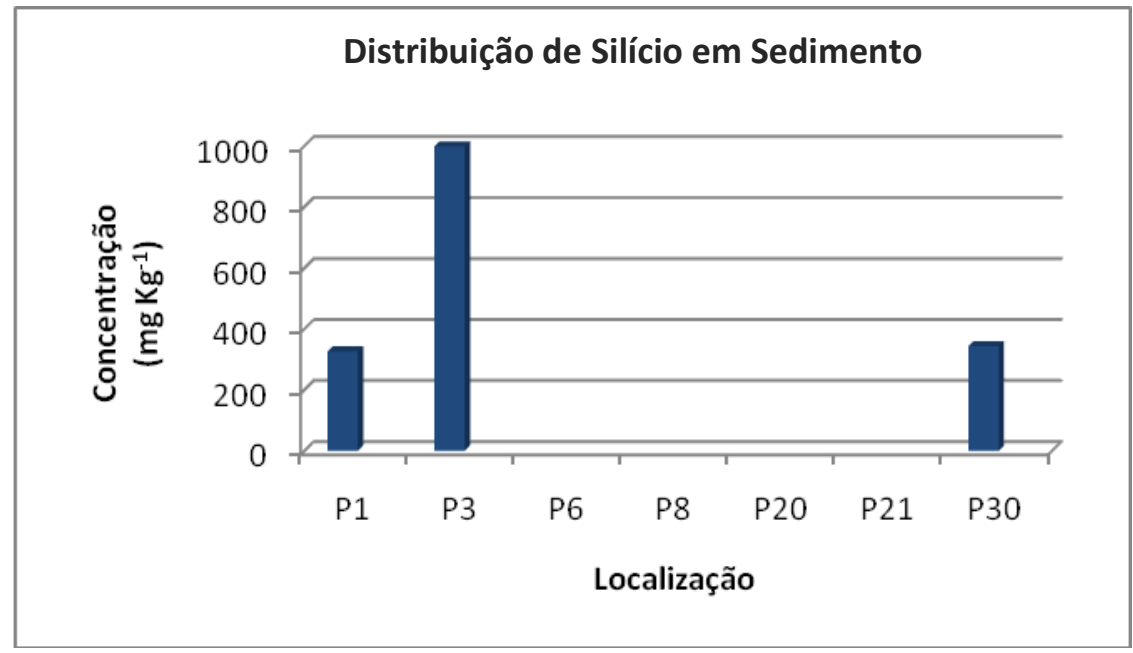

FIGURA 26 - Distribuição de Si nos sedimentos nos pontos de coleta 


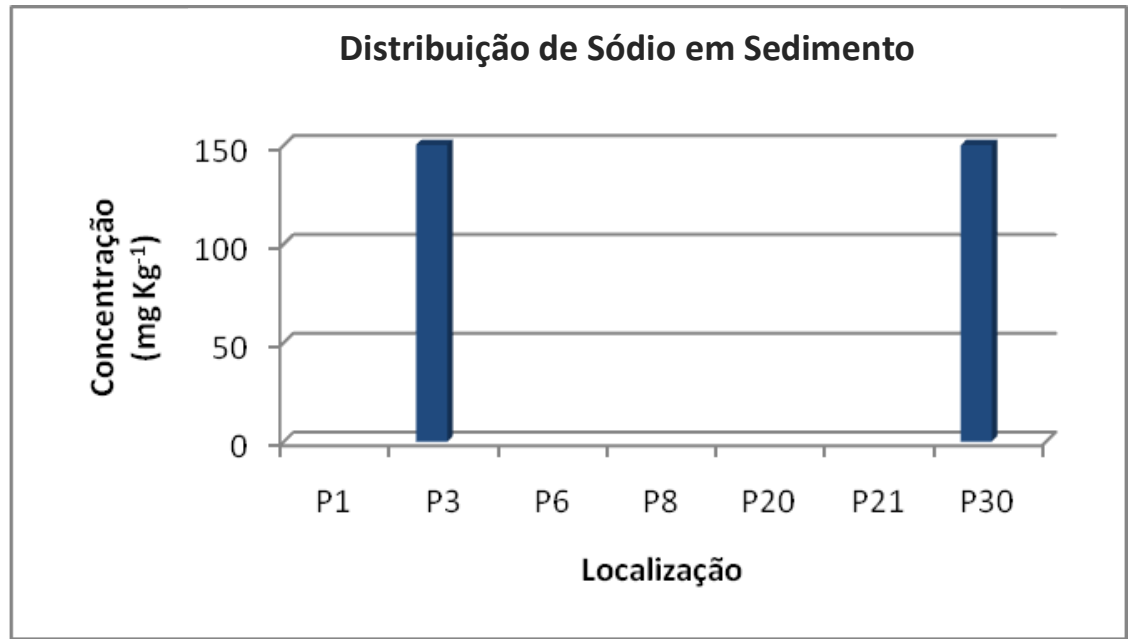

FIGURA 27 - Distribuição de Na nos sedimentos nos pontos de coleta

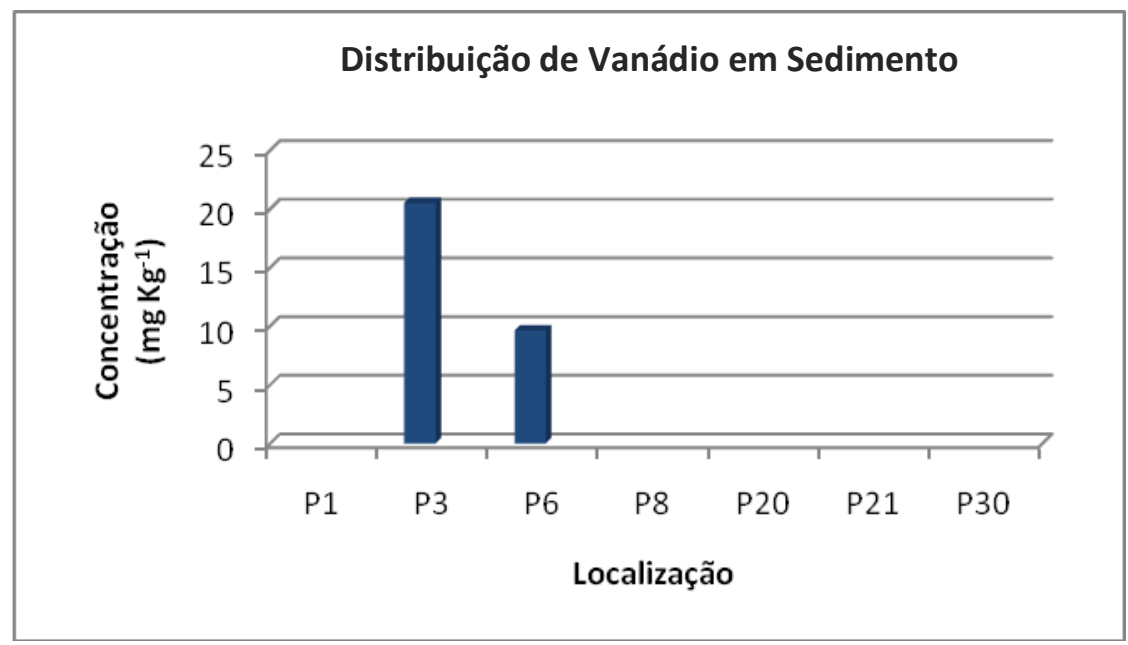

FIGURA 28 - Distribuição de V nos sedimentos nos pontos de coleta

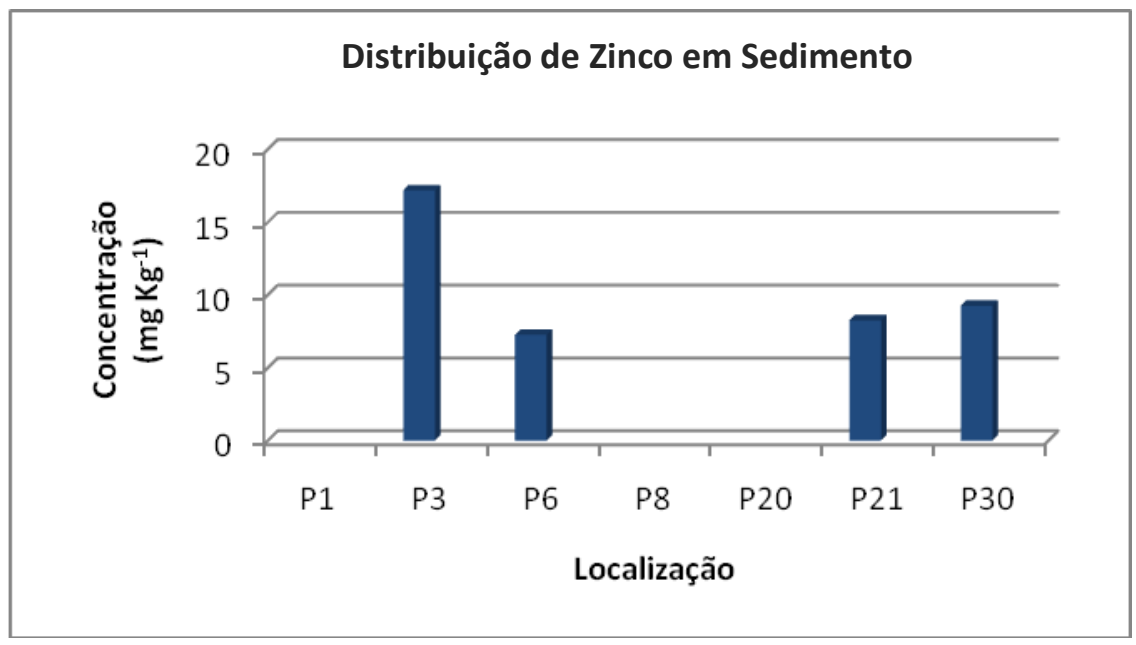

FIGURA 29 - Distribuição de Zn nos sedimentos nos pontos de coleta 
Analisando a distribuição dos elementos nos sedimentos pode-se perceber que o ponto de coleta 03 (Córrego Côco) apresentou as maiores concentrações de Al (1725 mg Kg$\left.{ }^{-1}\right), \mathrm{Ba}\left(542,5 \mathrm{mg} \mathrm{Kg}^{-1}\right)$, Ca $\left(1318 \mathrm{mg} \mathrm{Kg}^{-1}\right), \mathrm{Cd}$ $\left(0,048 \mathrm{mg} \mathrm{Kg}^{-1}\right), \mathrm{Pb}\left(4,5 \mathrm{mg} \mathrm{Kg}^{-1}\right)$, Co $\left(6,8 \mathrm{mg} \mathrm{Kg}^{-1}\right)$, Cu $\left(14,3 \mathrm{mg} \mathrm{Kg}^{-1}\right)$, Fe $(7600$ $\left.\mathrm{mg} \mathrm{Kg}{ }^{-1}\right), \mathrm{Mn}\left(257,5 \mathrm{mg} \mathrm{Kg}^{-1}\right), \mathrm{K}\left(148 \mathrm{mg} \mathrm{Kg}^{-1}\right)$, Si $\left(997,5 \mathrm{mg} \mathrm{Kg}^{-1}\right), \mathrm{V}\left(20,5 \mathrm{mg} \mathrm{Kg}^{-}\right.$ $\left.{ }^{1}\right), \mathrm{Zn}\left(17,2 \mathrm{mg} \mathrm{Kg}^{-1}\right)$. Um dos fatores que pode ter sido responsável pela elevada mobilização de metais neste ponto é o teor de matéria orgânica encontrado, visto que este ponto apresentou as maiores porcentagens de matéria orgânica, ultrapassando os $10 \%$. Tais elementos podem ser de origem antrópica, devido à entrada pelo carreamento de poluentes, oriundos principalmente das atividades de agricultura e pecuária realizadas em pequenas propriedades próximas ao local de coleta, como também pode ser em decorrência de sua origem natural, visto que o local encontra-se em uma região de formação geológica diferente dos demais pontos de coleta, localizado em um ambiente geológico de Embasamentos de Estilos Complexos, enquanto que os outros pontos localizamse em Bacias Sedimentares ou Depósitos Sedimentares Inconsolidados.

O Mg, pelo contrário, foi encontrado em maior concentração (300 mg $\mathrm{Kg}^{-1}$ ) no ponto 30 (Córrego Água Suja), enquanto que o $\mathrm{Na}$ foi encontrado na mesma quantidade (150 $\mathrm{mg} \mathrm{Kg}^{-1}$ ) nos pontos 03 e 30 .

Os elementos $\mathrm{Al}, \mathrm{Ba}, \mathrm{Fe}, \mathrm{K}$ e $\mathrm{Pb}$ foram encontrados em todos os pontos coletados, enquanto que o Co foi determinado apenas no ponto 03 .

A avaliação da qualidade dos sedimentos deste estudo foi realizada comparando os dados obtidos de concentração dos elementos com aqueles utilizados como valores orientadores de qualidade de sedimento estabelecidos pelo Canadian Council of Ministers of the Environment (CCME).

No Apêndice D são apresentados os valores de concentração (em mg $\mathrm{Kg}^{-1}$ ) determinados para todos os elementos analisados neste estudo, bem como os valores orientadores TEL e PEL. Os elementos que possuem tal referência são As, $\mathrm{Cd}, \mathrm{Cr}, \mathrm{Cu}, \mathrm{Hg}, \mathrm{Ni}$ (baseado na Resolução CONAMA n 344/2004), Pb e Zn. Os elementos $\mathrm{As}, \mathrm{Cr}, \mathrm{Hg}$ e $\mathrm{Ni}$ não foram quantificados em nenhum local amostrado, visto que todos eles resultaram em concentrações abaixo do limite de 
quantificação dos métodos utilizados. Já os elementos $\mathrm{Cd}, \mathrm{Cu}, \mathrm{Pb}$ e $\mathrm{Zn}$, apesar de terem sido quantificados, apresentaram concentrações abaixo dos valores de TEL: a maior concentração de Cd foi $0,048 \mathrm{mg} \mathrm{Kg}^{-1}$, enquanto que o TEL é 0,6 $\mathrm{mg} \mathrm{Kg}{ }^{-1}$; o Cu teve como maior concentração detectada, $14,3 \mathrm{mg} \mathrm{Kg}^{-1}$ e o valor de seu TEL é $35,7 \mathrm{mg} \mathrm{Kg}^{-1}$; o $\mathrm{Pb}$ possui um TEL de $35,0 \mathrm{mg} \mathrm{Kg}^{-1}$ e a maior concentração observada foi $4,5 \mathrm{mg} \mathrm{Kg}^{-1}$; e o $\mathrm{Zn}$, foi encontrado numa concentração de 17,2 $\mathrm{mg} \mathrm{Kg}^{-1}$, enquanto que seu valor orientador TEL é $123 \mathrm{mg}$ $\mathrm{Kg}^{-1}$. Com os valores obtidos abaixo dos valores orientadores estabelecidos pelo CCME, pode-se considerar que tais sedimentos não causam efeitos adversos para a biota.

Outra comparação que pode ser feita é utilizando os valores de concentração obtidos para $\mathrm{As}, \mathrm{Cd}, \mathrm{Pb}, \mathrm{Cu}, \mathrm{Cr}, \mathrm{Hg}, \mathrm{Ni}$ e $\mathrm{Zn}$ com os valores de concentração adotados pela CETESB para a classificação de contaminantes em sedimentos de água doce (Tabela 5). Por meio desta análise pode-se observar que, pelo fato de todas as concentrações obtidas terem sido inferiores ao valor orientador TEL, os sedimentos coletados nas águas do sistema hidrográfico Tocantins-Araguaia podem ser classificados como de qualidade ótima para todos os contaminantes considerados.

A presença de baixa quantidade de matéria orgânica (menos que 10\% na maioria dos sedimentos coletados) e as concentrações mais baixas de metais tóxicos (todos os valores obtidos foram abaixo do limite TEL) corroboram com as menores proporções de sedimentos de granulação fina (menos de $5 \%$ de silte e argila na maioria dos sedimentos coletados).

Para auxiliar na avaliação da qualidade dos sedimentos, bem como as possíveis fontes dos níveis de concentração encontrados, foi realizado o tratamento estatístico dos dados. 


\subsubsection{Análise Estatística}

Na Tabela 22 é apresentado um resumo da análise fatorial realizada, na qual são apresentados os autovalores obtidos para cada componente, bem como sua variabilidade explicada e a variabilidade acumulada.

TABELA 22 - Resumo da análise fatorial com extração dos componentes principais

\begin{tabular}{cccc}
\hline Fator & Autovalor & $\begin{array}{c}\text { Variabilidade } \\
\text { explicada (\%) }\end{array}$ & $\begin{array}{c}\text { Variabilidade } \\
\text { acumulada (\%) }\end{array}$ \\
\hline 1 & 12,59 & 74,06 & 74,06 \\
2 & 1,95 & 11,49 & 85,55 \\
3 & 1,12 & 6,60 & 92,15 \\
\hline
\end{tabular}

Com o tratamento estatístico realizado inicialmente e considerando apenas os autovalores acima de 1, foram gerados 3 fatores significativos, ou seja, 3 conjuntos de variáveis com dimensões de variabilidade comuns existentes, que conseguem explicar $92,15 \%$ da variabilidade total dos elementos. Observa-se que o fator 1 é o responsável por explicar a maior fração de variabilidade dos dados, $74,06 \%$, enquanto que o fator 2 explica apenas $11,49 \%$ e o fator $3,6,60 \%$. Podese notar ainda uma relação entre a variabilidade explicada e o autovalor, visto que a variabilidade dos dados é cada vez menos explicada à medida que o autovalor de cada fator diminui.

Na Tabela 23 são apresentados os agrupamentos gerados com a base de dados obtida e as correlações existentes entre as variáveis. Foram considerados como representativos os coeficientes de correlação que apresentam valores maiores a 0,75 . 
TABELA 23 - Resultado da análise fatorial com extração dos componentes principais e rotação Varimax (valores $>0,75$ selecionados)

\begin{tabular}{|c|c|c|c|}
\hline Variáveis & Fator 1 & Fator 2 & Fator 3 \\
\hline$\overline{\mathrm{Al}}$ & 0,94 & 0,24 & $-0,14$ \\
\hline $\mathrm{Ba}$ & 0,86 & 0,22 & $-0,23$ \\
\hline $\mathrm{Ca}$ & 0,65 & 0,68 & $-0,02$ \\
\hline $\mathrm{Cd}$ & 0,89 & 0,20 & $-0,07$ \\
\hline Co & 0,92 & 0,29 & 0,19 \\
\hline $\mathrm{Cu}$ & 0,53 & 0,58 & 0,33 \\
\hline $\mathrm{Fe}$ & 0,83 & 0,55 & 0,01 \\
\hline K & 0,91 & 0,17 & 0,32 \\
\hline $\mathrm{Mg}$ & 0,10 & 0,98 & 0,11 \\
\hline $\mathrm{Mn}$ & 0,81 & 0,55 & 0,10 \\
\hline $\mathrm{Na}$ & 0,36 & 0,89 & 0,14 \\
\hline $\mathrm{Pb}$ & 0,91 & 0,39 & 0,03 \\
\hline $\mathrm{Si}$ & 0,73 & 0,58 & 0,30 \\
\hline V & 0,90 & 0,17 & $-0,11$ \\
\hline $\mathrm{Zn}$ & 0,71 & 0,59 & $-0,31$ \\
\hline $\begin{array}{l}\text { Fração de ensaio } \\
\qquad(<0,250 \mathrm{~mm})\end{array}$ & 0,03 & $-0,18$ & $-0,93$ \\
\hline Matéria Orgânica & 0,93 & 0,30 & 0,05 \\
\hline
\end{tabular}


A partir dos dados apresentados nas Tabelas 22 e 23, as seguintes associações podem ser feitas:

- Fator 1 (corresponde a $74,06 \%$ da variância total) é formado pelos elementos $\mathrm{Al}, \mathrm{Ba}, \mathrm{Cd}, \mathrm{Co}, \mathrm{Fe}, \mathrm{K}, \mathrm{Mn}, \mathrm{Pb}, \mathrm{V}$ e pela matéria orgânica. Os metais compreendidos possuem uma correlação positiva com a matéria orgânica, indicando que a distribuição destes elementos nos sedimentos coletados é controlada, principalmente, pelo teor de matéria orgânica. Segundo Fernandes et al. (2011), matéria orgânica juntamente com óxidos de ferro e manganês são considerados importantes sorventes de metais devido à sua grande área superficial.

- Fator 2 (corresponde a $11,49 \%$ da variância total) é formado pelos elementos $\mathrm{Mg}$ e $\mathrm{Na}$. Estes elementos apresentam uma alta correlação, acima de 0,89 , pelo fato de serem comumente encontrados em fontes naturais.

- Fator 3 (corresponde a $6,60 \%$ da variância total) é formado apenas pela variável fração de ensaio, que provavelmente não teve correlação com os níveis de concentração determinados para os elementos estudados, não influenciando, portanto, na retenção dos metais no sedimento.

Como os fatores 1 e 2 conseguem explicar $85,55 \%$ da variabilidade total dos dados, foi gerada a Figura 30 para auxiliar a interpretação. 


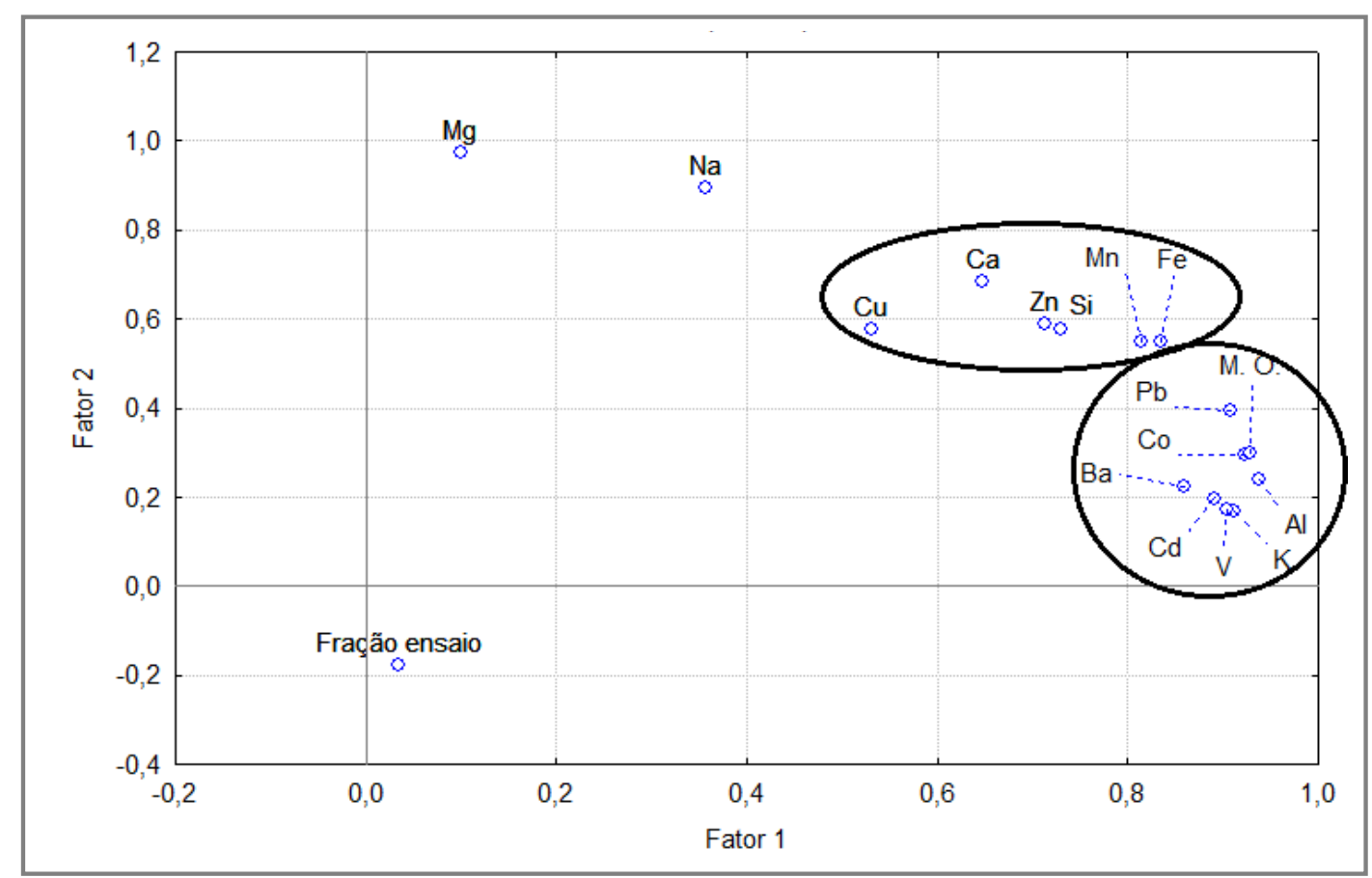

FIGURA 30 - Análise de fatores: Fator 1 x Fator 2

Por meio do gráfico acima é possível notar a formação de dois grupos de correlação de variáveis, apesar de ambos situarem-se no mesmo quadrante:

- O primeiro grupo é formado pelos elementos $\mathrm{Cu}, \mathrm{Ca}, \mathrm{Si}, \mathrm{Zn}, \mathrm{Fe}$ e $\mathrm{Mn}$. Os elementos $\mathrm{Ca}, \mathrm{Si}$ e $\mathrm{Fe}$ estão relacionados pelo fato de serem elementos abundantemente encontrados na crosta terrestre, enquanto que o $\mathrm{Mn}$ é um metal presente em quase todos os tipos de solos. $\mathrm{O}$ elemento $\mathrm{Zn}$, apesar de não ser um elemento de constituição, segundo Quináglia (2006), é um elemento que ocorre em sedimentos geralmente com a adsorção sobre o ferro e óxidos de manganês, argila mineral e materiais orgânicos.

- O segundo grupo é formado pelos elementos $\mathrm{Co}, \mathrm{Pb}, \mathrm{V}, \mathrm{Al}, \mathrm{Ba}, \mathrm{K}, \mathrm{Cd}$ e pela matéria orgânica. Com exceção do $\mathrm{Al}$, que é um elemento bastante encontrado nos solos da região (Latossolo VermelhoAmarelado e Plintossolo Pétrico) e do K, que é um elemento abundante na crosta terrestre, os outros elementos podem estar correlacionados por serem de origem antrópica. Os elementos $\mathrm{Co}, \mathrm{Pb}$ e $\mathrm{V}$ são adsorvidos por ácidos húmicos e fúlvicos num teor de 1 a 10\% (peso 
seco), sendo a matéria orgânica grande responsável pelo enriquecimento destes metais nos sedimentos (LEMES, 2001). A presença de $\mathrm{Pb}$ em águas naturais é atribuída, principalmente, às atividades humanas por ser amplamente utilizado na forma de arseniato de chumbo em pesticidas (ALENCAR, 2011), enquanto que 0 Ba é bastante conhecido como um resíduo de mineração, sendo a mineração e o uso inadequado de fertilizantes e pesticidas, algumas das atividades que contribuem para a contaminação dos corpos d'água da região (ANA, 2009). Além destes, a presença de $\mathrm{Cd}$ em sistemas aquáticos deve-se, dentre outros fatores, ao uso de fertilizantes na agricultura (QUINÁGLIA, 2006).

Além da análise fatorial, outra ferramenta estatística utilizada foi a análise de conglomerados (clusters analysis). Nas Figuras 31 e 32 são apresentados os dendogramas obtidos.

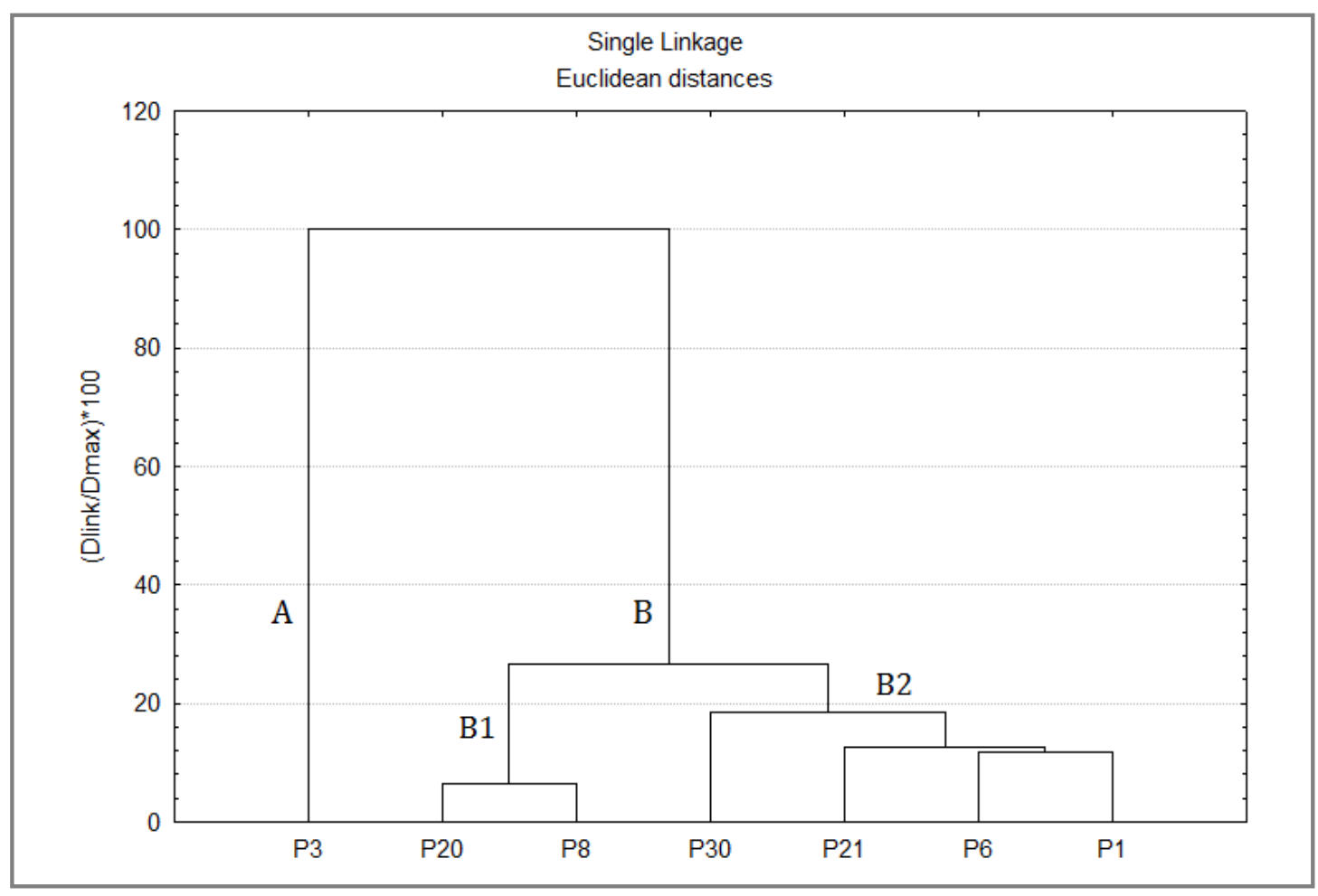

FIGURA 31 - Dendograma resultante da análise de agrupamento utilizando os pontos de amostragem como variáveis 
Observa-se na Figura 31 a formação de dois grupos principais A e B, com o grupo $A$ formado apenas pelo ponto 03 e o grupo $B$ formado pelos pontos 01, 06, 08, 20, 21 e 30. A dissimilaridade do ponto 03 (Córrego Côco) em relação aos outros pontos de amostragem está no teor de matéria orgânica encontrado, sendo o único que apresentou mais que 10\% de matéria orgânica em peso seco, e também por apresentar as maiores concentrações dos elementos $\mathrm{Al}, \mathrm{Ba}, \mathrm{Cd}$, $\mathrm{Ca}, \mathrm{Co}, \mathrm{Cu}, \mathrm{Fe}, \mathrm{Mn}, \mathrm{K}, \mathrm{Pb}, \mathrm{Si}, \mathrm{V}$ e $\mathrm{Zn}$. Tais elementos podem ser de origem antrópica, por carreamento de poluentes, como também pode ser de origem natural, associada com a formação do ambiente geológico.

O grupo B é constituído de 2 sub-grupos:

- B1: formado pelos pontos 08 e 20, o que se deve provavelmente pelo fato destes locais serem constituídos pelos sedimentos que apresentaram os teores mais baixos de matéria orgânica. Além disso, nestes pontos não foi verificada distribuição dos elementos $\mathrm{Ca}, \mathrm{Cd}, \mathrm{Co}$, $\mathrm{Na}, \mathrm{Si}, \mathrm{V}$ e $\mathrm{Zn}$, e para os elementos $\mathrm{Al}$, Fe e $\mathrm{Pb}$, estes são os pontos que apresentam as menores concentrações obtidas.

- B2: formado pelos pontos 01, 06, 21 e 30, que apresentam como similaridade as concentrações dos elementos $\mathrm{Al}, \mathrm{Ca}, \mathrm{Pb}, \mathrm{Fe}$ e $\mathrm{Mn}$ acima dos pontos 08 e 20, e abaixo do ponto 03. Neste sub-grupo observa-se uma semelhança dos pontos 21 e 30 quanto ao teor de matéria orgânica. Em todos estes pontos de amostragem não foi verificada distribuição do elemento $\mathrm{Co}$, enquanto que nos pontos 01,06 e 30 não foi encontrado o elemento $\mathrm{Cd}$. 


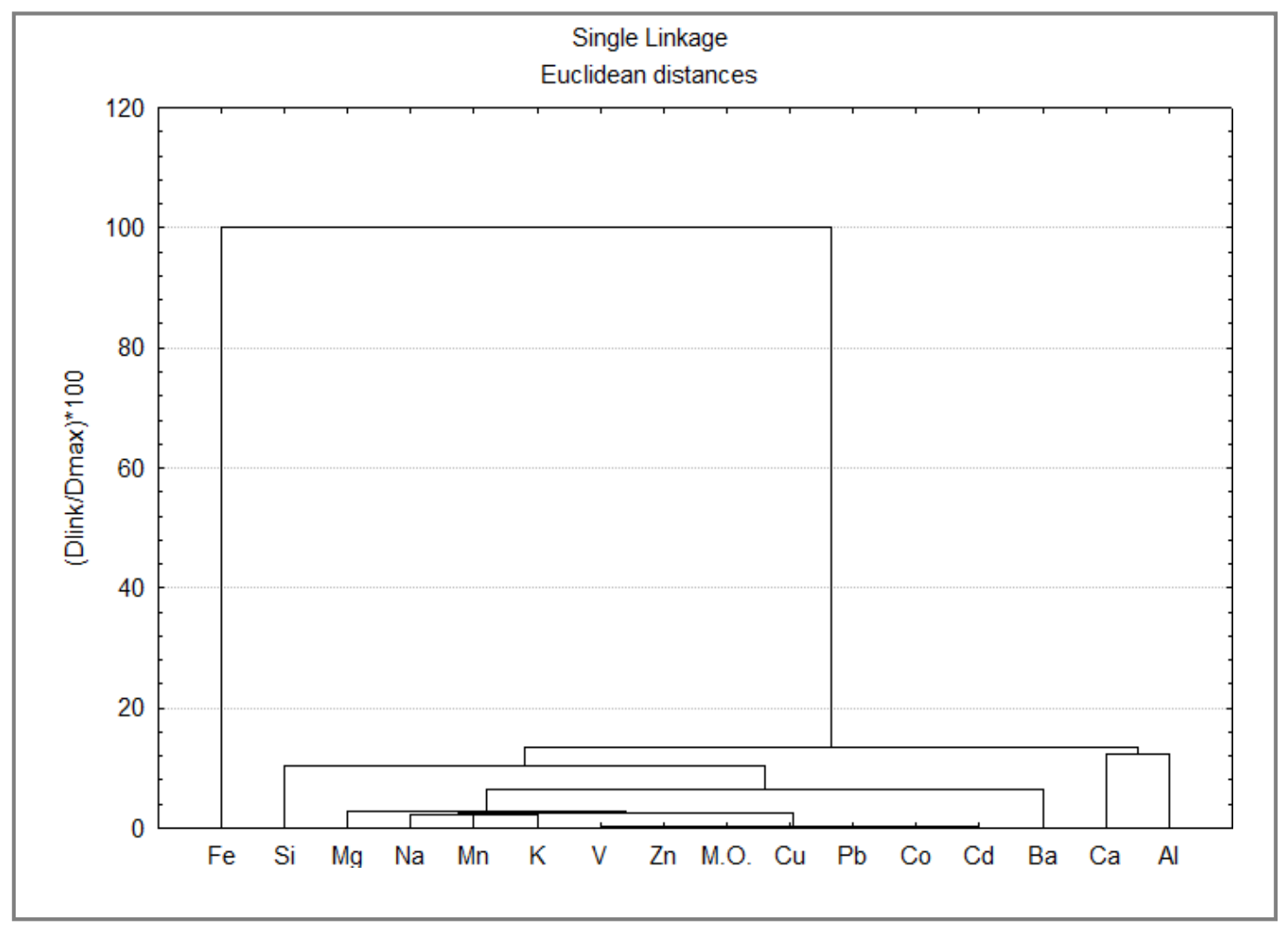

FIGURA 32 - Dendograma resultante da análise de agrupamento utilizando os metais analisados e o teor de matéria orgânica

Observa-se na Figura 32 que o elemento Fe fica separado de todas as outras variáveis consideradas: $\mathrm{Si}, \mathrm{Mg}, \mathrm{Na}, \mathrm{Mn}, \mathrm{K}, \mathrm{V}, \mathrm{Zn}$, matéria orgânica, $\mathrm{Cu}, \mathrm{Pb}$, $\mathrm{Co}, \mathrm{Cd}, \mathrm{Ba}, \mathrm{Ca}$ e Al. A dissimilaridade do elemento $\mathrm{Fe}$ se deve pelo fato dele estar presente em grande quantidade nos solos da região, tanto os Latossolos Vermelho-Amarelados, quanto os Plintossolos Pétricos, apresentam altos teores de óxidos de ferro. Outros elementos que se distanciam do resto das variáveis são $\mathrm{Si}, \mathrm{Al}$ e $\mathrm{Ca}$, sendo que os dois primeiros também estão presentes nos solos da região, tanto como óxido de alumínio como na forma do mineral caulinita (mineral de alumínio e silício) e o cálcio, como sendo um dos elementos mais abundantes da crosta terrestre e que pode surgir em ambientes aquáticos devido ao intemperismo de silicatos e bicarbonatos. Outro elemento que apresenta-se sozinho é o $\mathrm{Ba}$, presente em sistemas aquáticos tanto em função de fontes antrópicas quanto pela mineralogia da região. 
As variáveis restantes formam dois sub-grupos:

- $1^{\circ}$ sub-grupo ( $\mathrm{Mg}, \mathrm{Na}, \mathrm{Mn}$ e $\mathrm{K}$ ): considerados elementos de origem natural, sendo abundantes na crosta terrestre e em muitos tipos de solo. Tais elementos podem estar associados à fatores mineralógicos, ou seja, à formação do ambiente geológico, em que há um predomínio de rochas sedimentares provenientes do Paleozóico e Mesozóico.

- $2^{\circ}$ sub-grupo ( $\mathrm{V}, \mathrm{Zn}$, matéria orgânica, $\left.\mathrm{Cu}, \mathrm{Pb}, \mathrm{Co}, \mathrm{Cd}\right)$ : neste grupo são predominantes os elementos de origem antropogênica. Estes elementos são fortemente complexados pela matéria orgânica, bem como adsorvidos por óxidos de ferro e manganês. Neste sub-grupo localizam-se metais tóxicos, como $\mathrm{Pb}$ e $\mathrm{Cd}$, que não são elementos relacionados com fontes naturais. A correlação entre as variáveis $\mathrm{Zn}$, matéria orgânica e Cu pode estar associada com a fonte antrópica de efluentes das cidades e aplicações de pesticidas. Em estudo nas bacias hidrográficas dos rios Mogi-Guaçu e Pardo, no estado de São Paulo, Lemes (2001) encontrou forte relação entre Cu e Zn, e sugeriu que tal fato pode estar relacionado com o lançamento na região de pesticidas como o sulfato de zinco e oxicloreto de cobre. Segundo Varol e Sen (2012), elementos como $\mathrm{Zn}, \mathrm{Cu}, \mathrm{Pb}$, Co e Cd são derivados de fontes antropogênicas, podendo ser decorrentes, por exemplo, de descargas metálicas de usina de mineração de cobre. Chabukdhara e Nema (2012) também afirmam que metais tóxicos tais como $\mathrm{Cu}, \mathrm{Pb}, \mathrm{Zn}, \mathrm{Ni}$ e $\mathrm{Cd}$ estão associados com fontes antropogênicas, enquanto que o $\mathrm{Fe}$ está normalmente presente em sedimentos em concentrações relativamente altas em condições naturais. 


\subsection{DISCUSSÃO DOS RESULTADOS OBTIDOS}

- O estudo de comparação de metodologias de solubilização de metais ambientalmente disponíveis em amostras de sedimento apresentou como resultado a existência de diferenças significativas entre os dois métodos. O primeiro processo de digestão baseado no método da USEPA 3051A resultou em recuperações dos elementos estudados acima de $80 \%$, que estão dentro da faixa de aceitabilidade do processo $(75 \%<\mathrm{R}<125 \%)$, podendo ser considerado um método de solubilização quase total dos sedimentos, que fornece uma boa estimativa do teor de metais, produzindo uma eficiente solubilização do sedimento, não atingindo apenas a matriz silicato do compartimento. Por outro lado, foi observado no método de digestão com $\mathrm{HCl}$ diluído em temperatura ambiente, que este apresenta níveis de extração de metais mais baixos que os obtidos pelo primeiro método, além de não ser eficiente para a recuperação do elemento Se, fato que pode estar relacionado com a insolubilidade de alguns sais de selênio em ácido clorídrico, como é o caso do $\mathrm{SeS}_{2}$, que não se decompõe em $\mathrm{HCl}$, porém se decompõe em $\mathrm{HNO}_{3}$. Este processo, apesar de apresentar uma recuperação mais baixa dos elementos $\mathrm{As}, \mathrm{Cd}$ e $\mathrm{Pb}$ e não apresentar recuperação de Se, pode ser considerado mais representativo para a solubilização dos metais ambientalmente disponíveis, pois é um método mais brando, relativamente simples, com um mínimo ataque à matriz, suficiente para disponibilizar os metais presentes nas fases mais lábeis e instáveis do sedimento. Por estas razões e por ser um método que mais se aproxima das condições encontradas na natureza, o processo de digestão com $\mathrm{HCl}$ 0,1 M e agitação em temperatura ambiente foi escolhido para ser utilizado nos laboratórios do CQMA, nos quais estas análises foram realizadas.

- A análise estatística foi mais uma ferramenta utilizada para a avaliação da qualidade dos sedimentos, que contribuiu para o estudo por 
correlacionar algumas das variáveis determinadas bem como para direcionar os elementos com as possíveis fontes de contribuição para o sistema hidrográfico estudado. A análise fatorial mostrou que as variabilidades comuns existentes entre os conjuntos de variáveis conseguem explicar $92,15 \%$ da variabilidade total dos elementos. Esta análise mostrou que grande parte da distribuição dos elementos pode estar relacionada com 0 teor de matéria orgânica presente nos sedimentos, como $\mathrm{Al}, \mathrm{Ba}, \mathrm{Cd}, \mathrm{Co}, \mathrm{Fe}, \mathrm{K}, \mathrm{Mn}, \mathrm{Pb}$ e $\mathrm{V}$, visto que tais elementos apresentaram uma correlação positiva com a matéria orgânica, enquanto que os elementos $\mathrm{Mg}$ e $\mathrm{Na}$ podem estar relacionados por serem encontrados abundantemente na natureza. Já a fração na qual foram realizados os ensaios $(<0,250 \mathrm{~mm})$ não influenciou na retenção dos metais. A análise de conglomerados (clusters analysis) mostrou dissimilaridade entre o ponto de coleta $03 \mathrm{e}$ os outros pontos, o que provavelmente se deve ao fato deste ponto ter apresentado as maiores concentrações dos elementos $\mathrm{Al}, \mathrm{Ba}, \mathrm{Cd}, \mathrm{Ca}$, $\mathrm{Co}, \mathrm{Cu}, \mathrm{Fe}, \mathrm{Mn}, \mathrm{K}, \mathrm{Pb}, \mathrm{Si}, \mathrm{V}$ e $\mathrm{Zn}$, bem como o maior teor de matéria orgânica. Foi observado que o Fe é um elemento que se distancia dos demais, provavelmente em virtude de ser abundante nos tipos de solo locais (Latossolos Vermelho-Amarelados e Plintossolos Pétricos) fato que também pode ter influenciado na dissimilaridade do $\mathrm{Si}$, Ca e Al, em relação aos demais elementos, em conseqüência destes serem abundantes na crosta terrestre, e, com exceção do $\mathrm{Ca}$, também aparecem na pedologia local. Foi encontrada uma relação entre $\mathrm{Mg}$, $\mathrm{Na}, \mathrm{Mn}$ e K, que pode ser em virtude de sua abundância natural, e uma outra relação entre $\mathrm{V}, \mathrm{Zn}$, matéria orgânica, $\mathrm{Cu}, \mathrm{Pb}$, $\mathrm{Co}$ e $\mathrm{Cd}$, sendo que tais elementos podem ser de origem antrópica. Os elementos Co, $\mathrm{Pb}$ e V são fortemente adsorvidos por matéria orgânica, enquanto que o Zn, a matéria orgânica e o $\mathrm{Cu}$ podem estar associados com o lançamento de efluentes das cidades locais, bem como com o lançamento de pesticidas utilizados nas atividades de agricultura na região. 
- Os sedimentos da região hidrográfica do Tocantins-Araguaia são caracterizados como de natureza mineral, com moderado conteúdo de matéria orgânica, visto que, com exceção do ponto de coleta 03 , todos os outros locais apresentaram sedimentos com menos de $10 \%$ de teor de matéria orgânica. Outra característica dos sedimentos coletados é sua granulometria mais arenosa, visto que a maioria dos sedimentos coletados não apresentou nem $5 \%$ de fração silte e argila, sendo tais resultados em conseqüência, provavelmente, de coletas em regiões mais superficiais do compartimento aquático.

- A determinação dos metais ambientalmente disponíveis em sedimento foi realizada pelas técnicas GFAAS, CVAAS e ICP-OES. Os resultados obtidos mostraram baixos níveis de concentração dos elementos, sendo que alguns deles, Ag, As, B, Be, Cr, Hg, Li, Mo, Ni, P, Sb, Sc, Se e Ti não apresentaram concentrações quantificáveis. Os elementos que possuem valores orientadores TEL e PEL estabelecidos pelo Canadian Council of Ministers of the Environment (CCME) resultaram em níveis de concentração abaixo do limite TEL (Threshold Effect Level), concentração na qual raramente são esperados efeitos adversos para os organismos. Estes resultados também foram comparados com os valores adotados pela CETESB e com esta análise foi possível classificar os sedimentos coletados com uma qualidade ótima para os contaminantes considerados. Portanto, pode-se dizer que os sedimentos da região não são causadores de efeitos deletérios para a biota aquática e possuem uma qualidade satisfatória, não sendo capazes de provocar mudanças prejudiciais no meio aquático local caso sejam realizadas atividades de dragagem. 


\section{CONCLUSÕES}

\subsection{COMPARAÇÃO DOS MÉTODOS DE DIGESTÃO DE SEDIMENTO}

$\mathrm{O}$ método 3051A da USEPA que utiliza $\mathrm{HNO}_{3} 8 \mathrm{M}$ e aquecimento em equipamento microondas e o método não normatizado que utiliza $\mathrm{HCl} 0,1 \mathrm{M} \mathrm{e}$ agitação em temperatura ambiente foram utilizados na solubilização parcial das amostras de sedimento para determinação dos metais ambientalmente disponíveis. A comparação entre as duas solubilizações mostrou haver diferenças significantes entre os dois métodos. O primeiro processo resultou em recuperações dos elementos acima de $80 \%$, podendo ser considerado um método de digestão quase total dos sedimentos, fornecendo uma boa estimativa do teor de metais, enquanto que o segundo processo apresentou níveis de recuperação mais baixos, porém é o método que mais se aproxima das condições ambientais, sendo, portanto, o método utilizado nos laboratórios do CQMA.

\subsection{CARACTERIZAÇÃO FíSICA DO SEDIMENTO}

Quanto ao teor de matéria orgânica, os sedimentos da região hidrográfica do Tocantins-Araguaia são caracterizados como de natureza mineral, com moderado conteúdo de matéria orgânica. Enquanto que em relação à granulometria, tais sedimentos são caracterizados como de composição arenosa.

\subsection{AVALIAÇÃO DA QUALIDADE DO SEDIMENTO}

Os elementos que possuem valores orientadores TEL e PEL estabelecidos pelo CCME apresentaram concentrações abaixo do limite TEL, o que mostra que os sedimentos dos locais de coleta raramente são causadores de 
efeitos adversos para os organismos. A comparação com a classificação de contaminantes em sedimentos estabelecidos pela CETESB mostra que os sedimentos estudados apresentam qualidade ótima para os contaminantes considerados.

Portanto, pode-se afirmar que, até o presente momento, os sedimentos dos locais estudados não se encontram impactados, sendo considerados locais ainda preservados, mesmo o ponto 03 que apresentou as maiores concentrações para a maioria das variáveis estudadas. 


\section{APÊNDICES}

APÊNDICE A - Resultado da análise dos elementos As, $\mathrm{Cd}, \mathrm{Pb}$ e Se utilizando o método USEPA $3051 \mathrm{~A}\left(\mathrm{em} \mathrm{mg} \mathrm{Kg}{ }^{-1}\right.$ )

\begin{tabular}{|c|c|c|c|c|c|c|c|}
\hline & \multicolumn{7}{|c|}{ Concentração dos metais e elementos-traço em sedimentos $\left(\mathrm{mg} \mathrm{Kg}^{-1}\right)$} \\
\hline Elemento & P1 & P3 & P6 & P8 & P20 & P21 & P30 \\
\hline \multirow{2}{*}{ As } & 18,5 & 6,65 & 5,8 & 3,50 & 24,5 & 10,5 & 6,5 \\
\hline & $\pm 0,2$ & $\pm 0,05$ & $\pm 0,1$ & $\pm 0,08$ & $\pm 0,8$ & $\pm 0,3$ & $\pm 0,8$ \\
\hline $\mathrm{Cd}$ & $<\mathrm{LQ}$ & $\begin{array}{c}0,050 \\
\pm 0,003\end{array}$ & $<\mathrm{LQ}$ & $<\mathrm{LQ}$ & $<\mathrm{LQ}$ & $\begin{array}{c}0,0308 \\
\pm 0,0005\end{array}$ & $<\mathrm{LQ}$ \\
\hline \multirow{2}{*}{$\mathrm{Pb}$} & 10,8 & 13,0 & 6,8 & 5,3 & 9,88 & 11,8 & 7,5 \\
\hline & $\pm 0,8$ & $\pm 0,5$ & $\pm 0,2$ & $\pm 0,1$ & $\pm 0,08$ & $\pm 0,5$ & $\pm 0,8$ \\
\hline Se & $<\mathrm{LQ}$ & $\begin{array}{c}1,279 \\
\pm 0,001\end{array}$ & $\begin{array}{c}0,78 \\
\pm 0,20\end{array}$ & $<\mathrm{LQ}$ & $<\mathrm{LQ}$ & $<\mathrm{LQ}$ & $<\mathrm{LQ}$ \\
\hline
\end{tabular}

APÊNDICE B - Resultado da análise dos elementos As, Cd, Pb e Se utilizando $\mathrm{HCl}$ 0,1 M e agitação em temperatura ambiente (em mg Kg${ }^{-1}$ )

\begin{tabular}{cccccccc} 
& \multicolumn{7}{c}{ Concentração dos metais e elementos-traço em sedimentos $\left(\mathbf{m g ~ K g}^{-1}\right)$} \\
\hline Elemento & $\mathbf{P 1}$ & $\mathbf{P 3}$ & $\mathbf{P 6}$ & $\mathbf{P 8}$ & $\mathbf{P 2 0}$ & $\mathbf{P 2 1}$ & $\mathbf{P 3 0}$ \\
\hline $\mathrm{As}$ & $<\mathrm{LQ}$ & $<\mathrm{LQ}$ & $<\mathrm{LQ}$ & $<\mathrm{LQ}$ & $<\mathrm{LQ}$ & $<\mathrm{LQ}$ & $<\mathrm{LQ}$ \\
$\mathrm{Cd}$ & $<\mathrm{LQ}$ & 0,048 & $<\mathrm{LQ}$ & $<\mathrm{LQ}$ & $<\mathrm{LQ}$ & 0,028 & $<\mathrm{LQ}$ \\
& 1,3 &, \pm 5 & 1,23 & 0,7 & 0,94 & 2,0 & 1,48 \\
$\mathrm{~Pb}$ & $\pm 0,1$ & $\pm 0,2$ & $\pm 0,08$ & $\pm 0,2$ & $\pm 0,02$ & $\pm 0,3$ & $\pm 0,08$ \\
$\mathrm{Se}$ & $<\mathrm{LQ}$ & $<\mathrm{LQ}$ & $<\mathrm{LQ}$ & $<\mathrm{LQ}$ & $<\mathrm{LQ}$ & $<\mathrm{LQ}$ & $<\mathrm{LQ}$ \\
\hline
\end{tabular}


APÊNDICE C - Resultado da análise de metais e elementos-traço nos sedimentos coletados (em $\mu \mathrm{g} \mathrm{mL} \mathrm{L}^{-1}$ )

\begin{tabular}{|c|c|c|c|c|c|c|c|c|}
\hline \multirow[b]{2}{*}{ Elemento } & \multirow[b]{2}{*}{$\begin{array}{c}\text { LQ } \\
\left(\mu \mathrm{gL}^{-1}\right)\end{array}$} & \multicolumn{7}{|c|}{ Concentração dos metais e elementos-traço em sedimentos $\left(\mu \mathrm{g} \mathrm{mL}^{-1}\right)$} \\
\hline & & P1 & P3 & P6 & P8 & P20 & P21 & P30 \\
\hline Ag & 0,100 & $<L Q$ & $<\mathrm{LQ}$ & $<\mathrm{LQ}$ & $<L Q$ & $<L Q$ & $<L Q$ & $<\mathrm{LQ}$ \\
\hline \multirow{2}{*}{ Al } & \multirow{2}{*}{0,500} & 2,1 & 6,9 & 3,5 & 1,08 & 0,97 & 2,3 & 1,55 \\
\hline & & $\pm 0,3$ & $\pm 0,8$ & $\pm 0,1$ & $\pm 0,04$ & $\pm 0,05$ & $\pm 0,4$ & $\pm 0,07$ \\
\hline As & 0,0015 & $<L Q$ & $<\mathrm{LQ}$ & $<\mathrm{LQ}$ & $<L Q$ & $<L Q$ & $<\mathrm{LQ}$ & $<L Q$ \\
\hline B & 0,100 & $<L Q$ & $<L Q$ & $<L Q$ & $<L Q$ & $<L Q$ & $<L Q$ & $<\mathrm{LQ}$ \\
\hline \multirow{2}{*}{$\mathrm{Ba}$} & \multirow{2}{*}{0,010} & 0,27 & 2,17 & 0,63 & 0,33 & 0,33 & 1,6 & 0,508 \\
\hline & & $\pm 0,03$ & $\pm 0,04$ & $\pm 0,03$ & $\pm 0,01$ & $\pm 0,02$ & $\pm 0,3$ & $\pm 0,007$ \\
\hline $\mathrm{Be}$ & 0,010 & $<L Q$ & $<L Q$ & $<L Q$ & $<L Q$ & $<L Q$ & $<L Q$ & $<L Q$ \\
\hline $\mathrm{Ca}$ & 1,000 & $\begin{array}{c}2,7 \\
\pm 0,3\end{array}$ & $\begin{array}{c}5,27 \\
\pm 0,08\end{array}$ & $\begin{array}{c}1,47 \\
\pm 0,05\end{array}$ & $<L Q$ & $<L Q$ & $\begin{array}{c}2,2 \\
\pm 0,4\end{array}$ & $\begin{array}{c}3,1 \\
\pm 0,4\end{array}$ \\
\hline Cd & 0,0001 & $<L Q$ & $\begin{array}{c}0,00019 \\
\pm 0,00002\end{array}$ & $<\mathrm{LQ}$ & $<L Q$ & $<L Q$ & $\begin{array}{c}0,000110 \\
\pm 0,000009\end{array}$ & $<\mathrm{LQ}$ \\
\hline Co & 0,020 & $<L Q$ & $\begin{array}{c}0,0272 \\
\pm 0,0006\end{array}$ & $<\mathrm{LQ}$ & $<L Q$ & $<L Q$ & $<\mathrm{LQ}$ & $<\mathrm{LQ}$ \\
\hline $\mathrm{Cr}$ & 0,020 & $<L Q$ & $<L Q$ & $<L Q$ & $<L Q$ & $<L Q$ & $<L Q$ & $<\mathrm{LQ}$ \\
\hline $\mathrm{Cu}$ & 0,020 & $\begin{array}{c}0,0262 \\
\pm 0,0003\end{array}$ & $\begin{array}{c}0,057 \\
\pm 0,002\end{array}$ & $<L Q$ & $\begin{array}{c}0,025 \\
\pm 0,002\end{array}$ & $<\mathrm{LQ}$ & $<L Q$ & $\begin{array}{r}0,0285 \\
\pm 0,0006\end{array}$ \\
\hline \multirow{2}{*}{$\mathrm{Fe}$} & \multirow{2}{*}{1,000} & 7,7 & 30,4 & 7,57 & 3,2 & 2,0 & 9,3 & 12,0 \\
\hline & & $\pm 0,7$ & $\pm 0,5$ & $\pm 0,09$ & $\pm 0,1$ & $\pm 0,2$ & $\pm 1,5$ & $\pm 0,3$ \\
\hline $\mathrm{Hg}$ & 0,0008 & $<L Q$ & $<L Q$ & $<L Q$ & $<L Q$ & $<L Q$ & $<L Q$ & $<\mathrm{LQ}$ \\
\hline \multirow{2}{*}{$\mathbf{K}$} & \multirow{2}{*}{0,100} & 0,20 & 0,59 & 0,21 & 0,16 & 0,296 & 0,20 & 0,18 \\
\hline & & $\pm 0,01$ & $\pm 0,04$ & $\pm 0,01$ & $\pm 0,04$ & $\pm 0,003$ & $\pm 0,03$ & $\pm 0,04$ \\
\hline Li & 0,010 & $<L Q$ & $<L Q$ & $<L Q$ & $<L Q$ & $<L Q$ & $<L Q$ & $<\mathrm{LQ}$ \\
\hline \multirow{2}{*}{$\mathrm{Mg}$} & \multirow{2}{*}{0,050} & 0,2707 & 0,776 & 0,115 & \multirow{2}{*}{$<L Q$} & 0,15 & 0,25 & 1,2 \\
\hline & & $\pm 0,0009$ & $\pm 0,006$ & $\pm 0,004$ & & $\pm 0,01$ & $\pm 0,03$ & $\pm 0,2$ \\
\hline $\mathrm{Mn}$ & 0,050 & 0,24 & 1,03 & 0,118 & $<L Q$ & 0,100 & 0,37 & 0,389 \\
\hline Mo & 0,100 & $<L Q$ & $<L Q$ & $<\mathrm{LQ}$ & $<L Q$ & $<L Q$ & $<L Q$ & $<L Q$ \\
\hline $\mathrm{Na}$ & 0,500 & $<L Q$ & 0,6 & $<\mathrm{LQ}$ & $<L Q$ & $<L Q$ & $<L Q$ & 0,60 \\
\hline $\mathrm{Ni}$ & 0,500 & $<\mathrm{LQ}$ & $\begin{array}{l} \pm 0,1 \\
<\mathrm{LQ}\end{array}$ & $<L Q$ & $<L Q$ & $<L Q$ & $<L Q$ & $\begin{array}{c} \pm 0,02 \\
<L Q\end{array}$ \\
\hline $\mathbf{P}$ & 0,050 & $<L Q$ & $<L Q$ & $<L Q$ & $<L Q$ & $<L Q$ & $<L Q$ & $<\mathrm{LQ}$ \\
\hline $\mathrm{Pb}$ & 0,0015 & 0,0050 & 0,0179 & 0,0049 & 0,0026 & 0,00377 & 0,008 & 0,0059 \\
\hline rid & כ & $\pm 0,0004$ & $\pm 0,0006$ & $\pm 0,0003$ & $\pm 0,0006$ & $\pm 0,00008$ & $\pm 0,001$ & $\pm 0,0003$ \\
\hline Sb & 0,050 & $<L Q$ & $<\mathrm{LQ}$ & $<\mathrm{LQ}$ & $<L Q$ & $<L Q$ & $<\mathrm{LQ}$ & $<\mathrm{LQ}$ \\
\hline Sc & 0,020 & $<L Q$ & $<L Q$ & $<L Q$ & $<L Q$ & $<L Q$ & $<L Q$ & $<\mathrm{LQ}$ \\
\hline Se & 0,0020 & $<L Q$ & $<L Q$ & $<L Q$ & $<L Q$ & $<L Q$ & $<L Q$ & $<\mathrm{LQ}$ \\
\hline Si & 1,000 & $\begin{array}{c}1,3 \\
\pm 0,1\end{array}$ & $\begin{array}{c}3,99 \\
\pm 0,03\end{array}$ & $<L Q$ & $<L Q$ & $<L Q$ & $<L Q$ & $\begin{array}{c}1,37 \\
\pm 0,05\end{array}$ \\
\hline $\mathrm{Ti}$ & 0,100 & $<L Q$ & $<L Q$ & $<L Q$ & $<L Q$ & $<L Q$ & $<L Q$ & $<\mathrm{LQ}$ \\
\hline v & 0,030 & $<L Q$ & $\begin{array}{c}0,082 \\
\pm 0,001\end{array}$ & $\begin{array}{c}0,0385 \\
\pm 0,0007\end{array}$ & $<L Q$ & $<\mathrm{LQ}$ & $<L Q$ & $<\mathrm{LQ}$ \\
\hline $\mathrm{Zn}$ & 0,020 & $<L Q$ & $\begin{array}{c}0,0687 \\
\pm 0,0008\end{array}$ & $\begin{array}{c}0,029 \\
\pm 0,005\end{array}$ & $<L Q$ & $<\mathrm{LQ}$ & $\begin{array}{c}0,033 \\
\pm 0,003\end{array}$ & $\begin{array}{c}0,037 \\
\pm 0,007\end{array}$ \\
\hline
\end{tabular}


APÊNDICE D - Resultado da análise de metais e elementos-traço nos sedimentos coletados (em $\mathrm{mg} \mathrm{Kg}^{-1}$ ). Comparação com TEL e PEL.

\begin{tabular}{|c|c|c|c|c|c|c|c|c|c|}
\hline \multirow[b]{2}{*}{ Elemento } & \multicolumn{9}{|c|}{ Concentração dos metais e elementos-traço em sedimentos $\left(\mathrm{mg} \mathrm{Kg}^{-1}\right)$} \\
\hline & TEL & PEL & P1 & P3 & P6 & P8 & P20 & P21 & P30 \\
\hline $\mathrm{Ag}$ & - & - & $<L Q$ & $<L Q$ & $<\mathrm{LQ}$ & $<L Q$ & $<\mathrm{LQ}$ & $<L Q$ & $<L Q$ \\
\hline \multirow[b]{2}{*}{ Al } & \multirow[b]{2}{*}{ - } & \multirow[b]{2}{*}{ - } & 525 & 1725 & 875 & 270 & 242,5 & 575 & 387,5 \\
\hline & & & \pm 75 & \pm 200 & \pm 25 & \pm 10 & $\pm 12,5$ & \pm 100 & $\pm 17,5$ \\
\hline As & 5,9 & 17,0 & $<L Q$ & $<L Q$ & $<\mathrm{LQ}$ & $<L Q$ & $<\mathrm{LQ}$ & $<\mathrm{LQ}$ & $<\mathrm{LQ}$ \\
\hline B & - & - & $<\mathrm{LQ}$ & $<\mathrm{LQ}$ & $<\mathrm{LQ}$ & $<L Q$ & $<\mathrm{LQ}$ & $<\mathrm{LQ}$ & $<\mathrm{LQ}$ \\
\hline \multirow{2}{*}{$\mathrm{Ba}$} & \multirow{2}{*}{ - } & \multirow[b]{2}{*}{ - } & 67,5 & 542,5 & 157,5 & 82,5 & 82,5 & 400 & 127 \\
\hline & & & $\pm 7,5$ & $\pm 10,0$ & $\pm 7,5$ & $\pm 2,5$ & $\pm 5,0$ & \pm 75 & \pm 2 \\
\hline $\mathrm{Be}$ & - & - & $<\mathrm{LQ}$ & $<\mathrm{LQ}$ & $<\mathrm{LQ}$ & $<L Q$ & $<\mathrm{LQ}$ & $<L Q$ & $<L Q$ \\
\hline \multirow{2}{*}{$\mathrm{Ca}$} & \multirow{2}{*}{ - } & \multirow{2}{*}{-} & 675 & 1318 & 367,5 & \multirow{2}{*}{$<L Q$} & \multirow{2}{*}{$<\mathrm{LQ}$} & 550 & 775 \\
\hline & & & \pm 75 & \pm 20 & $\pm 12,5$ & & & \pm 100 & \pm 100 \\
\hline Cd & 0,6 & 3,5 & $<\mathrm{LQ}$ & $\begin{array}{c}0,048 \\
\pm 0,005\end{array}$ & $<L Q$ & $<L Q$ & $<\mathrm{LQ}$ & $\begin{array}{c}0,028 \\
\pm 0,003\end{array}$ & $<L Q$ \\
\hline Co & - & - & $<\mathrm{LQ}$ & $\begin{array}{c}6,8 \\
\pm 0,2\end{array}$ & $<L Q$ & $<L Q$ & $<\mathrm{LQ}$ & $<L Q$ & $<L Q$ \\
\hline $\mathrm{Cr}$ & 37,3 & 90,0 & $<L Q$ & $<\mathrm{LQ}$ & $<\mathrm{LQ}$ & $<L Q$ & $<L Q$ & $<L Q$ & $<L Q$ \\
\hline $\mathrm{Cu}$ & 35,7 & 197 & $\begin{array}{r}6,55 \\
\pm 0,08\end{array}$ & $\begin{array}{r}14,3 \\
\pm 0,5\end{array}$ & $<L Q$ & $\begin{array}{c}6,3 \\
\pm 0,5\end{array}$ & $<\mathrm{LQ}$ & $<L Q$ & $\begin{array}{c}7,1 \\
\pm 0,2\end{array}$ \\
\hline \multirow{2}{*}{$\mathrm{Fe}$} & \multirow{2}{*}{ - } & \multirow[b]{2}{*}{-} & 1925 & 7600 & 1892,5 & 800 & 500 & 2325 & 3000 \\
\hline & & & \pm 175 & \pm 125 & $\pm 22,5$ & \pm 25 & \pm 50 & \pm 375 & \pm 75 \\
\hline $\mathrm{Hg}$ & 0,17 & 0,486 & $<L Q$ & $<L Q$ & $<\mathrm{LQ}$ & $<L Q$ & $<\mathrm{LQ}$ & $<\mathrm{LQ}$ & $<\mathrm{LQ}$ \\
\hline \multirow{2}{*}{$\mathrm{K}$} & \multirow[b]{2}{*}{ - } & & 50,0 & 148 & 52,5 & 40 & 74,0 & 50 & 45 \\
\hline & & - & $\pm 2,5$ & \pm 10 & $\pm 2,5$ & \pm 10 & $\pm 0,8$ & $\pm 7,5$ & \pm 10 \\
\hline Li & - & - & $<L Q$ & $<\mathrm{LQ}$ & $<\mathrm{LQ}$ & $<L Q$ & $<\mathrm{LQ}$ & $<\mathrm{LQ}$ & $<\mathrm{LQ}$ \\
\hline & & - & 67,7 & 194,0 & 28,75 & & 37,5 & 62,5 & 300 \\
\hline Mg & - & - & $\pm 0,2$ & $\pm 1,5$ & $\pm 1,0$ & $<$ LQ & $\pm 2,5$ & $\pm 7,5$ & \pm 50 \\
\hline $\mathrm{Mn}$ & - & - & 60 & 257,5 & 29,5 & $<10$ & 25,0 & 92,5 & 97,3 \\
\hline $\mathrm{IVin}$ & - & - & \pm 5 & $\pm 2,5$ & $\pm 0,8$ & $<\mathrm{LQ}$ & $\pm 1,3$ & $\pm 17,5$ & $\pm 0,3$ \\
\hline Mo & - & - & $<L Q$ & $<L Q$ & $<\mathrm{LQ}$ & $<L Q$ & $<L Q$ & $<L Q$ & $<L Q$ \\
\hline $\mathrm{Na}$ & - & - & $<\mathrm{LQ}$ & $\begin{array}{r}150 \\
\pm 25\end{array}$ & $<L Q$ & $<\mathrm{LQ}$ & $<\mathrm{LQ}$ & $<L Q$ & $\begin{array}{l}150 \\
\pm 5\end{array}$ \\
\hline $\mathrm{Ni}$ & 18 & 35,9 & $<L Q$ & $<L Q$ & $<L Q$ & $<L Q$ & $<L Q$ & $<L Q$ & $<L Q$ \\
\hline $\mathbf{P}$ & - & - & $<\mathrm{LQ}$ & $<\mathrm{LQ}$ & $<\mathrm{LQ}$ & $<\mathrm{LQ}$ & $<\mathrm{LQ}$ & $<L Q$ & $<L Q$ \\
\hline $\mathrm{Pb}$ & 35,0 & 91,3 & 1,3 & 4,5 & 1,23 & 0,7 & 0,94 & 2,0 & 1,48 \\
\hline & & כ, & $\pm 0,1$ & $\pm 0,2$ & $\pm 0,08$ & $\pm 0,2$ & $\pm 0,02$ & $\pm 0,3$ & $\pm 0,08$ \\
\hline Sb & - & - & $<\mathrm{LQ}$ & $<\mathrm{LQ}$ & $<\mathrm{LQ}$ & $<\mathrm{LQ}$ & $<\mathrm{LQ}$ & $<L Q$ & $<L Q$ \\
\hline Sc & - & - & $<L Q$ & $<\mathrm{LQ}$ & $<\mathrm{LQ}$ & $<\mathrm{LQ}$ & $<L Q$ & $<\mathrm{LQ}$ & $<\mathrm{LQ}$ \\
\hline Se & - & - & $<L Q$ & $<L Q$ & $<\mathrm{LQ}$ & $<L Q$ & $<L Q$ & $<\mathrm{LQ}$ & $<\mathrm{LQ}$ \\
\hline Si & - & - & 325 & 997,5 & $<L Q$ & $<\mathrm{LO}$ & $<\mathrm{LO}$ & $<\mathrm{LQ}$ & 342,5 \\
\hline SI & - & - & \pm 25 & $\pm 7,5$ & $<\mathrm{LQ}$ & $<\mathrm{LQ}$ & $<\mathrm{LQ}$ & $<\mathrm{LQ}$ & $\pm 12,5$ \\
\hline $\mathrm{Ti}$ & - & - & $<L Q$ & $<L Q$ & $<\mathrm{LQ}$ & $<L Q$ & $<L Q$ & $<\mathrm{LQ}$ & $<\mathrm{LQ}$ \\
\hline v & - & - & $<L Q$ & $\begin{array}{r}20,5 \\
\pm 0,3\end{array}$ & $\begin{array}{c}9,6 \\
\pm 0,2\end{array}$ & $<\mathrm{LQ}$ & $<\mathrm{LQ}$ & $<L Q$ & $<L Q$ \\
\hline $\mathrm{Zn}$ & 123 & 315 & $<\mathrm{LQ}$ & $\begin{array}{l}17,2 \\
\pm 0,2\end{array}$ & $\begin{array}{c}7,3 \\
\pm 1,3\end{array}$ & $<\mathrm{LQ}$ & $<L Q$ & $\begin{array}{c}8,3 \\
\pm 0,8\end{array}$ & $\begin{array}{c}9,3 \\
\pm 1,8\end{array}$ \\
\hline
\end{tabular}




\section{REFERÊNCIAS BIBLIOGRÁFICAS}

AGÊNCIA NACIONAL DE VIGILÂNCIA SANITÁRIA. Resolução RE $n^{\circ}$ 899, de 29 de maio de 2003. Guia para validação de métodos analíticos e bioanalíticos. Diário Oficial da União, Brasília, 02 jun. 2003. Disponível em:

<http://www.anvisa.gov.br/legis/resol/2003/re/899_03re.htm>. Acesso em: 05 jul. 2012.

AGUIAR, J. E.; MARINS, R. V.; ALMEIDA, M. D. Comparação de metodologias de digestão de sedimentos marinhos para caracterização da geoquímica de metais-traço na Plataforma Continental Nordeste Oriental Brasileira. Geochimica Brasiliensis, v. 21, n. 3, p. 304-323, 2007.

ALENCAR, A. M. Estabelecimento de valores de referência a partir de estudo qualitativo das substâncias naturalmente presentes em águas de captação para abastecimento público. 2011. Dissertação (Mestrado em Ciências do Ambiente) - Universidade Federal do Tocantins, Palmas, 2011.

ANA - Agência Nacional de Águas. Cadernos de recursos hídricos 1 Panorama da qualidade das águas superficiais no Brasil. Superintendência de Planejamento de Recursos Hídricos - Agência Nacional de Águas. Brasília: TDA Desenho \& Arte Ltda, 2005. $172 \mathrm{p}$.

ANA - Agência Nacional de Águas. Plano estratégico de recursos hídricos da bacia hidrográfica dos rios Tocantins e Araguaia: relatório síntese. Agência Nacional de Águas. Brasília: ANA; SPR, 2009. 256 p.

ARAIN, M. B.; KAZI, T. G.; JAMALI, M. K.; JALBANI, N.; AFRIDI, H. I.; SHAH, A. Total dissolved and bioavailable elements in water and sediment samples and their accumulation in Oreochromis mossambicus of polluted Manchar Lake. Chemosphere, v. 70, p. 1845-1856, 2008.

ASSOCIAÇÃO BRASILEIRA DE NORMAS TÉCNICAS. Solo: determinação do teor de matéria orgânica por queima a $440^{\circ} \mathrm{C}$. Método de ensaio. Rio de Janeiro: ABNT, 1996. 2 p. (NBR 13600).

BAIRD, C. Química ambiental. $2^{\text {a }}$ ed. Porto Alegre: Bookman, 2002. 622p.

BARTOLI, G.; PAPA, S; SAGNELLA, E.; FIORETTO, A. Heavy metal content in sediments along the Calore river: Relationships with physical-chemical characteristics. Journal of Environmental Management, v. 95, p. S9-S14, 2012.

BELO, A.; QUINÁIA, S. P.; PLETSCH, A. L. Avaliação da contaminação de metais em sedimentos superficiais das praias do Lago de Itaipu. Química Nova, v. 33, n. 3, p. 613617, 2010. 
BetTIOL, C.; STIEVANO, L.; BERTELLE, M.; DELFINO, F.; ARGESE, E. Evaluation of microwave-assisted acid extraction procedures for the determination of metal content and potential bioavailability in sediments. Applied Geochemistry, v. 23, p. 1140-1151, 2008.

BEVILACQUA, J. E.; SILVA, I. S.; LICHTIG, J.; MASINI, J. C. Extração seletiva de metais pesados em sedimentos de fundo do rio Tietê, São Paulo. Química Nova, v. 32, n. 1, p. 2633, 2009.

BONAI, N. C.; SOUZA-FRANCO, G. M.; FOGOLARI, O.; MOCELIN, D. J. C.; DAL MAGRO, J. Distribution of metals in the sediment of the Itá Reservoir, Brazil. Acta Limnol. Bras., v. 21, n. 2, p. 245-250, 2009.

BOSTELMANN, E. Avaliação da concentração de metais em amostras de sedimento do Reservatório Billings, Braço Rio Grande, São Paulo, Brasil. 2006. Dissertação (Mestrado em Ciências na área de Tecnologia Nuclear) - Instituto de Pesquisas Energéticas e Nucleares, Universidade de São Paulo, São Paulo, 2006.

BRITO, N. M.; JUNIOR, O. P. A.; POLESE, L.; RIBEIRO, M. L. Validação de métodos analíticos: estratégia e discussão. Pesticidas: R. Ecotoxicol. e Meio Ambiente, v. 13, p. 129-146, 2003.

CCME - CANADIAN COUNCIL OF MINISTERS OF THE ENVIRONMENT. Protocol for the derivation of Canadian Sediment Quality Guidelines for the protection of aquatic life. 1995. Disponível em: <http://www.ccme.ca/assets/pdf/pn_1176_e.pdf>.

Acesso em: 10 jul. 2011.

CCME - CANADIAN COUNCIL OF MINISTERS OF THE ENVIRONMENT. Canadian Sediment Quality Guidelines for the Protection of Aquatic Life. Update 2002.

Disponível em: <http://www.ccme.ca/assets/pdf/sedqg_summary_table.pdf >.

Acesso em: 05 maio 2011.

CHABUKDHARA, M.; NEMA, A. K. Assessment of heavy metal contamination in Hindon River sediments: a chemometric and geochemical approach. Chemosphere, v. 87, p. 945953, 2012.

COMPANHIA AMBIENTAL DO ESTADO DE SÃO PAULO. Sedimentos: determinação da distribuição granulométrica. São Paulo: CETESB, 1995. 15p. (L6.160).

COMPANHIA AMBIENTAL DO ESTADO DE SÃO PAULO. Critérios para avaliação da qualidade de sedimento - Anexo VI. Série Relatórios. São Paulo: CETESB, 2006. 4p.

COMPANHIA AMBIENTAL DO ESTADO DE SÃO PAULO. Significado ambiental e sanitário das variáveis de qualidade das águas e dos sedimentos e metodologias analíticas de amostragem - Apêndice A. Série Relatórios. São Paulo: CETESB, 2009. 44p. 
COMPANHIA AMBIENTAL DO ESTADO DE SÃO PAULO. Índices de qualidade das águas, critérios de avaliação da qualidade dos sedimentos e indicador de controle de fontes Apêndice B. Série Relatórios. São Paulo: CETESB, 2010. 21p.

COMPANHIA AMBIENTAL DO ESTADO DE SÃO PAULO. Guia nacional de coleta e preservação de amostras: água, sedimento, comunidades aquáticas e efluentes líquidos. São Paulo: CETESB; Brasília: ANA, 2011. 326p.

CONSELHO NACIONAL DO MEIO AMBIENTE. Resolução CONAMA n 344, de 25 de março de 2004. Estabelece as diretrizes para a avaliação do material a ser dragado em águas jurisdicionais brasileiras. Diário Oficial da União, Brasília, 07 maio 2004. Disponível em:

<http://www.mma.gov.br/port/conama/legiabre.cfm?codlegi=445>.

Acesso em: 05 jul. 2012.

CONSELHO NACIONAL DO MEIO AMBIENTE. Resolução CONAMA $n^{\circ}$ 357, de 17 de março de 2005. Dispõe sobre a classificação dos corpos de água e diretrizes ambientais para o seu enquadramento, bem como estabelece as condições e padrões de lançamento de efluentes. Diário Oficial da União, Brasília, 18 mar. 2005. Disponível em:

<http://www.mma.gov.br/port/conama/legiabre.cfm?codlegi=459>. Acesso em: 05 jul. 2012.

CONSELHO NACIONAL DO MEIO AMBIENTE. Resolução CONAMA n 396, de 03 de abril de 2008. Dispõe sobre a classificação e diretrizes ambientais para o enquadramento das águas subterrâneas. Diário Oficial da União, Brasília, 07 abr. 2008. Disponível em:

<http://www.mma.gov.br/port/conama/legiabre.cfm?codlegi=562>

Acesso em: 05 jul. 2012.

CONSELHO NACIONAL DO MEIO AMBIENTE. Resolução CONAMA $n^{\circ} 421$, de 03 de fevereiro de 2010. Dispõe sobre revisão e atualização da Resolução CONAMA $n^{\circ} 344$, de 25 de março de 2004. Diário Oficial da União, Brasília, 04 fev. 2010. Disponível em:

<http://www.mma.gov.br/port/conama/legiabre.cfm?codlegi=621>. Acesso em: 05 jul. 2012.

CORRAR, L. J.; PAULO, E.; FILHO, J. M. D. Análise multivariada para os cursos de administração, ciências contábeis e economia. $1^{\text {a }}$ ed. Editora Atlas, 2007. 568 p.

COTRIM, M. E. B. Avaliação da qualidade da água na Bacia Hidrográfica do Ribeira de Iguape com vistas ao abastecimento público. 2006. Tese (Doutorado em Ciências na área de Tecnologia Nuclear) - Instituto de Pesquisas Energéticas e Nucleares, Universidade de São Paulo, São Paulo, 2006.

COTTA, J. A. O.; REZENDE, M. O. O.; PIOVANI, M. R. Avaliação do teor de metais em sedimento do rio Betari no Parque Estadual Turístico do Alto Ribeira - PETAR, São Paulo, Brasil. Química Nova, v. 29, n. 1., p. 40-45, 2006. 
DANTAS, E. S. K. Procedimentos analíticos em determinações multi elementares de particulados do aerossol atmosférico para uso em modelo receptor. 1999. Tese (Doutorado em Ciências na área de Química Analítica) - Instituto de Química, Universidade de São Paulo, São Paulo, 1999.

DOBROWOLSKI, R.; ADAMCZYK, A.; OTTO, M. Comparison of action of mixed permanent chemical modifiers for cadmium and lead determination in sediments and soils by slurry sampling graphite furnace atomic absorption spectrometry. Talanta, v. 82, p. 1325-1331, 2010.

EISLER, R. Handbook of Chemical Risk Assessment. Health Hazards to Humans, Plants, and Animals. Three Volume Set. New York: CRC Press, 2000.

ESTEVES, F. A. Fundamentos de limnologia. $3^{\mathrm{a}}$ ed. Rio de Janeiro: Interciência, 2011. 826 p.

FERNANDES, L.; NAYAK, G. N.; ILANGOVAN, D.; BOROLE, D.V. Accumulation of sediment, organic matter and trace metals with space and time, in a creek along Mumbai coast, India. Estuarine, Coastal and Shelf Science, v. 91, p. 388-399, 2011.

FERREIRA, A. P.; HORTA, M. A. P.; CUNHA, C. L. N. Avaliação das concentrações de metais pesados no sedimento, na água e nos órgãos de Nycticorax nycticorax (Garça-da-noite) na Baía de Sepetiba, RJ, Brasil. Revista da Gestão Costeira Integrada, v. 10, n. 2, p. 229-241, 2010.

FISZMAN, M.; PFEIFFER, W. C.; LACERDA, L. D. Comparison of methods used for extraction and geochemical distribution of heavy metals in bottom sediments from Sepetiba Bay, R.J. Environmental Technology Letters, v. 5, p. 567-575, 1984.

FRANKLIN, R. L. Determinação de mercúrio total e orgânico e avaliação dos processos de metilação e desmetilação em sedimentos do Reservatório Rio Grande, Estado de São Paulo. 2010. Dissertação (Mestrado em Ciências na área de Tecnologia Nuclear) Instituto de Pesquisas Energéticas e Nucleares, Universidade de São Paulo, São Paulo, 2010.

FRANKLIN, R. L.; FERREIRA, F. J.; BEVILACQUA, J. E.; FÁVARO, D. I. T. Assessment of metals and trace elements in sediments from Rio Grande Reservoir, Brazil, by neutron activation analysis. J. Radioanal. Nucl. Chem., v. 291, p. 147-153, 2012.

GUILHEN, S. N. Validação de metodologia analítica para determinação de mercúrio total em amostras de urina por Espectrometria de Absorção Atômica com Geração de Vapor Frio (CV-AAS). 2009. Dissertação (Mestrado em Ciências na área de Tecnologia Nuclear) Instituto de Pesquisas Energéticas e Nucleares, Universidade de São Paulo, São Paulo, 2009.

HARRIS, D. C. Análise Química Quantitativa. 6ª ed. Editora LTC, 2005. 
IARC - INTERNATIONAL AGENCY FOR RESEARCH ON CANCER. Arsenic, metals, fibres and dusts: a review of human carcinogens. v. 100 C. IARC Monographs, 2012. 526p. Disponível em: <http://monographs.iarc.fr/ENG/Monographs/vol100C/mono100C.pdf>. Acesso em: 05 jul. 2012.

INMETRO. DOQ-CGCRE-008: Orientações sobre validação de métodos de ensaios químicos. Revisão 01, 2003. 35 p. Disponível em:

<http://www.inmetro.gov.br/Sidoq/Arquivos/CGCRE/DOQ/DOQ-CGCRE-8_01.pdf>. Acesso em: 06 jan. 2012.

INMETRO. DOQ-CGCRE-008: Orientação sobre validação de métodos analíticos. Revisão 03, 2010. 20 p. Disponível em:

<http://www.inmetro.gov.br/Sidoq/Arquivos/CGCRE/DOQ/DOQ-CGCRE-8_03.pdf>. Acesso em: 06 jan. 2012.

JESUS, T. A. Avaliação do histórico de impactos antrópicos na bacia de drenagem do Lago das Garças (São Paulo-SP), durante o século XX, com base nos estoques de nutrientes, metais pesados e compostos orgânicos em sedimento lacustre. 2008. Tese (Doutorado em Hidráulica e Saneamento) - Escola de Engenharia de São Carlos, Universidade de São Paulo, São Carlos, 2008.

KRUG, F. J.; NÓBREGA, J. A.; OLIVEIRA, P. V. Espectrometria de absorção atômica. Seminário: tópicos avançados em espectrometria de absorção atômica. Instituto de Química, Universidade de São Paulo, São Paulo, 2001.

LAGALANTE, A. F. Atomic Absorption Spectroscopy: A Tutorial Review. Applied Spectroscopy Reviews, v. 34, n. 3, p. 173-189, 2004.

LAJUNEN, L. H. J.; PERÄMÄKI, P. Spectrochemical analysis by atomic absorption and emission. 2. ed. Cambridge: The Royal Society of Chemistry, 2004.

LEMES, M. J. L. Avaliação de metais e elementos-traço em águas e sedimentos das Bacias Hidrográficas dos rios Mogi-Guaçu e Pardo, São Paulo. 2001. Dissertação (Mestrado em Ciências na área de Tecnologia Nuclear) - Instituto de Pesquisas Energéticas e Nucleares, Universidade de São Paulo, São Paulo, 2001.

LEPRI, F. G.; WELZ, B.; DESSUY, M. B.; VALE, M. G. R.; BOHRER, D.; LOOS-VOLLEBREGT, M. T. C.; HUANG, M. D.; BECKER-ROSS, H. Investigation of the feasibility to use Zeeman-effect background correction for the graphite furnace determination of phosphorus using highresolution continuum source atomic absorption spectrometry as a diagnostic tool. Spectrochimica Acta Part B, v. 65, p. 24-32, 2010.

MACÊDO, J. A. B. Introdução à química ambiental. $2^{a}$ ed. CRQ-MG, 2006. 1028p.

MANNING, T. J.; GROW, W. R. Inductively coupled plasma - atomic emission spectrometry. The Chemical Educator, v. 2, n. 1, p. 1-19, 1997. 
MARQUES, A. K. Avaliação da qualidade da água do Ribeirão Taquaruçu Grande e da área de sua influência no Reservatório da Usina Hidrelétrica Luis Eduardo Magalhães, TO. 2011. Tese (Doutorado em Ciências na área de Tecnologia Nuclear) - Instituto de Pesquisas Energéticas e Nucleares, Universidade de São Paulo, São Paulo, 2011.

MMA - Ministério do Meio Ambiente. Água: Manual de uso. Alguns passos na implementação do Plano Nacional de Recursos Hídricos. Ministério do Meio Ambiente, Secretaria de Recursos Hídricos. Brasília: MMA, 2006a. 109 p.

MMA - Ministério do Meio Ambiente. Caderno da Região Hidrográfica do TocantinsAraguaia. Ministério do Meio Ambiente, Secretaria de Recursos Hídricos. Brasília: MMA, 2006b. 132 p.

PERKIN ELMER. Concepts, instrumentation and techniques in atomic absorption spectrophotometry. The Perkin Elmer Corporation, Norwalk, CT, USA, 1993.

PERKIN ELMER. Guide to inorganic analysis. Perkin Elmer Life and Analytical Sciences. Shelton, USA, 2004. $16 \mathrm{p}$.

PIVELI, R. P.; KATO, M. T. Qualidade das águas e poluição: aspectos físico-químicos. $1^{\mathrm{a}}$ ed. São Paulo: ABES - Associação Brasileira de Engenharia Sanitária e Ambiental, 2005.

QUINÁGLIA, G. A. Caracterização dos níveis basais de concentração de metais nos sedimentos do Sistema Estuarino da Baixada Santista. 2006. Tese (Doutorado em Química) - Instituto de Química, Universidade de São Paulo, São Paulo, 2006.

RIBEIRO, F. A. L.; FERREIRA, M. M. C.; MORANO, S. C.; SILVA, L. R.; SCHNEIDER, R. P. Planilha de validação: uma nova ferramenta para estimar figuras de mérito na validação de métodos analíticos univariados. Química Nova, v. 31, n. 1, p. 164-171, 2008.

ROCHA, J. C.; ROSA, A. H.; CARDOSO, A. A. Introdução à química ambiental. Porto Alegre: Bookman, 2004. 154p.

SANTOS, J. S.; SANTOS, M. L. P.; OLIVEIRA, E. Estudo da mobilização de metais e elementos traços em ambientes aquáticos do semi-árido brasileiro aplicando análises de componentes principais. Química Nova, v. 31, n. 5, p. 1107-1111, 2008.

SILVÉRIO, P. F. Bases técnico-científicas para a derivação de valores-guias de qualidade de sedimentos para metais: experimentos de campo e laboratório. 2003. Tese (Doutorado em Ciências na área de Engenharia Ambiental) - Escola de Engenharia de São Carlos, Universidade de São Paulo, São Carlos, 2003.

SIMPSON, S. L.; BATLEY, G. E.; CHARLTON, A. A.; STAUBER, J. L.; KING, C. K.; CHAPMAN, J. C.; HYNE, R. V.; GALE, S. A.; ROACH, A. C.; MAHER, W. A. Handbook for sediment quality assessment. Bangor: CSIRO, 2005. 
SNAPE, I.; SCOULLER, R. C.; STARK, S. C.; STARK, J.; RIDDLE, M. J.; GORE, D. B. Characterisation of the dilute $\mathrm{HCl}$ extraction method for the identification of metal contamination in Antarctic marine sediments. Chemosphere, v. 57, p. 491-504, 2004.

TOCANTINS. Atlas do Tocantins: subsídios ao planejamento da gestão territorial. Secretaria do Planejamento e da Modernização da Gestão Pública - SEPLAN, Superintendência de Pesquisa e Zoneamento Ecológico-Econômico, Diretoria de Zoneamento Ecológico-Econômico - DZE. 6. ed. rev. atu. Palmas: Seplan, 2012. 80 p.

TOWNSEND, A. T.; SNAPE, I.; PALMER, A. S.; SEEN, A. J. Lead isotopic signatures in Antarctic marine sediment cores: A comparison between $1 \mathrm{M} \mathrm{HCl}$ partial extraction and HF total digestion pre-treatments for discerning anthropogenic inputs. Science of the Total Environment, v. 408, p. 382-389, 2009.

U.S. EPA - United States Environmental Protection Agency. Priority chemicals: chemical name \& summary fact sheet. Disponível em:

<http://www.epa.gov/waste/hazard/wastemin/minimize/factshts/cadmium.pdf> Acesso em: 30 maio 2011.

U.S. EPA - United States Environmental Protection Agency. Method 3051A: microwave assisted acid digestion of sediments, sludges, soils and oils. United States, Revision 01, 2007. $30 \mathrm{p}$.

VAROL, M.; SEN, B. Assessment of nutrient and heavy metal contamination in surface water and sediments of the upper Tigris River, Turkey. Catena, v. 92, p. 1-10, 2012.

WELZ, B; SPERLING, M. Atomic absorption spectrometry. 3. ed. WILEY-VCH, 1999.

YU, X.; YAN, Y.; WANG, WX. The distribution and speciation of trace metals in surface sediments from the Pearl River Estuary and the Daya Bay, Southern China. Marine Pollution Bulletin, v. 60, n. 8, p. 1364-1371, 2010. 